Key Words: Heat Exchanger Leak KCTA Code

Radionuclide Relese

Retention: Lifetime

\title{
A MODEL FOR RADIONUCLIDE TRANSPORT IN THE COOLING WATER SYSTEM (U)
}

S. D. Kahook

Issued: August 1992

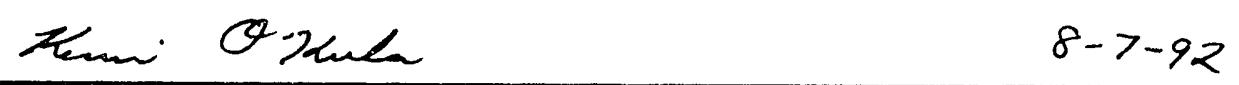

K. R. O'Kula, Authorized Derivative Classifier 
Document:

Title:

\section{Revision Number: 0}

\section{Approvals}

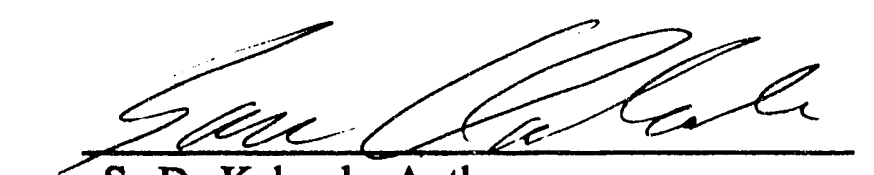

S. D. Kahook, Author
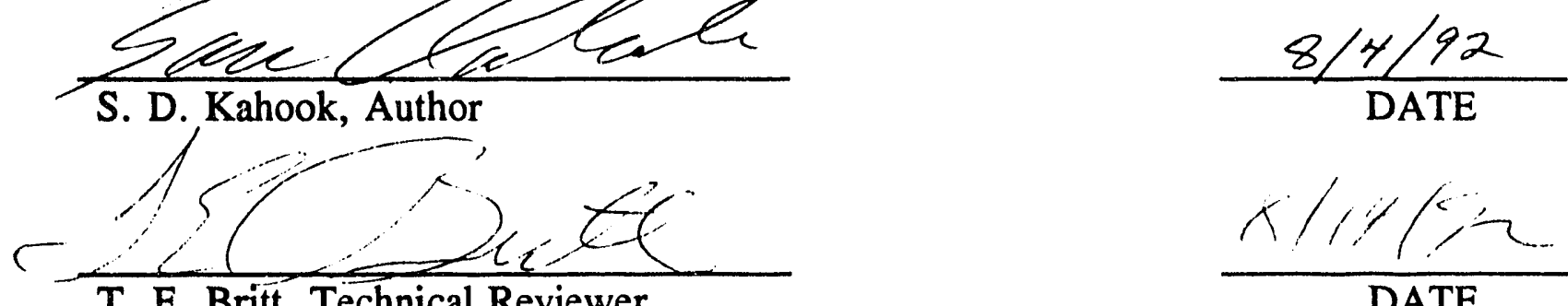

T. E. Britt, Technical Reviewer
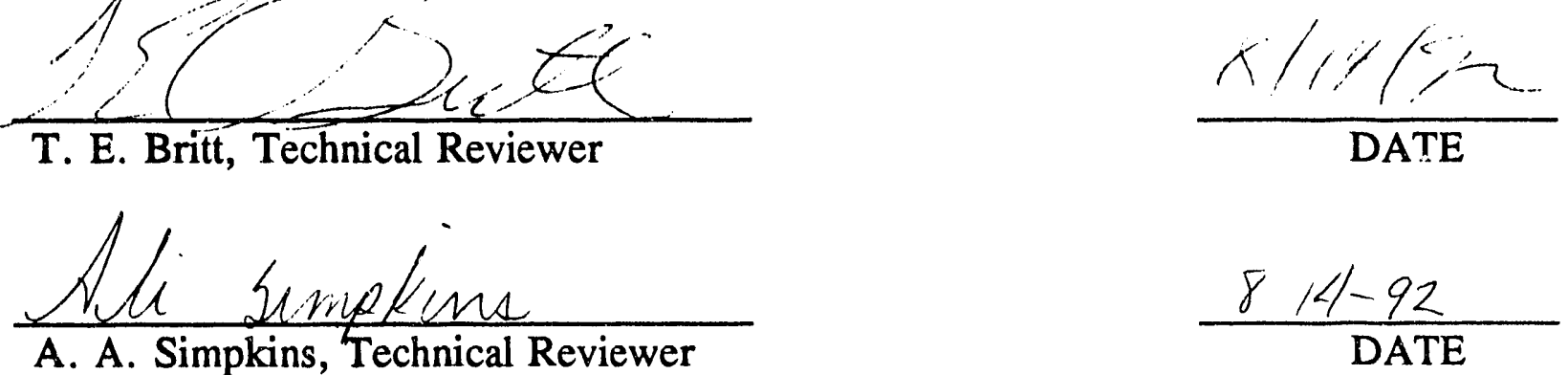

$\frac{\text { Tami Or. Tula }}{\text { K. R. O'Kula, Manager }}$
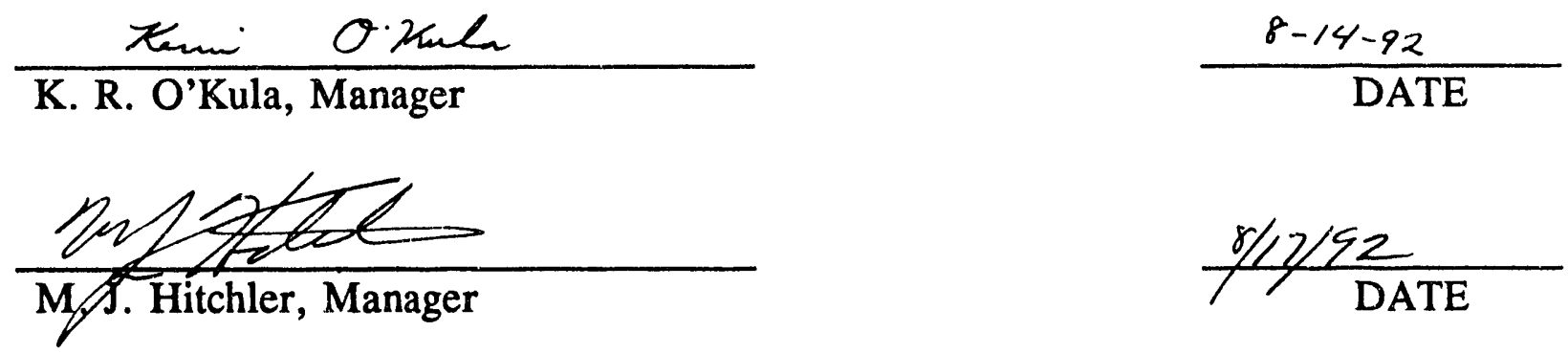


\section{ABSTRACT}

A radionuclide transport model developed to assess radiological levels in the K-reactor Cooling Water System (CWS) in the event of an inadvertent process water (PW) leakage to the cooling water (CW) in the heat exchangers (HX) is described. During and following a process water leak, the radionuclide transport model determines the timedependent release rates of radionuclide from the cooling water system to the environment via evaporation to the atmosphere and blow-down to the Savannah River. The developed model allows for delay times associated with the transport of the cooling water radioactivity through cooling water system components. Additionally, this model simulates the time-dependent behavior of radionuclides levels in various CWS components. The developed model is incorporated into the $\mathbf{K}$-reactor Cooling Tower Activity (KCTA) code. KCTA allows the accident (heat exchanger leak rate) and the cooling tower blow-down and evaporation rates to be described as time-dependent functions. Thus, the postulated leak and the consequence of the assumed leak can be modelled realistically.

This model is the first of three models to be ultimately assembled to form a comprehensive Liquid Pathway Activity System (LPAS). LPAS will offer integrated formation, transport, deposition, and release estimates for radionuclides formed in a SRS facility. Process water and river water modules are forthcoming as input and downstream components, respectively, for KCTA. 
LIST OF FIGURES

LIST OF TABLES

LIST OF ACRONYMS AND SYMBOLS

viii

viii

1.0 INTRODUCTION

1.1 Introduction

1.2 Summary

1.3 Expected Radiological Impacts of the Cooling Tower

1.4 Report Organization

ix

2.0 MODEL DEVELOPMENT

2.1 General Radionuclide Transport Model

2.2 K-Reactor Cooling Tower Water System

2.2.1 Steady-State Solution

$\begin{array}{ll}\text { 3.0 DESCRIPTION OF THE KCTA CODE } & 13\end{array}$

3.1 Introduction

3.2 Description of the KCTA

3.2.1 The MAIN Module

3.2.2 The REED Module

3.2.3 The STEADY Module $\quad 15$

3.2.4 The RITE1 Module 16

3.2.5 The ERRCHK Module 16

$\begin{array}{ll}\text { 3.2.6 The TRANS Module } & 17\end{array}$

$\begin{array}{lr}\text { 4.0 CASE STUDY } & 19\end{array}$

4.1 Introduction 19

4.2 Description of Event 19

4.3 CWS Without an On-Line Cooling Tower 19

4.4 CWS With a Cooling Tower On-Line 19

4.4.1 Tritium Concentration Levels in CWS Components 20

4.4.2 Tritium Release Rate 28

4.4.3 Tritium Dose Rates 31

4.5 References 31

$\begin{array}{ll}\text { 5.0 LIMITATIONS AND FUTURE WORK } & 34\end{array}$

5.1 Introduction $\quad 34$

5.2 Limitations $\quad 34$

5.3 Path Forward $\quad 35$ 


\section{APPENDIX A DESCRIPTION OF THE}

DATA FILES USED BY THE KCTA CODE 38

A.1 Input Data File

A.1.1 Block I, Simulation/Output Data 38

A.1.2 Block II, CTW Specific Data

A.1.3 Block III, Nuclide-Dependent Data 39

A.1.4 Block IV, Function Definition Data 40

A.1.4.1 Heat Exchanger Leak Function $\quad 40$

A.1.4.2 Cooling Tower Blow-Down Rate Function $\quad 40$

A.1.4.3 Cooling Tower Evaporation Rate Function 41

A.1.5 Sample Input Data File $\quad 41$

A.2 Output Data File

A.2.1 Output Data File, Part (1) 43

A.2.2 Output Data File, Part (2) 43

A.2.3 Output Data File, Part (3) 46

A.2.4 Output Data File, Part (4) 46

A.3 Data Base File $\quad 46$

APPENDIX B FORTRAN LISTING OF THE KCTA CODE 50

B.1 The MAIN Module $\quad 50$

B.2 The REED Module $\quad 57$

B.3 The STEADY module $\quad 61$

B.4 The RITE1 Module 63

B.5 The ERRCHK Module $\quad 66$

B.6 The TRANS Module $\quad 69$ 


\section{LIST OF FIGURES}

2-1. Schematic of the K-Reactor Cooling Tower Water System 7

4-1. KCTA Code Input File for December 1991 Event 20

4-2. Tritium Concentration in CWS Components During the December 1991 Leak

4-3. Tritium Concentration in CWS Components During the First Two Hours of the December 1991 Leak

4-4. KCTA Code Input File for December 1991 Event With "Mocked-Up" CWS Description

4-5. Tritium Release Rates from the "Mocked-Up" CWS to the Environment During the First Two-hours of the December 1991 Leak

4-6. Tritium Release Rates from the "Mocked-Up" CWS to the Environment During the December 1991 Leak

4-7. Tritium Release Rates from the CWS to the Environment During the December 1991 Leak

4-8. Cumulative Tritium Release from the CWS to the Environment During the December 1991 Leak

4-9. Expected Dose to Workers Near the Cooling Tower During the December 1991 Leak

5-1. Schematic of an Example SRS LPAS

A-1. Example of the KCTA Code Input File 42

A-2. First Part of the Output File Produced by KCTA 44

A-3. Second Part of the Output File Produced by KCTA 45

A-4. Third Part of the Output File Produced by KCTA 47

A-5. Fourth Part of the Output File Produced by KCTA 48 


\section{LIST OF TABLES}

4-1. Volumes of the Actual and "Mocked-Up" CWS

4-2. Tritium Release Rates and Cumulative Releases to the Environment at the End of the Event

4-3. Maximum Expected Dose to Workers Near The Cooling Tower Due to Continual Process Water Leaks

A-1. Names and Identification Numbers of The Radionuclides

Employed in "KCTA.d" 


\section{LIST OF ACRONYMS AND SYMBOLS}

ALARA As Low As Reasonably Achievable;

$A_{i}^{e} \quad$ initial steady state rate of release of the $i^{\text {th }}$ radionuclide to the environment by means of evaporation;

$A_{i}^{B d} \quad$ initial steady state rate of release of the $i^{\text {th }}$ radionuclide to the environment by means of blow down to the river;

$A_{i}^{\text {rel }} \quad$ inititial total steady state rate of release of the $i^{\text {th }}$ radionuclide to the environment by all pathways;

$\mathrm{Bd}(\mathrm{t}) \quad$ cooling tower blow-down rate (gpm: gallons per minute);

$\mathrm{Ci} \quad$ curie which is equal to $3.7 \times 10^{10}$ disintegrations per second;

$c_{i}^{\top}(t) \quad i^{\text {th }}$ radionuclide concentration in the cooling tower;

Cw Cooling Water;

CV Control Volume;

CWS Cooling Water System;

CY Calendar Year;

DOE Department of Energy;

$\mathrm{E}(\mathrm{t}) \quad$ cooling tower evaporation rate $(\mathrm{gpm})$;

$\mathrm{R}(\mathrm{t}) \quad$ recirculation flow rate from the cooling tower to the 186-Basin (gpm);

HX Heat Exchanger;

I/O Input/Output;

KCTA K-reactor Cooling Tower Activity code;

$N_{i}^{m}(t) \quad$ activity level of the $i^{\text {th }}$ radionuclide in the $m^{\text {th }} C V$;

$N_{i}^{m-n}(t)$ activity level of the $i^{\text {th }}$ radionuclide transported from the $n^{\text {th }}$ to the $m^{\text {th }} C V$; 
$N_{i}^{m}-j(t) \quad$ activity level of the $i^{\text {th }}$ radionuclide's parent (the $j^{\text {th }}$ parent);

LPAS Liquid Pathway Activity System;

$f^{m+n} \quad$ ratio of radionuclides that reach the $\mathrm{n}^{\text {th }} \mathrm{CV}$ to the radionuclides that left the $\mathrm{m}^{\text {th }}$ $\mathrm{CV}$;

$\lambda_{i} \quad$ decay constant of the $i^{\text {th }}$ radionuclide;

$\tau_{\mathrm{r}}^{\mathrm{m}} \quad$ effective residence time of radionuclides in the $\mathrm{m}^{\text {th }} \mathrm{CV}$;

$\tau_{\ell}^{m+n} \quad$ effective delay time for the transport of radionuclides from the $n^{\text {th }}$ to the $m^{\text {th }}$ $\mathrm{CV}$;

NF number of control volumes in the system;

NR number of radionuclides in the system;

PC Personal Computer;

PW Process Water;

RHS Right Hand Side;

RW River Water;

$S_{i 0}^{C w} \quad$ initial steady-state cooling water makeup flow;

$S_{i 0}^{P w} \quad$ initial steady-state process water in-leakage;

SAR Safety Analysis Report;

SRS Savannah River Site;

SRTC Savannah River Technology Center;

$T_{1 / 2} \quad$ radionuclide's radiological half-life (sec);

V\&V Verification and Validation;

WSRC Westinghouse Savannah River Company; 


\subsection{INTRODUCTION}

\subsection{Introduction}

A thermal discharge mitigation system, the K-reactor cooling tower, is to be tied-in to the cooling water system by end of CY 1992. Previously, environmental discharge of core heat transferred from the process water system (PWS) to the cooling water system (CWS) was directly to the Savannah River via surface streams. Cooling water discharge to the K-011 effluent canal was at a maximum flow of $179,000 \mathrm{gpm}$ and at $171^{\circ} \mathrm{F}$ for reactor power levels of $2400-2500 \mathrm{MW}$. Implementation of the Cooling Tower in the CWS for the K-reactor reduces the effluent cooling water discharge to a constant flow of $20,000 \mathrm{gpm}$ at a maximum temperature of $90^{\circ} \mathrm{F}$. Thus, the Cooling Tower results in a significant reduction in the thermal energy released to the Savannah River.

Additionally, prior to Cooling Tower tie-in, any PW heat exchanger leak is released to the Savannah River (via discharge to the K-011 effluent canal) at the same rate as the process water leakage is introduced to the cooling water. The incorporation of the Cooling Tower makes the cooling water a quasi-closed system, releases of radionuclides to the environment with the Cooling Tower installed needs to be addressed. That is, due to the differences between the two operating conditions, preand post-Cooling Tower tie-in, the radiological impacts (occupational and environmental) of leakage to the heat exchangers are different. Therefore, a radionuclide transport code has been developed in order to assess the radiological impact of the Cooling Tower to the public by means of radionuclide releases to the environment (evaporation and blow-down to the river) and to employees by means of radionuclide levels in CWS components as a results of an inadvertent heat exchanger leak.

\subsection{Summary}

This report describes a radionuclide transport model developed to assess radiological levels in the K-reactor Cooling Water System (CWS) in the event of operational and accidental process water (PW) leaks to the cooling water (CW) in the heat exchangers (HX). During and following a PW leaks the radionuclide transport model determines the time-dependent release rates of radionuclides from the CWS to the environment via evaporation to the atmosphere and blow-dowr. to the Savannah River. Additionally, this model simulates the time-dependent behavior of radionuclide levels in various CWS components. Results obtained from this model will be used to determine 
occupational radiological exposures and to determine population dose rates as a result of releases of radionuclides via evaporation and blow-down.

Additional models are forthcoming. The model presented in this report will be integrated with additional models. This will allow comprehensive treatment of liquidborne radionuclide production, deposition, and transport in the process and cooling water systems. Ultimate radiological impacts to workers and the general public will also be predicted upon model completion.

\subsection{Expected Radiological Impacts of the Cooling Tower}

With regard to radionuclide releases to the environment, there are three main differences between operating with and without a Cooling Tower. They are:

1. Release Pathways. In the case of the online Cooling Tower, aqueous radionuclides are released to the environment via evaporation from the cooling tower and blow-down to the river. For the case of the Cooling Tower not implemented, the only pathway to introduce aqueous radionuclides to the environment is by means of cooling water discharge to the river.

2. Rates of Release. The rate of radionuclide release to the environment is higher for the case without a Cooling Tower provided that the leak duration is not prolonged. This is due to the fact that the CWS with the Cooling Tower is a quasi-closed loop. Since only a fraction of the CWS water inventory is released to the environment, only a fraction of the radionuclides present in the CWS is released to the environment. However, once the leaking heat exchanger(s) is(are) isolated, the case without the Cooling Tower will cease to release radionuclides to the environment while the CWS with online Cooling Tower continues to discharge radionuclides due to radionuclide inventory buildup in its components during the PW leak.

3. Amounts of Release. For short-lived radionuclides $\left(T_{1 / 2} \approx\right.$ hours or less), the CWS with the Cooling Tower online discharges less radioactivity to the environment. This is due to holding times in the Cooling Tower System being longer as a result of being a quasi-closed loop and due to long residence times in the CWS components. The residence time in the Cooling Tower System is about 2.6 hours due to both the 25 million gallon basin (186-Basin) and the 3 million gallon cooling tower basin. During the relatively long holding times, a fraction of the short-lived radionuclides are lost by means of radioactive decay. However, for long-lived radionuclides $\left(T_{1 / 2} \approx\right.$ days), the CWS with the 
online Cooling Tower will eventually release the same amount of radionuclides as the case without a Cooling Towi: (provided that a release pathway remains in existence, e.g., evaporation and/or blow-down), except the release is over an extended period of time, as mentioned in item 2 above. An example of this class of radionuclides is tritium $\left({ }^{3} \mathrm{H}\right)$. The delay times may be significant, so that effective precautions are available.

In Section 4.0 of this report, comparisons of the effects of operating with and without a cooling tower are presented for the December 1991 process water leak.

\subsection{Report Organization}

The report is divided into the following sections:

\subsection{INTRODUCTION}

A preview of the pre- and post-Cooling Tower conditions is included in this section. A qualitative description of the differences associated with operating the reactor with and without the cooling tower water system is also included in this section.

\subsection{MODEL DEVELOPMENT}

A description of the CWS radionuclide transport model is included in this section. Assumptions employed during development of this model and limitations of this model are also presented in this section.

\subsection{DESCRIPTION OF THE KCTA CODE}

This section describes the KCTA (K-reactor Cooling Tower Water System Activity) code which incorporates the CWS radionuclide transport model. The different modules, execution sequence, and input requirements are described in this section. 


\subsection{CASE STUDY}

This section compares the effect of operating with and without a cooling tower for the December 1991 process water leak.

\subsection{LIMITATIONS AND FUTURE WORK}

This section summarizes the work performed in this report. Assumptions and limitations employed in developing the model and the KCTA code are also presented. Recommendations for future work and modifications to the model are given.

\section{APPENDIX A}

The data files connected to the KCTA code during execution are described in this appendix. These files are the input data file, the output data file, and the data base file. A sample input file and the obtained output file are also described in Appendix A.

\section{APPENDIX B}

A Fortran listing of the KCTA code is included in Appendix B, and the variables used in the KCTA code are included in the Fortran source file. 


\subsection{MODEL DEVELOPMENT}

\subsection{General Radionuclide Transport Model}

The equation governing the time dependent behavior of the activity level for the $i^{\text {th }}$ radionuclide in the $\mathrm{m}^{\text {th }}$ control volume $(\mathrm{CV})$ is the following:

$$
\begin{aligned}
\frac{d}{d t} N_{i}^{m}(t)= & \sum_{k \neq m}^{N F} f^{m-k} N_{i}^{m-k}\left(t-\tau_{l}^{m+k}\right) e^{-\lambda_{1} r_{i}^{-k}} / \tau_{r}^{k}-N_{i}^{m}(t)\left\{\lambda_{i}+1 / \tau_{r}^{m}\right\} \\
& +\sum_{j \neq i}^{N R} \lambda_{j}\left\{N_{i \rightarrow j}^{m}(t)+\sum_{l \neq m}^{N F} N_{i \neq j}^{m+\ell}(t)\right\}
\end{aligned}
$$

where

$\mathrm{N}_{\mathrm{i}}^{\mathrm{m}}(\mathrm{t})$ activity level of the $\mathrm{i}^{\mathrm{th}}$ radionuclide in the $\mathrm{m}^{\mathrm{th}} \mathrm{CV}$;

$N_{i}^{m a-k}(t)$ activity level of the $i^{\text {th }}$ radionuclide transported from the $k^{\text {th }}$ to the $m^{\text {th }} C V$;

$N_{i \rightarrow j}^{m}(t)$ activity level of the $i^{\text {th }}$ radionuclide's parent (the $j^{\text {th }}$ parent) in the $m^{\text {th }} \mathrm{CV}$;

$\mathrm{N}_{\mathrm{i} \rightarrow \mathrm{j}}^{\mathrm{m}+\mathrm{f}}(\mathrm{t})$ activity level of the $\mathrm{i}^{\text {th }}$ radionuclide's parent (the $\mathrm{j}^{\text {th }}$ parent) in all loops connected to the $\mathrm{m}^{\text {th }} \mathrm{CV}$;

$f^{m-k} \quad$ fraction of the $k^{\text {th }} \mathrm{CV}$ radionuclides that are directed to the $\mathrm{m}^{\text {th }} \mathrm{CV}$;

$\lambda_{i} \quad$ decay constant of the $i^{\text {th }}$ radionuclide;

$\tau_{\mathrm{r}}^{\mathrm{m}} \quad$ effective residence time of radionuclides in the $\mathrm{m}^{\text {th }} \mathrm{CV}$;

$\tau_{\ell}^{m+k}$ effective delay time for the transport of radionuclides from the $k^{\text {th }}$ to the $\mathrm{m}^{\text {th }}$ $\mathrm{CV}$;

NF number of control volumes in the system;

NR number of different radionuclides present (or examined) in the system;

t time (sec). 
The first term on the right hand side (RHS) of Equation (2-1) describes the rate of inflow of the $\mathrm{i}^{\text {th }}$ radionuclide into the $\mathrm{m}^{\text {th }} \mathrm{CV}$ from all other control volumes. A correction factor is used in the first term to account for decay of the radionuclides in the loop connecting the $k^{\text {th }}$ to the $\mathrm{m}^{\text {th }} \mathrm{CV}$. The second term on the RHS of Equation (2-1) describes the loss rate of the $\mathrm{i}^{\text {th }}$ radionuclide as a result of radioactive decay in the $\mathrm{m}^{\text {th }} \mathrm{CV}$ and as a result of outflow from the $\mathrm{m}^{\text {th }} \mathrm{CV}$. The third term on the RHS of Equation (2-1) describes the production rate of the $\mathrm{i}^{\text {th }}$ radionuclide from the decay of parent radionuclides in the $\mathrm{m}^{\text {th }} \mathrm{CV}$ and in the loops connecting all other control volumes to the $\mathrm{m}^{\text {th }} \mathrm{CV}$. Implicit assumptions in Equation (2-1) are the following:

(1) perfect mixing of radionuclides in the control volumes, and

(2) slug flow outside the control volumes (in the connecting loops).

\subsection{K-Reactor Cooling Tower Water System}

Shown in Figure 2-1 is a block diagram of the K-reactor secondary cooling system. As indicated in the figure, there are only three control volumes that are of interest which may contain radionuclides. The control volumes are the heat exchanger system, the 186-Basin, and the cooling tower. Figure 2-1 also shows two additional potential sources for radionuclides: the cooling water makeup flow, $\mathrm{Cw}(\mathrm{t})$, and the process water leakage to the cooling water in the heat exchangers, $\mathrm{Pw}(\mathrm{t})$.

Employing Equation (2-1) to the control volumes of the block diagram shown in Figure 2-1 results in the following equations:

$$
\begin{aligned}
\frac{d}{d t} N_{i}^{X}(t)= & N_{i}^{B}\left(t-\tau_{\ell}^{X-B}\right) e^{-\lambda_{i} r_{i}^{X-B}} / \tau_{r}^{B}+N_{i}^{P_{W}}\left(t-\tau_{l}^{X+P_{w}}\right) e^{-\lambda_{l} r_{i}^{X+\infty}} / \tau_{r}^{P_{W}} \\
& +\sum_{j \approx i}^{N R} \lambda_{j}\left\{N_{i \neq j}^{X}(t)+N_{i \neq j}^{X+B}(t)+N_{i-j}^{X-P_{W}}(t)\right\} \\
& -N_{i}^{X}(t)\left\{\lambda_{i}+1 / \tau_{r}^{X}\right\}
\end{aligned}
$$




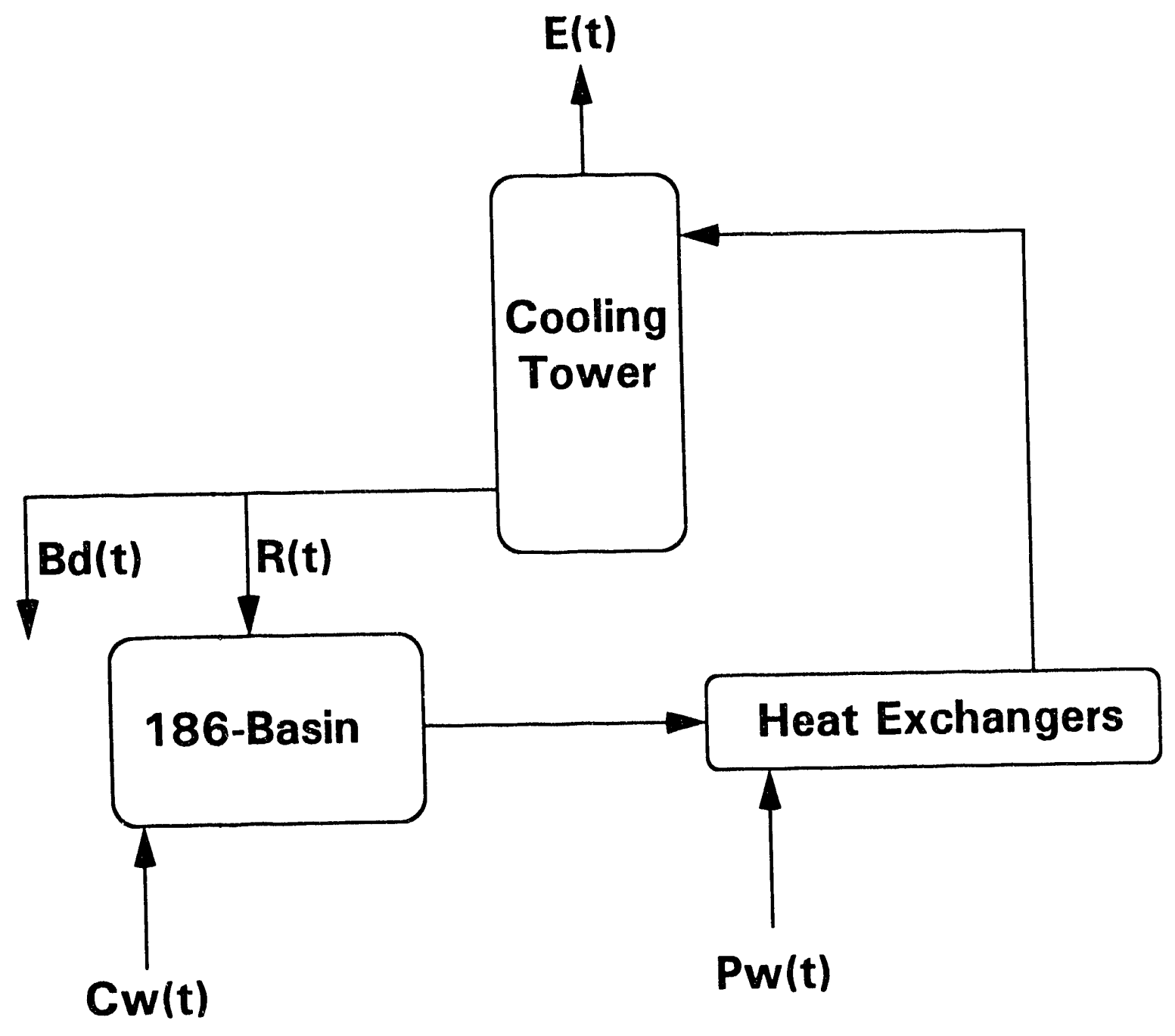

Figure 2-1.

Schematic of the K-Reactor Cooling Tower Water System 


$$
\begin{aligned}
& \frac{d}{d t} N_{i}^{B}(t)=f^{B-T} N_{i}^{T}\left(t-\tau_{l}^{B-T}\right) e^{-\lambda_{l} r_{i}^{-T}} / \tau_{r}^{T}+N_{i}^{C \omega}\left(t-\tau_{l}^{B-C \omega}\right) e^{-\lambda_{l} T_{i}^{-\infty}} / \tau_{r}^{C_{w}} \\
& +\sum_{j \neq i}^{N R} \lambda_{j}\left\{N_{i \rightarrow j}^{B}(t)+N_{i \leftarrow j}^{B-T}(t)+N_{i \propto j}^{B+C W}(t)\right\} \\
& -N_{i}^{B}(t)\left\{\lambda_{i}+1 / \tau_{r}^{B}\right\} \\
& \frac{d}{d t} N_{i}^{T}(t)=N_{i}^{X}\left(t-\tau_{l}^{T+X}\right) e^{-\lambda_{1} \tau_{i}^{+-X}} / \tau_{r}^{X}-N_{i}^{T}(t)\left\{\lambda_{i}+1 / \tau_{r}^{T}\right\} \\
& +\sum_{j \neq I}^{N R} \lambda_{j}\left\{N_{i \leftarrow j}^{T}(t)+N_{i \leftarrow j}^{T+X}(t)\right\}
\end{aligned}
$$

where superscripts "X," "T," "B," "Cw," and "Pw" are used exclusively to denote the heat exchanger system, the cooling tower, the 186-Basin, the cooling water makeup flow, and the process water in-leakage to the heat exchanger(s), respectively. The term $\mathrm{N}_{\mathrm{i}}^{\mathrm{T}} / \tau_{\mathrm{r}}^{\mathrm{T}}$ in Equation (2-3) denotes the rate at which the $\mathrm{i}^{\mathrm{ib}}$ radionuclide are lost from the cooling tower via all outflow processes and $f^{\mathrm{B}-\mathrm{T}}$ in Equation (2-3) is the fraction of $\mathrm{N}_{\mathrm{i}}^{\mathrm{T}} / \tau_{\mathrm{r}}^{\mathrm{T}}$ that reaches the $186-\mathrm{Basin}$. That is

$$
\begin{aligned}
& N_{i}^{T}(t) / \tau_{r}^{T}=c_{i}^{T}(t)\{B d(t)+E(t)+R(t)\} \\
& f^{B-T}=\frac{R(t)}{B d(t)+E(t)+R(t)}
\end{aligned}
$$

where

$c_{i}^{\top}(t) \quad i^{t h}$ radionuclide concentration in the cooling tower;

$\mathrm{Bd}(\mathrm{t}) \quad$ cooling tower blow-down rate;

$E(t) \quad$ cooling tower evaporation rate;

$R(t)$ recirculation flow rate of the CW from the cooling tower to the 186-Basin. 
If the production of the $\mathrm{i}^{\text {th }}$ radionuclide from the decay of all its parent(s) radionuclides in all control volumes and connecting loops can be neglected, then Equations (2-2), (2$3)$, and (2-4) become:

$\frac{d}{d t} N_{i}^{X}(t)=N_{i}^{B}\left(t-\tau_{l}^{X+B}\right) \epsilon_{i}^{X+B}-\lambda_{i}^{X} N_{i}^{X}(t)+S_{i}^{P \omega}(t)$

$\frac{d}{d t} N_{i}^{B}(t)=f^{B+T} N_{i}^{T}\left(t-\tau_{l}^{B-T}\right) \epsilon_{i}^{B+T}-\lambda_{i}^{B} N_{i}^{B}(t)+S_{i}^{C_{W}}(t)$

$\frac{d}{d t} N_{i}^{T}(t)=N_{i}^{X}\left(t-\tau_{l}^{T+X}\right) \epsilon_{i}^{T+X}-\lambda_{i}^{T} N_{i}^{T}(t)$

where in Equations (2-7) through (2-9), the definitions and coefficients used to reduce the complexity of analytical representations are as follows:

$$
\begin{aligned}
& S_{i}^{k}(t)=N_{i}^{k}\left(t-\tau_{l}^{m-k}\right) e^{-\lambda_{i} \tau_{i}^{-k}} / \tau_{r}^{k} \\
& \epsilon_{i}^{m-k}=e^{-\lambda_{i} \tau_{i}^{-k}} / \tau_{r}^{k} \\
& \lambda_{i}^{m}=\lambda_{i}+1 / \tau_{r}^{m}
\end{aligned}
$$

\subsubsection{Steady-State Solution}

In order to obtain the steady state conditions for the $\mathrm{i}^{\text {th }}$ radionuclide activity levels in the relevant control volumes, Equations (2-7) through (2-9) are set to zero. Rearranging terms in the resultant equations and solving in terms of the initial steadystate cooling water makeup flow, $S_{i 0}^{c w}$, and in terms of the initial steady-state process water in-leakage, $S_{i 0}^{P w}$, yields the following:

$$
N_{i 0}^{X}=\left(\frac{\lambda_{i}^{T} \lambda_{i}^{B}}{\Lambda_{i}-\Gamma_{i} f^{B-T}}\right] S_{i 0}^{P_{W}}+\left(\frac{\lambda_{i}^{T} \epsilon_{i}^{X+B}}{\Lambda_{i}-\Gamma_{i} f^{B-T}}\right] S_{i 0}^{C \omega}
$$


$N_{i 0}^{T}=\left(\frac{\lambda_{i}^{B} \epsilon_{i}^{T+X}}{\Lambda_{i}-\Gamma_{i} f^{B+T}}\right) S_{i 0}^{P_{10}}+\left(\frac{\epsilon_{i}^{T-X} \epsilon_{i}^{X+B}}{\Lambda_{i}-\Gamma_{i} f^{B-T}}\right) S_{i 0}^{C w}$

$N_{i 0}^{B}=\left(\frac{f^{B+T} \epsilon_{i}^{B+T} \epsilon_{i}^{T+X}}{\Lambda_{i}-\Gamma_{i} f^{B-T}}\right) S_{i 0}^{P_{w}}+\left(\frac{\lambda_{i}^{X} \lambda_{i}^{T}}{\Lambda_{i}-\Gamma_{i} f^{B+T}}\right) S_{i 0}^{\mathrm{CW}}$

where

$$
\begin{aligned}
& \Lambda_{i}=\lambda_{i}^{X} \lambda_{i}^{B} \lambda_{i}^{T}=\left(\lambda_{i} \tau_{r}^{X}+1\right)\left(\lambda_{i} \tau_{r}^{B}+1\right)\left(\lambda_{i} \tau_{r}^{T}+1\right) /\left(\begin{array}{lll}
\tau_{r}^{X} & \tau_{r}^{B} & \tau_{r}^{T}
\end{array}\right) \\
& \Gamma_{i}=\epsilon_{i}^{B-T} \epsilon_{i}^{T-X} \epsilon_{i}^{X+B}=e^{-\lambda_{l}\left(\tau_{i}^{A-T}+\tau_{i}^{T-X}+\tau_{i}^{X+A}\right)} /\left(\begin{array}{lll}
\tau_{r}^{T} & \tau_{r}^{B} & \tau_{r}^{X}
\end{array}\right)
\end{aligned}
$$

where subscripts "0" denote parameters are at initial steady-state values. The initial steady state rate of release of the $\mathrm{i}^{\text {th }}$ radionuclide to the environment by means of evaporation $\left(A_{i}^{0}\right)$ and blow down to the river $\left(A_{i}^{B d}\right)$, and the total release rate to the environment $\left(A_{i}^{\text {rel }}\right)$ are given by the following Equations:

$A_{i 0}^{e}=\frac{f^{E-T}}{\tau_{r}^{T}} N_{i 0}^{T}=\frac{E_{0} / \tau_{r}^{T}}{E_{0}+B d_{0}+R_{0}} N_{i 0}^{T}$

$A_{i 0}^{B d}=\frac{f^{B d \omega-T}}{\tau_{r}^{T}} N_{i 0}^{T}=\frac{B d_{0} / \tau_{r}^{T}}{E_{0}+B d_{0}+R_{0}} N_{i 0}^{T}$

$A_{i 0}^{r e l}=\frac{1-f^{B-T}}{\tau_{r}^{T}} N_{i 0}^{T}=\frac{\left(E_{0}+B d_{0}\right) / \tau_{r}^{T}}{E_{0}+B d_{0}+R_{0}} N_{i 0}^{T}$

where

$$
f^{E-T}=\frac{E(t)}{B d(t)+E(t)+R(t)}
$$


$f^{B d-T}=\frac{B d(t)}{B d(t)+E(t)+R(t)}$

In Equation (2-18), evaporation losses to the environment from the 186-Basin are assumed to be included with the evaporation losses from the cooling tower. Additionally, an inherent assumption in the derivation of the above equations is that the cooling tower water flow rate is constant.

If the $\mathrm{i}^{\text {th }}$ radionuclide has a half-life that is quite large relative to the control volume's residence time and the delay time associated with the transport of the radionuclides via the connecting loops, then simplifications can be employed to the radionuclide transport model for the K-reactor cooling tower water system if the following is true:

$$
\begin{aligned}
& \epsilon_{i}^{m+k}=e^{\lambda_{1} \tau_{t}^{-k}} / \tau_{r}^{k} \approx 1 / \tau_{r}^{k} \\
& \lambda_{i}^{n}=\lambda_{l}+1 / \tau_{r}^{n} \approx 1 / \tau_{r}^{n} \\
& \Gamma_{i} \approx \Lambda_{t} \approx\left(\begin{array}{lll}
\tau_{r}^{X} & \tau_{r}^{B} & \tau_{r}^{\tau^{\prime}}
\end{array}\right)^{-1}
\end{aligned}
$$

Utilizing Equations (2-23) through (2-25) in Equations (2-13) through (2-15) yields the following initial steady state values:

$$
\begin{aligned}
& N_{i 0}^{X}=\frac{\tau_{r}^{X}}{1-f^{B-T}}\left\{S_{i 0}^{P^{W}}+S_{i 0}^{C w}\right\} \\
& N_{i 0}^{T}=\frac{\tau_{r}^{T}}{1-f^{B-T}}\left\{S_{i 0}^{P^{D}}+S_{i 0}^{C w}\right\} \\
& N_{i 0}^{B}=\frac{\tau_{r}^{B}}{1-f^{B-T}}\left\{f^{B-T} S_{i 0}^{P W}+S_{i 0}^{C W}\right\}
\end{aligned}
$$

Employing Equation (2-27) for the $\mathrm{i}^{\text {th }}$ radionuclide activity level in the cooling tower in Equation (2-20) and solving for the total rate of release of the $\mathrm{i}^{\mathrm{ith}}$ radionuclide yields the following: 
$A_{10}^{r e d}=S_{10}^{P w}+S_{10}^{C w}$

The above equation implies, as expected, that once $i^{\text {th }}$ radionuclide saturation levels are reached in the control volumes, then the rate of release of that radionuclide into the environment is the same as the rate it is introduced into the $\mathrm{K}$-reactor cooling tower water system. (This is only true for radionuclides with half-lives that are quite large compared with the time constants of the system being considered, e.g., ${ }^{3} \mathrm{H}$ ).

Equations (2-7) through (2-20) are incorporated in KCTA (K-reactor Cooling Tower Activity), a code developed as part of this work and described in Section 3. A Fortran listing of the KCTA code is presented in Appendix B. 


\subsection{DESCRIPTION OF THE KCTA CODE}

\subsection{Introduction}

The K-reactor Cooling Tower Activity (KCTA) code calculates the radionuclide levels in the heat exchangers, the cooling tower, and the 186-Basin (CTW components) of the Department of Energy (DOE) reactors at the Savannah River Site (SRS). The KCTA also calculates the release rates and total release of radionuclides to the environment via evaporation to the atmosphere and blow-down to the Savannah River during and following a postulated PW leak through the heat exchangers.

The KCTA code allows the PW leak and the cooling tower evaporation and blow-down rates to be all time-dependent, thus a realistic simulation of accident (leak) can be performed.

A description of the KCTA code is included in the following section. This includes description of the modules that constitute the KCTA code.

\subsection{Description of the KCTA}

KCTA is written in standard Fortran-77 and operates on a Personal Computer (PC). KCTA contains six modules: MAIN, REED, STEADY, RITE1, ERRCHK, and TRANS. The Fortran listing of the KCTA code is presented in Appendix B. The variables used in the KCTA code are also described in the Fortran source file (listed in Appendix B). Descriptions of the KCTA modules are included in the following subsections.

\subsubsection{The MAIN Module}

In addition to controlling the execution sequence of the other modules, the MAIN module performs the following tasks:

1. Checks if the default input file "KCTA.i" exist on the current drive. If it does, the file is opened as an old file and assigned to I/O unit 10. Otherwise, the user is prompted to enter the name of the file containing the input data. KCTA will continue to prompt the user until a file with the input filename is found on the current drive. The name of the input file is assigned to the INP variable-an A12 format variable. Description 
of the required input data along with the format of the input data file are included in Appendix A.

2. Checks if the default output file "KCTA.o" exists on the current drive. If it does, the user is prompted to enter a new filename to be used to write the output data to. KCTA will continue to prompt the user for an output file until a name for the output file is selected that does not exist on the current drive. Once a suitable output file is selected, it is opened as a new file and assigned to $\mathrm{I} / \mathrm{O}$ unit 20 . The name of the output file is assigned to the OUTP variable-an A12 format variable. The obtained output from the KCTA code is described in Appendix A.

3. Checks if the data base file "KCTA.d" exists on the current. If it does, it is opened as an old file and assigned to $I / O$ unit 60 . If the file "KCTA.d" does not exist on the curient drive, the user is informed of that and execution is aborted. This file is also described in Appendix A.

If execution is not aborted the MAIN module calls the remaining modules in the following sequence: REED, STEADY, RITE1, ERRCHK, and finally TRANS.

\subsubsection{The REED Module}

The REED module is used exclusively to read in all necessary input data from the file assigned to I/O unit 10 (whose name is contained in the INP variable) and to read in the corresponding radionuclide data found in the data base file "KCTA.d". Descriptions of the required input data and the data base file are presented in Appendix A.

In addition to reading in the input data, the REED module performs the following:

1. Checks if the number of radionuclides included in the input file is greater than the maximum number allowed (50 radionuclides). If so, REED informs the user if execution is to be continued with only the first 50 radionuclides included in the simulation, or if the user wishes to abort. If the user selects the option to include only 50 radionuclides in the simulation, the remaining data for the radionuclides are ignored.

2. Checks if the radionuclide concentration are entered in units of $\mathrm{Ci} /$ gallons or $\mathrm{Ci} /$ liter. If the data is in $\mathrm{Ci} /$ gallon, $\mathrm{REED}$ converts the data to $\mathrm{Ci} /$ liter. 
3. Searches for and reads in the required data for each radionuclide included in the simulation from the data base file "KCTA.d." If data for a selected radionuclide are not found in the data base file, REED informs the user and aborts execution.

4. Returns execution to the MAIN module.

\subsubsection{The STEADY Module}

The STEADY module calculates constants and coefficients that are nuclide- and cooling tower parameter-dependent. Initial steady-state radionuclide activity levels in the various CTW system components and initial steady-state release rates to the environment are also calculated by the STEADY module. The following are the tasks performed by the STEADY module:

1. Converts the process water and the cooling water make-up flow rates from gallons per minute to gallons per sec.

2. Calculates both the total cooling water flow rate in the CTW system and the flow fractions from the cooling tower to the atmosphere, to the Savannah River, and to the 186-Basin using Equations (2-21), (2-22), and $(2-6)$, respectively.

3. Calculates the resident and loop time constants using the following Equations:

$$
\begin{gathered}
\tau_{r}^{m}=V^{m} / \dot{V}_{f}^{m} \\
\tau_{l}^{m+n}=V^{m+n} / \dot{V}_{f}^{m+n}
\end{gathered}
$$

where $\mathrm{V}^{\mathrm{m}}$ and $\mathrm{V}^{\mathrm{m}+\mathrm{n}}$ are the volumes of the $\mathrm{m}^{\text {th }} \mathrm{CV}$ and the loop connecting the $\mathrm{n}^{\text {th }} \mathrm{CV}$ to the $\mathrm{m}^{\text {th }} \mathrm{CV}$, respectively, and $\dot{V}$ is the corresponding cooling water flow rate.

4. Calculates the nuclide-CV-dependent and the nuclide-loop-dependent constants using Equations (2-11) and (2-12).

5. Calculates the initial steady-state radionuclide activity levels in the CTW components using Equations (2-13), (2-14), and (2-15). 
6. Calculates the initial steady-state rate of radionuclide release to the environment via evaporation to the atmosphere and blow-down to the Savannah River using Equations (2-18), (2-19), and (2-20).

7. Returns execution to MAIN.

\subsubsection{The RITE1 Module}

The RITE1 module writes the input data read by the REED module and the constants and coefficients calculated by the STEADY module to the file assigned to I/O unit 20 whose name is contained in the OUTP variable. Description of the output obtained from KCTA is presented in Appendix A.

\subsubsection{The ERRCHK Module}

The ERRCHK module checks the following so that execution errors are minimized:

1. Checks if the pre-set array sizes for storing delayed term data are not exceeded by that required from the obtained loop times and requested step size. If the required array size is larger than that set by KCTA, ERRCHK aborts execution.

2. Checks if the requested time step for the simulation is within the recommended time step. The recommended time step is the smallest of the following:

a. Half of the smallest time increment between two adjacent points used in defining the leak function.

b. Half of the smallest of all CV residence times.

c. Half of the smallest of all loop connection times.

If ERRCHK detects that the requested time step is greater than any of the time steps given in item (a), (b), or (c) above, the user is given the option of continuing with the execution at the requested time step, changing the time step to that recommended by ERRCHK, or aborting the program. If the time step is changed to the value recommended by ERRCHK, then the test described in item (1) above is repeated. 


\section{Returns execution to MAIN.}

\subsubsection{The TRANS Module}

The TRANS module calculates the time-dependent nuclide activity level in each of the CTW components, the release rates to the environment, and the total release to the environment from $t=0 \mathrm{sec}$ up to the current time step for each radionuclide. For each radionuclide included in the simulation and at each time step, the TRANS module performs the following tasks:

1. Calculates the PW leak rate into the heat exchangers using linear interpolation between the points that define the leak function.

2. Obtains values for the delayed terms in Equations (2-7), (2-8), and (2-

9) using the following scheme:

a. if $\mathrm{t}-\tau_{\mathrm{l}}^{\mathrm{m}-\mathrm{a}} \leq 0 \mathrm{sec}$, the delayed term values are set to their initial steady-state values (calculated by the STEADY module $\left(\mathrm{N}_{\mathrm{i}}^{\mathrm{m}-\mathrm{n}}\left(\mathrm{t}-\tau_{\ell}^{\mathrm{m}-\mathrm{n}}\right)=\mathrm{N}_{\mathrm{i} 0}^{\mathrm{m}}\right)$.

b. if $\mathrm{t}-\tau_{\mathrm{l}}^{\mathrm{m}+\mathrm{a}} \geq 0 \mathrm{sec}$, the delayed terms are obtained by searching the delayed term arrays for the corresponding time. That is, since the time step is fixed throughout the simulation, the number of time steps executed from time $=0.0 \mathrm{sec}$ to time $=\mathrm{t}-\tau_{\mathrm{l}}^{\mathrm{m}+\mathrm{n}}$ is equal to $\left(\mathrm{t}-\tau_{\ell}^{\mathrm{m}+\mathrm{n}}\right) / \Delta \mathrm{t}$, where $\Delta \mathrm{t}$ is the time step. The delayed values are then obtained from the delayed term arrays.

3. Calculates the activity levels in heat exchangers, 186-Basin, and the cooling tower by integrating Equation (2-7), (2-8), and (2-9), respectively.

4. Calculates the release rates via blow-down to the Savannah River and evaporation to the atmosphere by use of Equations (2-19) and (2-20), respectively.

5. Calculates the total amount released to the environment since the initiation of the transient (i.e., since $\mathrm{t}=0 \mathrm{sec}$ ). 
6. Checks if the calculated values are to be printed for the current time step. If so, these values are written to the output file connected to $\mathrm{I} / \mathrm{O}$ unit 20.

7. Repeats steps (1) through (6) until the maximum time for the simulation is reached. If so, steps (1) through (6) are repeated for the other radionuclides included in the simulation.

8. Returns execution to MAIN.

Once execution is returned to the MAIN module from the TRANS module, MAIN will then close all $\mathrm{I} / \mathrm{O}$ ports and terminate execution. 


\subsection{CASE STUDY}

\subsection{Introduction}

Radionuclides release rates and total releases from the CWS to the environment due to process water leaks are investigated in this section for two CWS operational conditions: with and without an on-line cooling tower. The chosen leak scenario is the PW leak that occurred in December 1991. Although controls are now in place to prevent extended leaks such as this, it is assumed that the leak duration was again 64 hours before being isolated. Since the CWS with the cooling tower is a quasi-closed loop, radionuclides will be present for prolonged periods in CWS components, e.g., the 186-Basin. Therefore, doses to workers due to the presence of tritium in CWS components during the event are also presented in this section.

\subsection{Description of Event}

Approximately $5,700 \mathrm{Ci}$ of tritium were released from a leaking heat exchanger to the Savannah River during the period of December 22 through December 25, 1991' (leak duration was estimated to be 64 hours). For an assumed tritium concentration of 8.6 $\mathrm{Ci} /$ liter in the PW, the December 91 leak is a relatively large PW leak: $0.046 \mathrm{gpm}$ or $\approx 550 \mathrm{lb} /$ day. However, current controls preclude such a long leak duration. The leak rate was estimated to be constant during the 64 hour period, i.e., $\approx 89.1 \mathrm{Ci} / \mathrm{Hr}$ during the 64 hour event.

\subsection{CWS Without an On-Line Cooling Tower}

The CWS without an on-line cooling tower is a once-through open system. Thus, any leak releasing PW to the CWS will release the same amount of PW at the same rate to the environment. This indicates that a total of $5,700 \mathrm{Ci}$ of tritium is released to the environment at a constant rate of $\approx 89.1 \mathrm{Ci} / \mathrm{Hr}\left(2.47 \times 10^{-2} \mathrm{Ci} / \mathrm{sec}\right)$. Additionally, with the exception of the tritium evaporating as it flows in the canal connecting the CWS to the Savannah River, all the tritium is released in liquid form to the environment.

\subsection{CWS With a Cooling Tower On-Line}

In order to investigate the radiological effects of a CWS with an on-line cooling tower the following assumptions are employed: 
- The reactor is assumed to have been operating at $720 \mathrm{MW}$. This results in cooling water evaporation and blow-down rates of $6,000 \mathrm{gpm}$ and $14,000 \mathrm{gpm}$, respectively. The cooling water recirculation rate is assumed to be constant at $160,000 \mathrm{gpm}$.

- The leak continues for 64 hours. However, after 64 hours the reactor is shutdown and the cooling water evaporation and blow-down rates both drop to $0.0 \mathrm{gpm}$. The cooling water gamma monitor would indicate process water leakage as well as testing controls before 64 hours elapsed. Nonetheless, the same time length is used in the illustration as occurred in December 1991.

The input file to the KCTA code describing this event is listed in Figure 4-1. Appendix A discusses the required input to the KCTA code. Results obtained from the KCTA code are discussed in the following subsections.

\subsubsection{Tritium Concentration Levels in CWS Components}

Shown in Figure 4-2 on the following page are the time dependent behavior of the tritium concentration levels in the CWS components (186-Basin, heat exchangers, and the cooling tower) during the 64-hour leak. Also shown in Figure 4-2 are the steadystate tritium concentration levels in the heat exchangers and the cooling tower. The

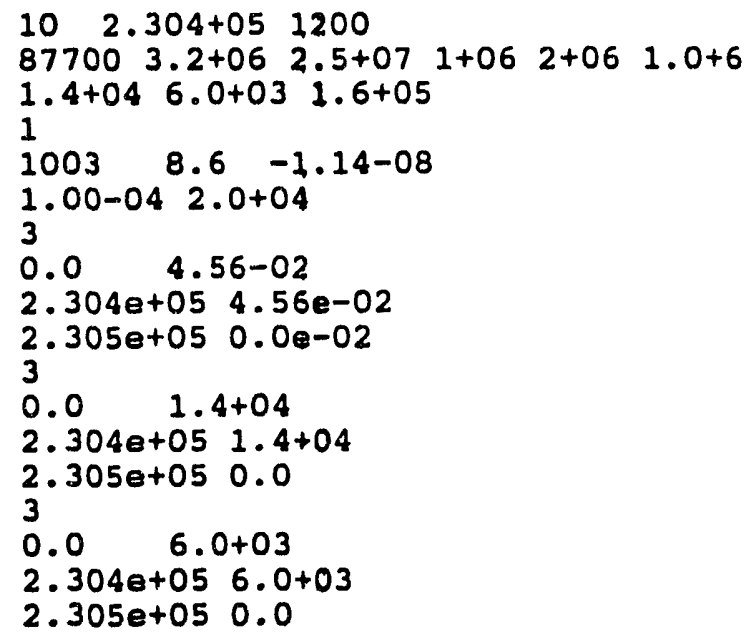

Figure 4-1. KCTA Code Input File for December 1991 Event 


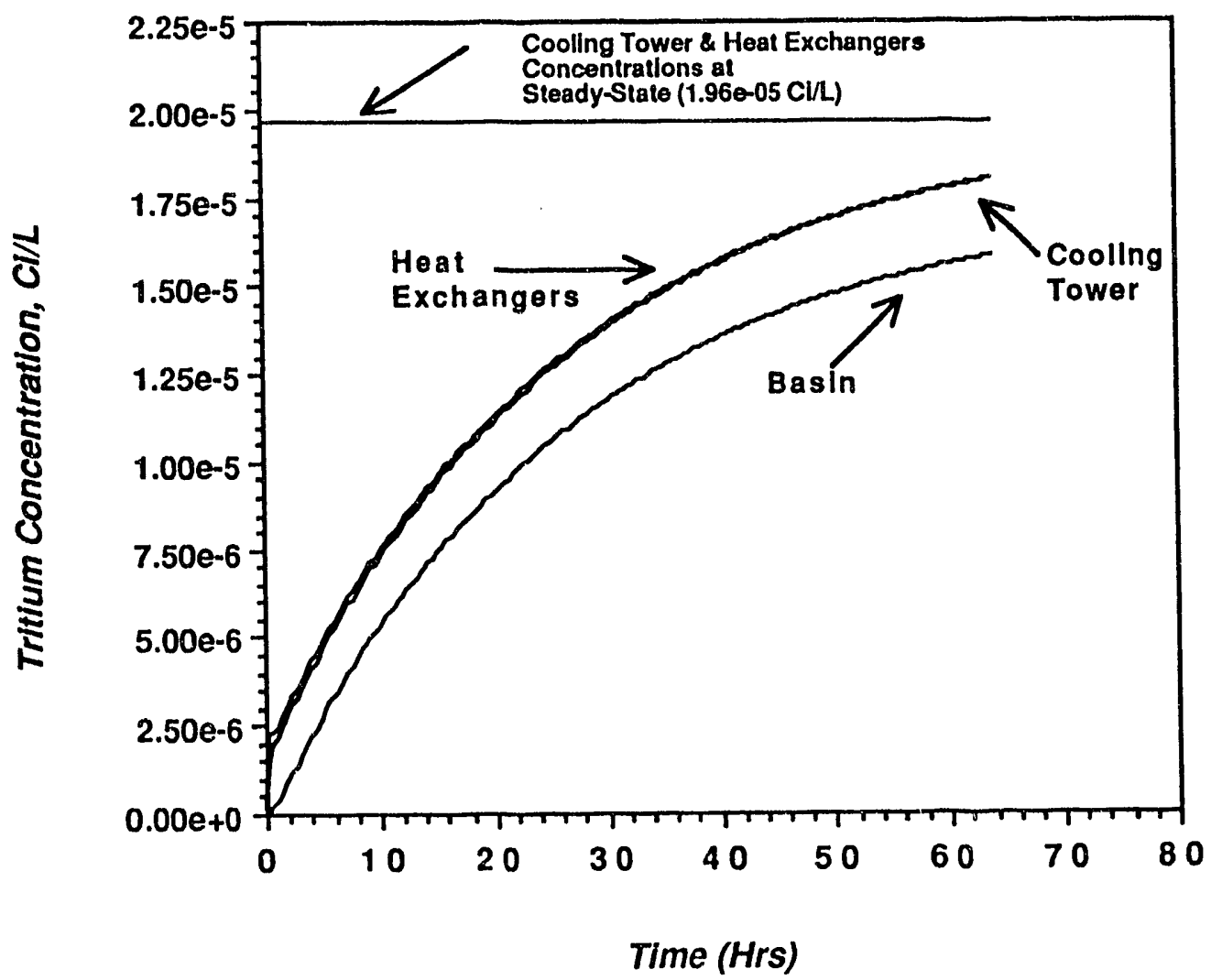

Figure 4-2. Tritium Concentration in CWS Components During the December 1991 Leak 
steady-state tritium concentration levels are obtained by allowing the leak to continue at normal CWS operations, i.e., normal cooling water evaporation and blow-down rates. The steady-state tritium level in the cooling tower and heat exchangers is 1.96 $\times 10^{-05} \mathrm{Ci} / \mathrm{L}$. This is also shown in Figure 4-2. The steady-state concentration of tritium in the 186-basin is $1.74 \times 10^{-05} \mathrm{Ci} / \mathrm{L}$. The concentration of any radionuclide in the basin is always lower than that in the cooling tower or in the heat exchanger due to the following:

- Decay of short-life radionuclides in the heat exchangers and the cooling tower prior to reaching the basin. However, for long-lived radionuclides, e.g., ${ }^{3} \mathrm{H}$, the lag time for transporting radionuclides from the heat exchangers to the cooling tower and then to the basin is negligible.

- The basin receives cooling water from two sources: recirculation flow from the cooling water and cooling water make-up from the Savannah River. The make-up cooling water dilutes radionuclides entering the basin from the cooling tower.

The time dependent behavior of tritium concentration levels in CWS components during the first two hours of the December 91 leak are plotted in Figure 4-3. The effect of the lag times associated with transporting radionuclides between the CWS components can be seen in Figure 4-3. Figure 4-3 indicates that the tritium concentration levels in the cooling tower and the basin begin to increase at about six and 20 minutes, respectively, following the initiation of the leak. These are due to the loop connection times between the heat exchangers and the cooling tower and the loop connection time between the cooling tower and the basin. However, in reality, the basin is expected to experience the effect of the leak at a much longer time $(\approx 40$ minutes). The longer lag time is due to the residence time of the radionuclides in the heat exchangers $(\approx 0.5 \mathrm{~min})$, loop time between the heat exchangers and the cooling tower $(\approx 6 \mathrm{~min})$, the residence time in the cooling tower $(\approx 18 \mathrm{~min})$, and the loop time between the cooling tower and the 186-Basin $(\approx 11 \mathrm{~min})$. The assumption embedded in the employed model of instantaneous perfect mixing in the CWS components causes the lag time to be underestimated. The effect of shorter lag time predicted by the model due to the perfect mixing assumption is compensated by the fact that tritium at reduced concentrations is transported to the basin.

Figure 4-3 also indicates that the tritium concentration level in the heat exchangers reaches a plateau only after a few minutes following the leak. The plateau o ${ }^{\text {nl }}$ lasts for about 20 minutes and the tritium level in the heat exchanger begins to rist igain. The obtained plateau is due to the relatively small volume of the heat exchangers 


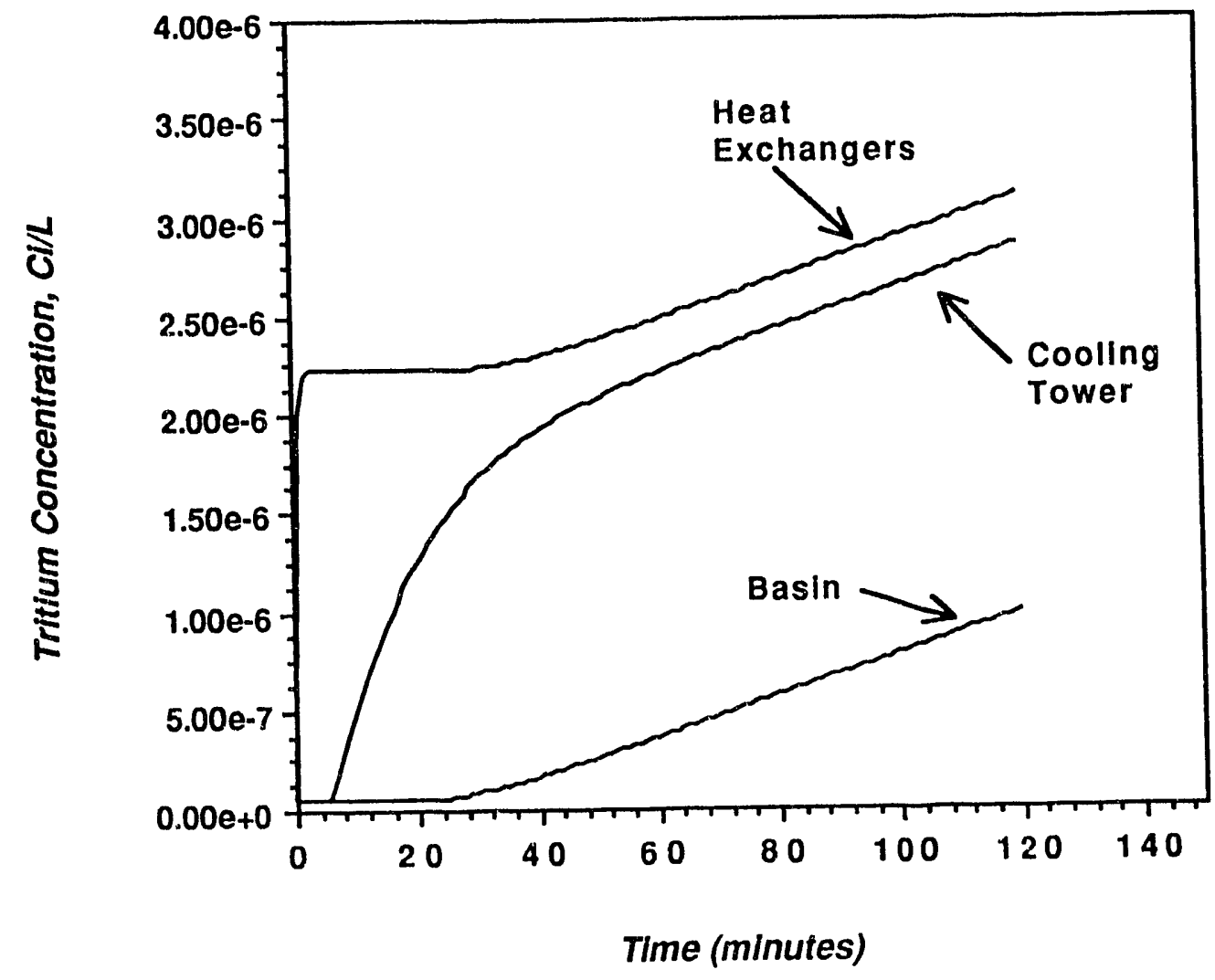

Figure 4-3. Tritium Concentration in CWS Components During the First Two Hours of the December 1991 Leak 
which causes a temporary tritium saturation level to be reached quickly. The temporary tritium concentration steady-state level ceases to exist due to the fact that at about 25 minutes into the event, the basin starts to contribute more tritium to the heat exchangers, thereby increasing the source of tritium. In reality, this occurs at about 200 minutes after the leak begins. (Residence time in the 186-Basin alone is about 160 minutes). This is also due to the assumption of perfect mixing in the CWS control volumes.

The effects of instantaneous perfect mixing in the CWS components can be reduced by one of two ways. These are the following:

- Dividing the CWS components into a number of control volumes. Then by employing lag times between the smaller control volumes, a more accurate treatment of lag times associated with transporting radionuclides through CWS components can be obtained. This task, sub-dividing the CWS control volumes into smaller control volumes is recommended for future work.

- Using a "mocked-up" description of the CWS in the input file to allow a better treatment of radionuclide mixing in the CVs. This can be accomplished by reducing the CV's volume and increasing the loop volume connecting the different CWS components. This will allow better treatment of lag times associated with transporting radionuclides through the CWS and reduce the effect of the instantaneous perfect mixing assumption embedded in the KCTA code. The input file with the "mocked-up" description of the CWS is presented in Figure 4-4. Table 4-1 list the volumes of the actual and the "mocked-up" CWS. The tritium concentration level in CWS components as a function of time during the even, obtained from performing a KCTA run on the "mockedup" CWS, are presented in Figures 4-5 and 4-6. Figure 4-5 is for the first two hours during the event and Figure 4-6 is for the entire period of the event.

Figures 4-5 and 4-6 indicate that a number of plateaus are obtained for each control volume. Each plateau last for $\approx 200$ minutes, which is equal to the loop cycle time. Figure 4-5 also indicates that the 186-Basin begins to experience the effects of the leak at about 40 minutes following the initiation of the leak, indicating that the lag times in the CWS are being accounted for. For the purpose of comparison, Table 4-2 lists the tritium release rates and total releases to the environment at the end of the event (64 hours) for the two different treatments of the CWS using the KCTA code.

The results, as shown in Table 4-2, indicate that the "mocked-up" CWS configuration releases $\approx 4 \%$ less tritium than the actual CWS configuration using the current model employed in the KCTA code. Table 4-2 also indicates that tritium is being released 


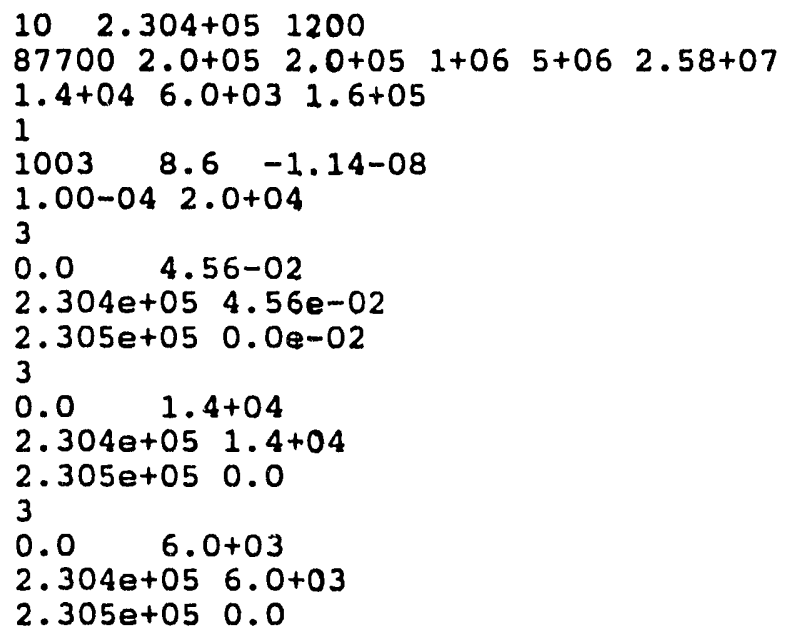

Figure 4-4. KCTA Code Input File for December 1991 Event With "Mocked-Up" CWS Description

Table 4-1. Volumes of the Actual and "Mocked-Up" CWS

\begin{tabular}{|l|r|r|}
\hline \multicolumn{1}{|c|}{ CWS Components } & Actual CWS & "Mocked-up" CWS \\
\hline Heat Exchangers (gallons) & 87,700 & 87,700 \\
\hline Cooling Tower (gallons) & $3,200,000$ & 200,000 \\
\hline 186-Basin (gallons) & $25,000,000$ & 200,000 \\
\hline HXs-to-CT (gallons) & $1,000,000$ & $1,000,000$ \\
\hline CT-to-Basin (gallons) & $2,000,000$ & $5,000,000$ \\
\hline Basin-to-Hxs (gallons) & $1,000,000$ & $25,800,000$ \\
\hline Total Volume (gallons) & $32,287,700$ & $32,287,700$ \\
\hline
\end{tabular}




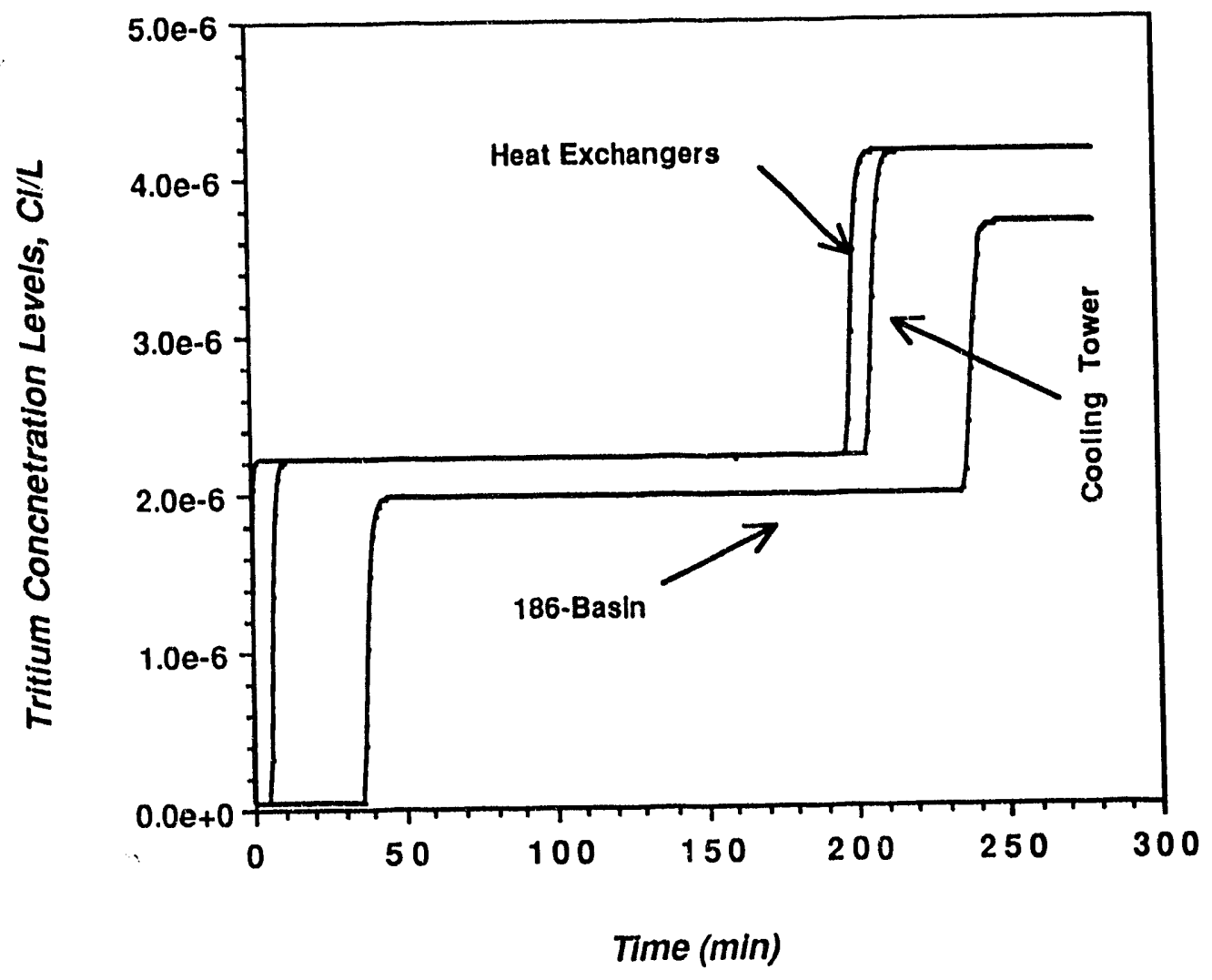

Figure 4-5. Tritium Release Rates from the "Mocked-Up" CWS to the Environment During the First Two-hours of the December 1991 Leak 


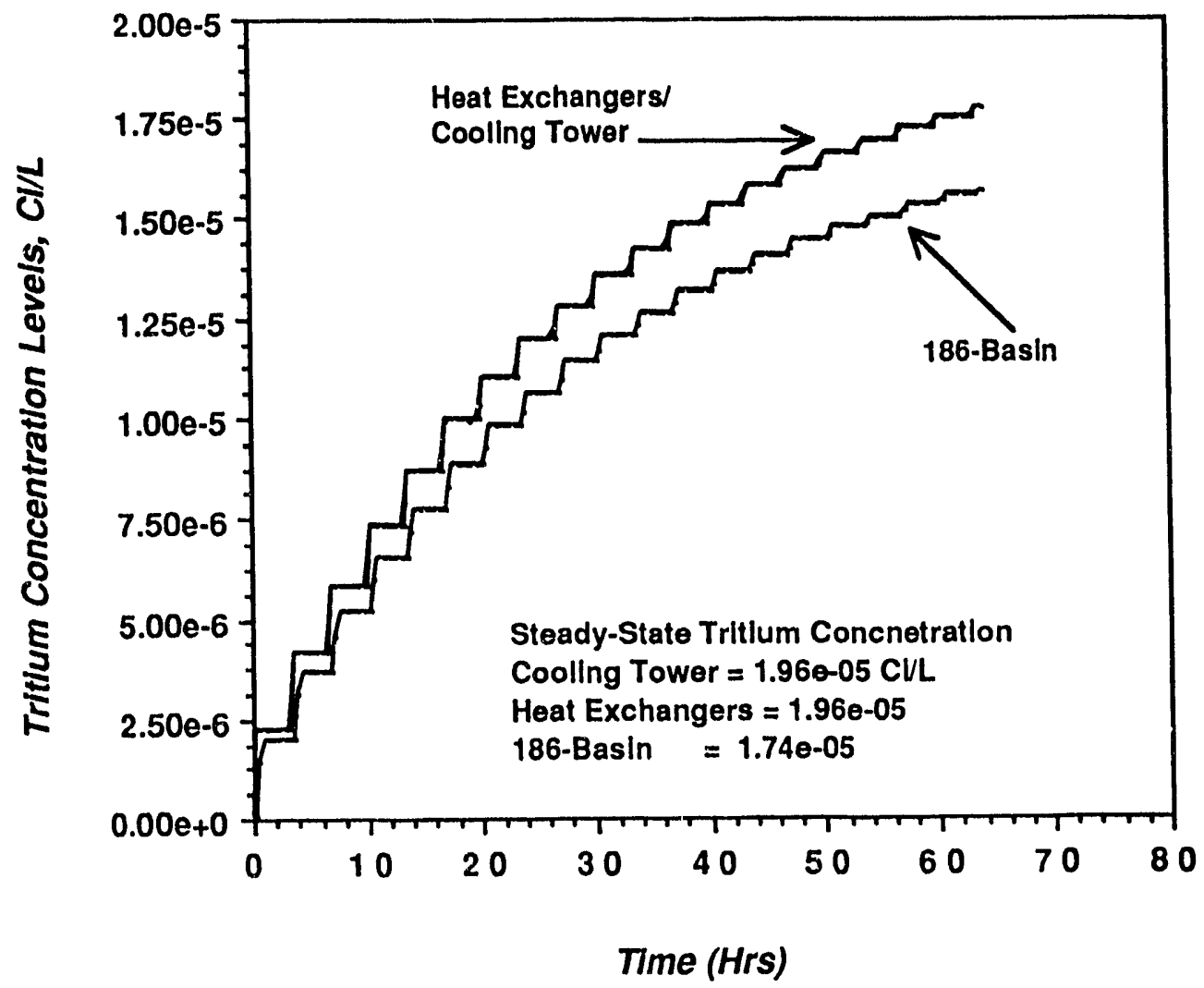

Figure 4-6. Tritium Release Rates from the "Mocked-Up" CWS to the Environment During the December 1991 Leak 
Table 4-2. Tritium Release Rates and Cumulative Releases to the Environment at the End of the Event

\begin{tabular}{|c|c|c|}
\hline Parameter & Actual CWS & "Mocked-Up" CWS \\
\hline $\begin{array}{r}\text { Release Rate }(\mathrm{Ci} / \mathrm{sec}) \\
\text { Evaporation } \\
\text { Blow-Down } \\
\text { Total } \\
\end{array}$ & $\begin{array}{l}6.81 \times 10^{-3} \\
1.59 \times 10^{-2} \\
2.27 \times 10^{-2} \\
\end{array}$ & $\begin{array}{l}6.27 \times 10^{-3} \\
1.57 \times 10^{-2} \\
2.24 \times 10^{-2} \\
\end{array}$ \\
\hline $\begin{array}{r}\text { Cumulative Release }(\mathrm{Ci}) \\
\text { Evaporation } \\
\text { Blow-Down } \\
\text { Total }\end{array}$ & $\begin{array}{l}1.11 \times 10^{3} \\
2.60 \times 10^{3} \\
3.71 \times 10^{3}\end{array}$ & $\begin{array}{l}1.07 \times 10^{3} \\
2.50 \times 10^{3} \\
3.57 \times 10^{3}\end{array}$ \\
\hline
\end{tabular}

at a lower rate in the "mocked-up" CWS than does the actual CWS. This is due to the fact that a longer effective CWS lag time is obtained using a "mocked-up" CWS configuration.

\subsubsection{Tritium Release Rate}

Shown in Figure 4-7 is a plot of the time-dependent tritium release rates from the CWS to the environment via evaporation to the atmosphere and blow-down to the Savannah River. Also shown in Figure 4-7 are the tritium steady-state release rates to the environment. Steady-state release rate of tritium is obtained from either the CWS without an on-line cooling tower or if the PW leak in the CWS with an on-line cooling tower is allowed to continue. This can be seen from Figure 4-7 where the total tritium release rate to the environment is approaching its asymptotic value of $\approx 2.5 \times 10^{-2} \mathrm{Ci} / \mathrm{sec}$.

The cumulative tritium release to the environment as a function of time is presented in Figure 4-8. Figure 4-8 indicates that at the time the leak is isolated and the reactor is shutdown, 3,714 $\mathrm{Ci}$ of tritium has been released to the environment for the case the CWS with an on-line cooling tower versus $5,700 \mathrm{Ci}$ for the CWS without an on-line cooling tower. 


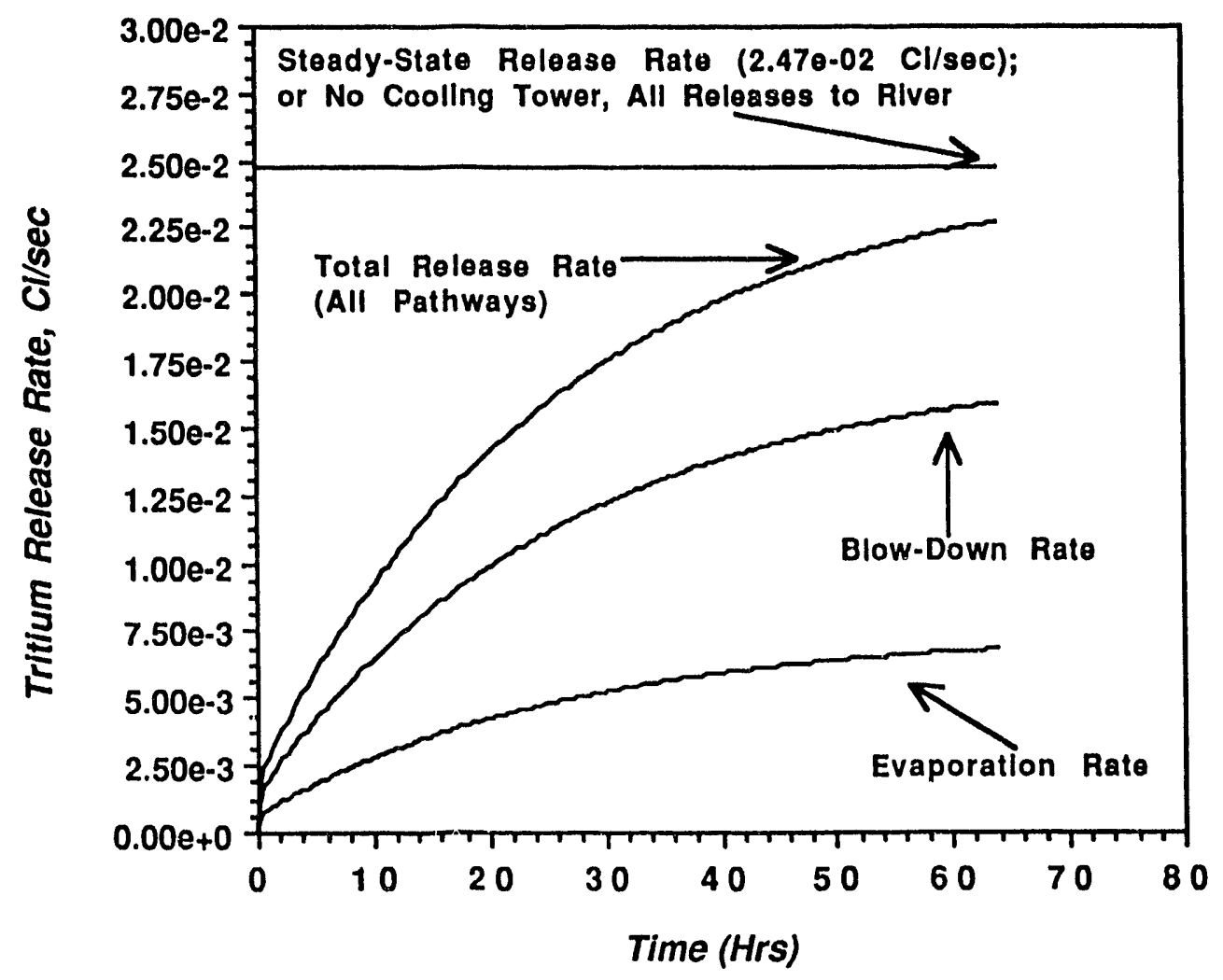

Figure 4-7. Tritium Release Rates from the CWS to the Environment During the December 1991 Leak 


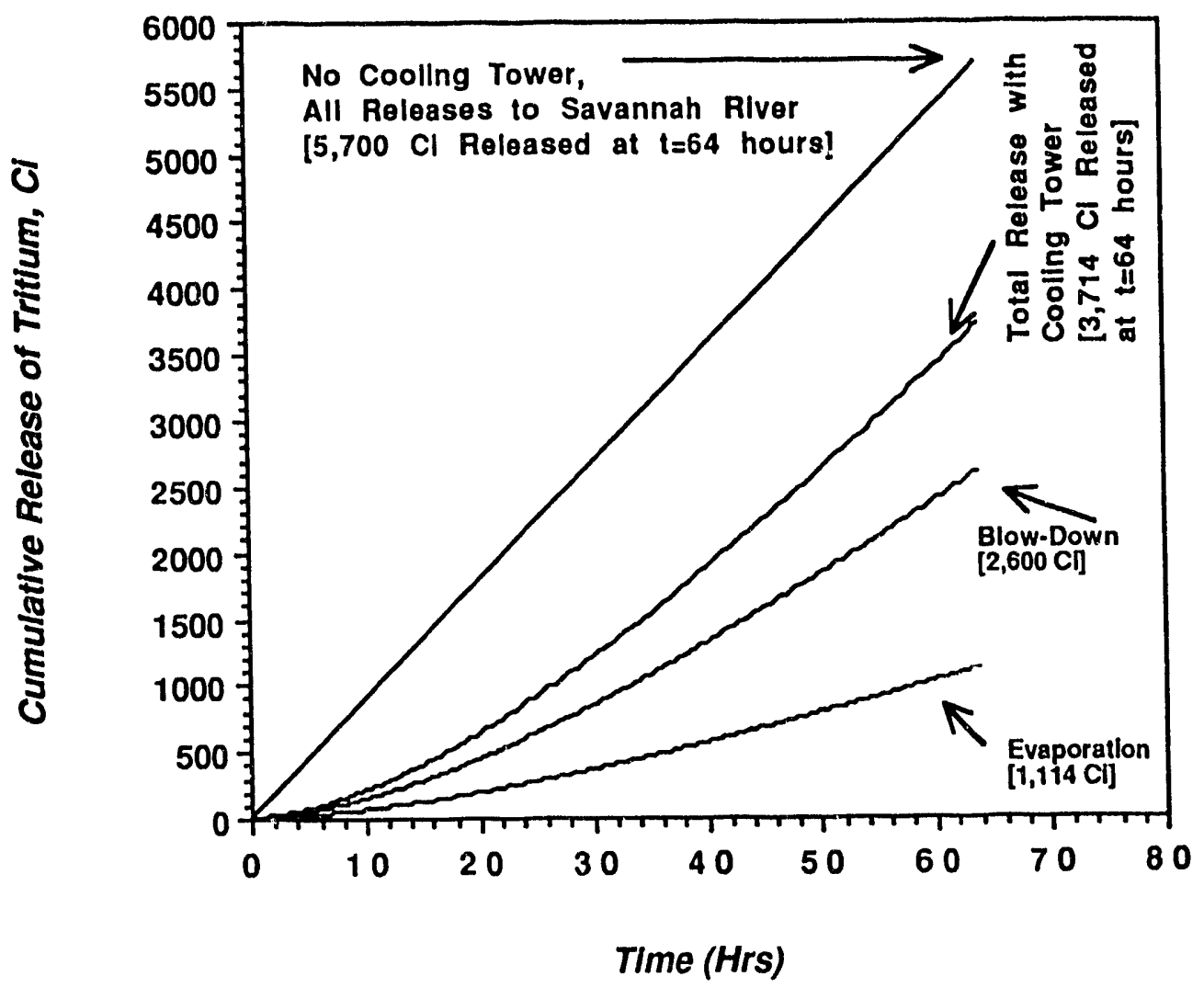

Figure 4-8. Cumulative Tritium Release from the CWS to the Environment During the December 1991 Leak 
During the 64 hour leak, $5,700 \mathrm{Ci}$ of tritium have been released through the leaking heat exchanger to the CWS. Of the $5,700 \mathrm{Ci}$, only 3,714 $\mathrm{Ci}$ have been released to the environment. The remaining $1,986 \mathrm{Ci}$ of tritium are stored in the CWS: $\approx 1,500 \mathrm{Ci}$ in the 186-Basin, $\approx 6 \mathrm{Ci}$ in the heat exchangers, $\approx 220$ in the cooling tower, and $\approx 260 \mathrm{Ci}$ in the loop connecting the CWS components. This indicates that the CWS with an on-line cooling tower system is acting as an electric circuit with a capacitor.

\subsubsection{Tritium Dose Rates}

The dose to workers around the cooling tower following the December 1991 leak as a function of time is presented in Figure 4-9. The given doses are due to inhalation of tritium, absorption of tritium through the skin, and immersion in the tritiated environment. Figure 4-9 also list the doses at the steady-state tritium concentration levels if the leak was allowed to continue. Although the December 1991 leak is a relatively large leak, the resultant dose to workers are relatively small, e.g., $\approx 7 \times$ $10^{-8} \mathrm{rem} / \mathrm{Hr}$. Additionally, the inhalation tose is computed $\mathrm{d}^{3}$ assuming saturated vapor condition for water at $90^{\circ} \mathrm{F}$, which yields higher concentration of tritium than would be expected and workers are assumed to be totally surrounded by a tritiated environment.

Since controls have been added to the CWS to prevent such large leaks, than the doses presented in Figure 4-9 are not expected. However, doses to workers at steady-state conditions for $\mathrm{PW}$ leaks of $0.5 \mathrm{lb} / \mathrm{h}$ and $0.5 \mathrm{lb} /$ day are presented in Table 4-3. These would be the maximum expected doses to workers for continuous leaks.

\subsection{References}

1. D.M. Hamby, R.P. Addis, D.M. Beals, J.R. Cadieux, W.H. Carlton, D.L. Dunn, G. Hall, D.W. Hayes, R. Lorenzo, M.V. Kantelo, and R.W. Taylor, "Emergency Response Monitoring Activities and Environmental Impact of the K-Reactor Aqueous Tritium Release of December 1991 (U)," WSRC-RP-92186, Westinghouse Savannah River Company, Aiken, SC, February 7, 1992.

2. DOE-EH-0071, "Internal Dose Conversion Factors for Calculating Dose to the Public," July 1988.

3. J.M. East and K.R. O'Kula, "Tritium Inhalation - Unprotected Doses (U)," SRL-STE-92-0045, Westinghouse Savannah River Company, Aiken, SC, February 26, 1992. 


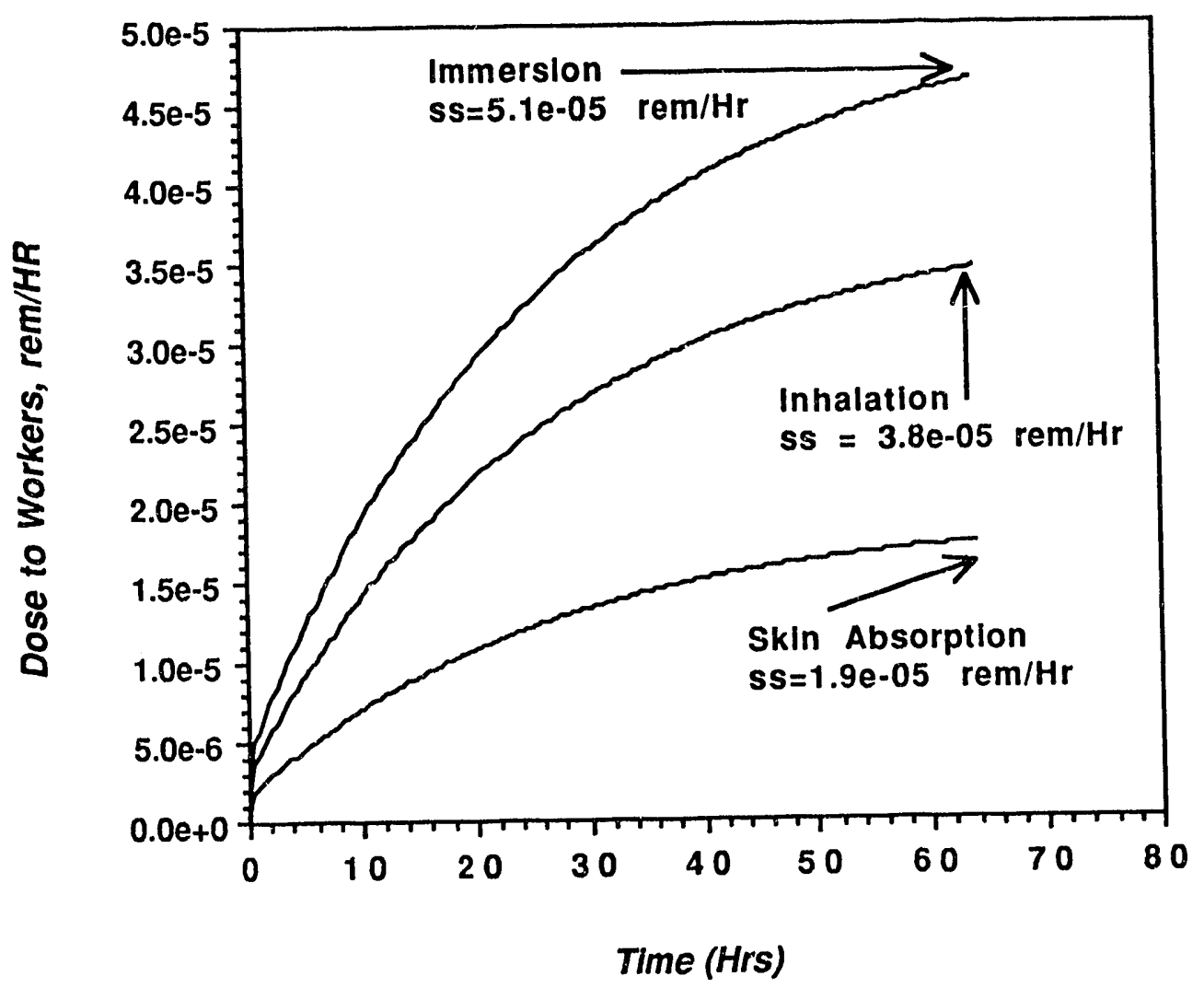

Figure 4-9. Expected Dose to Workers Near the Cooling Tower During the December 1991 Leak 
Table 4-3. Maximum Expected Dose to Workers Near The Cooling Tower Due to Continual Process Water Leaks

\begin{tabular}{|c|c|c|}
\hline PATHWAY & $0.5 \mathrm{lb} /$ day & $0.5 \mathrm{lb} / \mathrm{Hr}$ \\
\hline INHALATION & $5.1 \times 10^{-8} \mathrm{rem} / \mathrm{Hr}$ & $1.2 \times 10^{-6} \mathrm{rem} / \mathrm{Hr}$ \\
\hline SKIN ABSORPTION & $2.5 \times 10^{-8} \mathrm{rem} / \mathrm{Hr}$ & $6.0 \times 10^{-7} \mathrm{rem} / \mathrm{Hr}$ \\
\hline IMMERSION & $6.6 \times 10^{-8} \mathrm{rem} / \mathrm{Hr}$ & $1.6 \times 10^{-6} \mathrm{rem} / \mathrm{Hr}$ \\
\hline
\end{tabular}




\subsection{LIMITATIONS AND FUTURE WORK}

\subsection{Introduction}

Assumptions embedded in the development of the CWS radionuclide transport model along with limitations of the KCTA code are discussed in the following section. This is followed by a section outlining recommendations for further work.

\subsection{Limitations}

Assumptions embedded in the development of the radionuclide transport model include the following:

- instantaneous perfect mixing of radionuclides in all control volumes. However, the effects of this assumption can be reduced by employing a "mocked-up" description of CWS control volumes, e.g., Section 4.4.1.

- slug flow outside the control volumes (in the connecting loops);

- radionuclides are introduced to the cooling water system only by the PW leak (through the heat exchangers) and/or by the make-up cooling-water. Production of radionuclides from the decay of their parent(s) radionuclides is neglected;

- cooling tower water flow rate is constant;

- results included in the output file are all in tabular format without any graphical displays.

- all evaporation losses occur only in the cooling tower; and

- radionuclides have the same evaporation characteristics as water. This assumption may only be valid for tritium in the form of DTO, $\mathrm{T}_{2} \mathrm{O}$, or HTO. 


\subsection{Path Forward}

Verification and Validation (V\&V) of the KCTA code needs to be performed. This step will provide an assurance of the quality of its results is obtained. Following the $\mathrm{V} \& \mathrm{~V}$ process, comparison studies can be performed to examine effects of the cooling tower on the environment. This can be achieved by examining effects of various heat exchanger leak scenarios and various operator responses by means of varying the cooling tower blow-down and evaporation rates. Such studies can be useful in establishing procedures so that radionuclide releases to the environment and the consequences of these releases can be minimized.

Additionally, enhancements to the KCTA code may be required in the future. Recommended enhancements and modifications to the KCTA code include the following:

- Sub-divide the control volumes into smaller control volumes so that the effects of assuming perfect mixing in the control volumes can be reduced.

- Divide the heat exchangers into two control volumes. One CV should simulate the leaking heat exchanger and the other should simulate the remaining heat exchangers. This modification will allow proper accounting of radionuclide levels in all heat exchangers and will allow investigation into the detectability of the leaking heat exchanger if small PW leaks continue for prolonged periods during operations.

- Include the CWS connecting loops as control volumes so that radionuclide levels throughout the CWS can be determined.

- Improve the output format so that other parameters can be printed during the transient. Examples include total amount of radionuclides that have leaked into the CWS and amount of radionuclides present in each CV and in the CWS.

- Allow the cooling water make-up flow to be time-dependent or the concentration of radionuclides entering with the cooling water make-up flow to be time dependent.

- Employ evaporation coefficients for each radionuclide in the data base file or in the input file so that their evaporation relative to the evaporation of water can be accurately accounted for. 
- Employ a module that will account for the production of radionuclides through the decay of their parent radionuclides.

- Employ a module to estimate inhalation dose rates due to evaporation of the cooling water from the 186-Basin and the cooling tower basin. This can be accomplished by assuming saturated vapor conditions at 186- and cooling tower basins.

- Employ a module or enhance the TRANS module so that the release rates of radionuclides to the environment are calculated in radiological terms other than $\mathrm{Ci}$, e.g., $\mathrm{R} / \mathrm{Hr}$.

- Tie-in the KCTA code with other modules to form the SRS Liquid Pathway Activity System (LPAS). LPAS will offer integrated formation, transport, deposition, and release estimates for radionuclides formed in SRS facilities. Figure 5-1 presents a schematic of a possible SRS LPAS.

- Real-time tie-in capabilities could be introduced, with feedback. For example, The WIND system could provide current evaporation conditions at the cooling tower. 


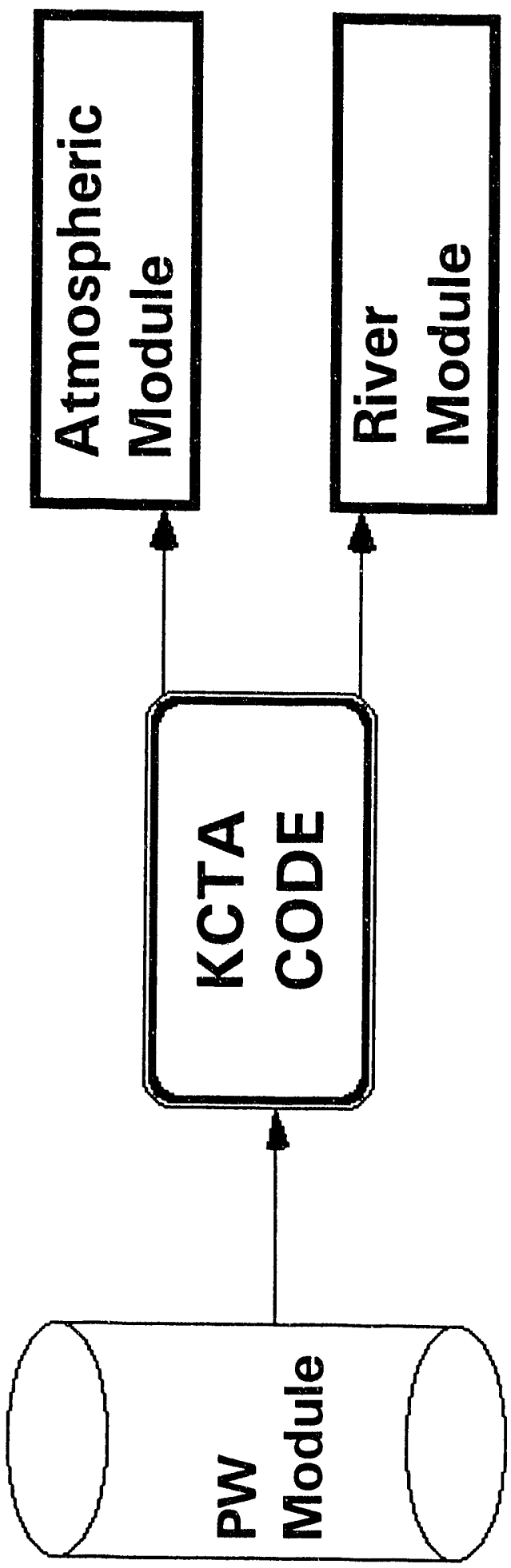

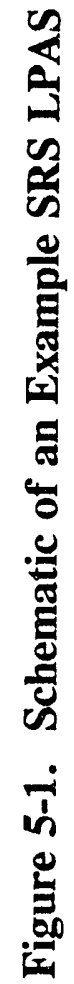




\section{APPENDIX A \\ DESCRIPTION OF THE DATA FILES \\ USED BY THE KCTA CODE}

There are three files connected to the I/O of the KCTA code. They are: the input data file, the output data file, and the data base file. These files are described in the sections that follow.

\section{A.1 Input Data File}

Upon execution of the KCTA code, the MAIN module checks for the default input file by the name of "KCTA.i" on the current drive (the drive, i.e., directory where the KCTA code is called from). If a file with the default name of "KCTA.i" does not exist on the current drive, the user is prompted to enter the name of the file that contains the input data. Once a file is found, input data are read into KCTA by the REED module.

The input data, contained in the input data file, consists of four data blocks: (I) simulation/output data block, (II) CTW specific data block, (III) nuclide-dependent data block, and (IV) function definition data block. These data blocks are described as follows:

\section{A.1.1 Block I, Simulation/Output Data}

This block consists of one card (line) with three input values in free format. It contains the following variables:

DT time step size (seconds)

TMX time to terminate simulation (seconds)

TPR time increment at which results are to be printed to the output file (seconds) 


\section{A.1.2 Block II, CTW Specific Data}

This data block contains cooling tower specific data. It consists of two cards. The first card consists of six variables, as follows:

VX volume of cooling water in all heat exchangers (gallons)

VT volume of cooling water in the cooling tower (gallons)

VB volume of cooling water in the 186-Basin (gallons)

VXT volume of the loop connecting the heat exchangers to the cooling tower (gallons)

VTB volume of the loop connecting the cooling tower to the 186-Basin (gallons)

VBX volume of the loop connecting the 186-Basin to the heat exchangers (gallons)

The second input card consists of three input variables, as follows:

Bd_0 cooling tower blow-down rate to the Savannah River (gallons per minute)

E_0 cooling tower evaporation rate to the atmosphere (gallons per minute)

R_0 cooling water recirculation rate from the cooling tower to the 186-Basin (gallons per minute)

\section{A.1.3 Block III, Nuclide-Dependent Data}

This data block consists of two types of input. The first is the number of radionuclides to be included in the problem. This value is reat into the variable NR. The second type of input consists of NR input cards with three input values per card, as follows:

NID(i) radionuclide identification number which has the form of ZZZAAA. Where $Z Z Z$ is the atomic number and $A A A$ is the mass number. For example, for ${ }^{24} \mathrm{Na} Z Z Z$ is 011 and $\boldsymbol{A A A}$ is 024 . Thus, the NID for ${ }^{24} \mathrm{Na}$ is 11024. (Table B-1, in Section B.3, lists the available radionuclides and their identification numbers.) 
$\mathbf{s P w ( i )}$ radionuclide activity in the process water

$\mathbf{s C w}(\mathbf{i})$ radionuclide activity in the make-up cooling water

If $\mathbf{s P w}$ and $\mathrm{sCw}$ are greater than zero, they are read in $\mathrm{Ci} /$ liter and then converted to $\mathrm{Ci} / g a l l o n$. If these variables are less than zero, they are read in $\mathrm{Ci} / \mathrm{gallon}$ and multiplied by -1 .

\section{A.1.4 Block IV, Function Definition Data}

Three functions are defined in this data block: (1) Heat exchanger PW leak rate, (2) cooling tower blow-down rate, and (3) cooling tower evaporation rate. Input format for these functions are described below:

\section{A.1.4.1 Heat Exchanger Leak Function}

Three types of input are needed to define this function. The first contains two variables, as follows:

Pw initial steady-state process water leak rate (gallons/min)

Cw cooling water make-up flow rate (gallons/min)

The second type of input is the number of data point pairs used in to define the timedependent process water leak function. This value is stored in the variable NLP. The third type of input consists of NLP data cards with two data points per card, as follows:

TLK(i) time (sec); and

CLK(i) process water leak-rate in gallons per minute at TLK(i).

\section{A.1.4.2 Cooling Tower Blow-Down Rate Function}

Only two types of input are needed to define the cooling tower blow-down rate function. The first is the num ${ }^{2} r$ of data points used in defining this function and is stored in the variable NBP. The second type of input consists of NBP data cards with two data points per card, as follows: 
TBD(i) time (sec); and

BDR(i) blow-down rate in gallons per minute at TBD(i).

\section{A.1.4.3 Cooling Tower Evaporation Rate Function}

This function also requires two types of input. The first is the number of data points used in defining this function and is stored in the variable NEP. The second type of input consists of NEP data cards with two data points per card, as follows:

TEV(i) time (sec); and

EVR(i) blow-down rate in gallons per minute at TEV(i).

\section{A.1.5 Sample Input Data File}

An example problem is presented in this section. The input file used to define this sample problem is shown in Figure A-1. It should be pointed out that this problem does not reflect the actual K-reactor cooling tower system. It is used only for illustrative purposes.

The sample input file shown in Figure B-1 assumes the following:

- Request a time-step of 5 seconds, terminate the simulation after 100 minutes, and print the output data at 100 seconds increments.

- The volumes of shell side of all heat exchangers, the cooling tower and its basin, the 186-basin, the loop connecting the heat exchangers to the cooling tower, the loop connecting the cooling tower to the 186-basin, and the loop connecting the 186-basin to the cooling tower are $8.77 \times 10^{4}, 3.2 \times 10^{6}, 2.5$ $\times 10^{7}, 1.0 \times 10^{6}, 2.0 \times 10^{6}$, and $1.0 \times 10^{6}$ gallons, respectively.

- The cooling tower blow-down rate to the Savannah River, evaporation rate to the atmosphere, and recirculation rate are $1.4 \times 10^{4}, 6.0 \times 10^{3}, 1.6 \times 10^{5}$ gpm, respectively.

- There is only one radionuclide to be processed, namely tritium $\left({ }^{3} \mathrm{H}\right)$. The concentration of ${ }^{3} \mathrm{H}$ is $8.6 \mathrm{Ci} /$ liter in the $\mathrm{PW}$ and $1.14 \times 10^{-8} \mathrm{Ci} /$ gallon in the make-up cooling water. 
have started closing down the necessary valves to stop the blow-down to the river. This process is assumed to take 400 seconds.

\section{A.2 Output Data File}

After checking the current directory for the input file, the MAIN module checks if a file with the name "KCTA.o" exists on the current drive. If such a file exists, the MAIN module prompts the user to enter a name of a file to be used for writing the output data to. Once a file is selected that does not exist on the current drive, this file is assigned to $\mathrm{I} / \mathrm{O}$ unit 20 and opened as a new file.

The output file is divided into four parts: (1) the input data and associated time constants, (2) the functions defining the PW leak and the cooling tower evaporation and blow-down rates, (3) the initial steady-state release rates, and (4) the transient data. The different parts of the output data are described in the following subsections.

\section{A.2.1 Output Data File, Part (1)}

The input data read by the REED module and the residence and delay loop times calculated by the STEADY module are printed out to the output file. Shown in Figure A-2 is a printout of the first part of the output data for the example input file shown in Figure B-1. Note that the name of the corresponding input file is printed on the first line of the output data. Additionally, the flow rates of make-up cooling water and the initial steady-state process water in-leakage are printed in units of gallons per minute. This part of the output file is printed to assure that the input data have been entered correctly.

\section{A.2.2 Output Data File, Part (2)}

The second part of the output data list the function definition data read by the REED module. These are shown in Figure A-3 where the PW leak function and the cooling tower evaporation and blow-down functions in gallons per sec and gallons per minute are printed out to assure that the input data have been entered correctly. 
The following data are obtained from the input file <KCTA.I >

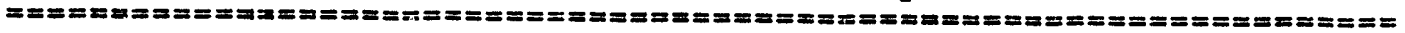

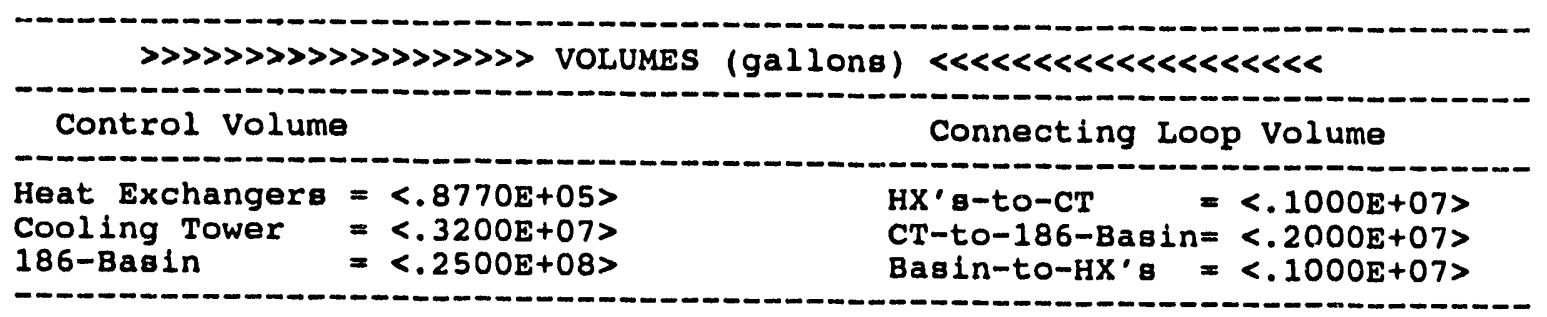

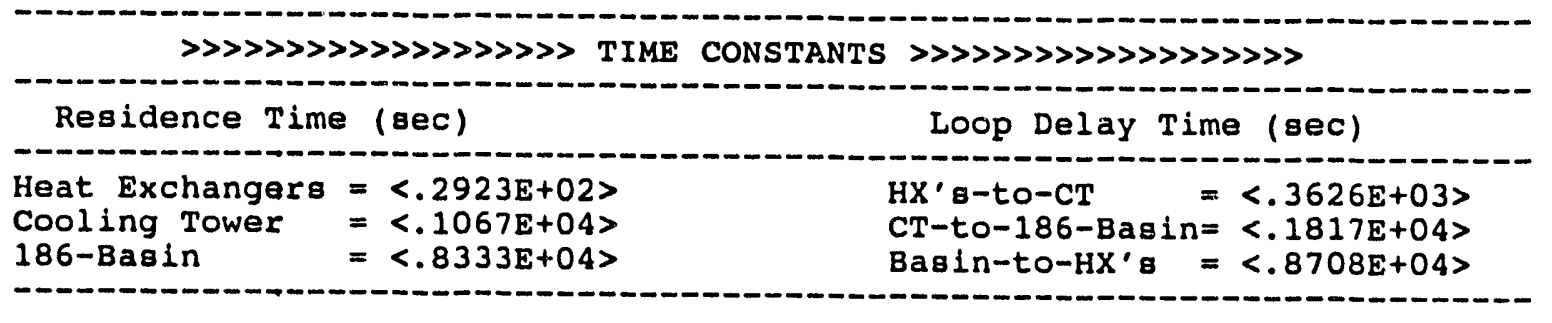

Make-up Water Flow Rate $=\langle .2000 E+05\rangle$ GPM
Process Water In-Leakage Rate $=\langle .1000 E-03\rangle$ GPM
Cooling Tower Blow-down Rate $=\langle .1400 E+05\rangle$ GPM
Cooling Tower evaporation Rate $=\langle .6000 E+04\rangle$ GPM
Cooling Tower Recirculation Rate $=\langle .1600 E+06\rangle$ GPM
Total Cooling Water Flow Rate $=\langle .1800 E+06\rangle$ GPM

Figure A-2. First Part of the Output File Produced by KCTA 
The following are the data used in defining the process water

in-leakage to the heat exchangers at $t>0$.

NOTE: ONLY < 6> points are used in defining the Process Water Leak

Rate Function, as follows:

$\begin{array}{lcc}\text { Time (sec) } & \text { Gallons/min } & \text { Gallons/sec } \\ === \pm==\pi== & .4200 \mathrm{E}-01 & .01 \\ .0000 \mathrm{E}+00 & .3800 \mathrm{E}-01 & .6333 \mathrm{E}-03 \\ .5000 \mathrm{E}+02 & .3400 \mathrm{E}-01 & .5667 \mathrm{E}-03 \\ .6000 \mathrm{E}+03 & .3200 \mathrm{E}-01 & .5333 \mathrm{E}-03 \\ .1200 \mathrm{E}+04 & .3100 \mathrm{E}-01 & .5167 \mathrm{E}-03 \\ .2400 \mathrm{E}+04 & .0000 \mathrm{E}+00 & .0000 \mathrm{E}+00 \\ .2500 \mathrm{E}+04 & & \end{array}$

The following are the data used in defining the blow-down rate function at $t>0$.

NOTE: ONLY < 3> points are used in defining this Function, as follows:

\begin{tabular}{|c|c|c|}
\hline $\begin{array}{l}\text { Time }(\mathrm{B \theta C}) \\
===\Rightarrow==x==\end{array}$ & $\begin{array}{l}\text { Gallong } / \mathrm{min} \\
=========x\end{array}$ & $\begin{array}{l}\text { Gallons/sec } \\
==========\end{array}$ \\
\hline $\begin{array}{l}.0000 E+00 \\
.3600 E+04 \\
.4000 E+04\end{array}$ & $\begin{array}{l}.1400 \mathrm{E}+05 \\
.1400 \mathrm{E}+05 \\
.0000 \mathrm{E}+00\end{array}$ & $\begin{array}{l}.2333 \mathrm{E}+03 \\
.2333 \mathrm{E}+03 \\
.0000 \mathrm{E}+00\end{array}$ \\
\hline
\end{tabular}

The following are the data used in defining the evaporation rate function at $t>0$.

NOTE: ONLY < 3> points are used in defining this Function, as follows:

\begin{tabular}{|c|c|c|}
\hline $\begin{array}{l}\text { Time (sec) } \\
==== \pm====\end{array}$ & $\begin{array}{l}\text { Gallons } / \mathrm{min} \\
===========\end{array}$ & $\begin{array}{l}\text { Gallons/sec } \\
=========\end{array}$ \\
\hline $\begin{array}{l}.0000 E+00 \\
.1500 E+04 \\
.1600 E+04\end{array}$ & $\begin{array}{l}.6000 E+04 \\
.6000 E+04 \\
.0000 E+00\end{array}$ & $\begin{array}{l}.1000 E+03 \\
.1000 E+03 \\
.0000 E+00\end{array}$ \\
\hline
\end{tabular}

Figure A-3. Second Part of the Output File Produced by KCTA 


\section{A.2.3 Output Data File, Part (3)}

The third part of the output data list the output produced by the STEADY module. That is, the initial steady-state release rates to the environment for each radionuclide and all radionuclides combined are listed in units of $\mathrm{Ci} / \mathrm{sec}, \mathrm{Ci} / \mathrm{day}$, and $\mathrm{Ci} /$ year. Shown in Figure A-4 is a printout of the second part of the output data for the example input file shown in Figure B-1.

\section{A.2.4 Output Data File, Part (4)}

The fourth part of the output file is the data calculated by the TRANS module and is printed by the TRANS module for each radionuclide at the requested print time interval. The printed data consist of the time-dependent radionuclide level in the 186Basin, all heat exchangers, and the K-reactor cooling tower. Additionally, the radionuclide release rates in $\mathrm{Ci} / \mathrm{sec}$ and integrated release since the initiation of the transient in $\mathrm{Ci}$ are printed out at the requested print time interval. The third part of the output file for the example input data given in Figure B-1 is presented in Figure A-5.

\section{A.3 Data Base File}

One of the requirements for a successful execution of the KCTA code is the existence of the data base file by the name of "KCTA.d" on the drive where the KCTA code is called from. This file is used to obtain two parameters for each radionuclide: the radiological half-life in seconds (stored in the variable HLF) and the symbol denoting the radionuclide (stored in the variable NME). The data base file, "KCTA.d," contains data for 65 radionuclides. Table B-1 lists the nuclides (NME) and their identification numbers (NID) currently employed in "KCTA.d." 


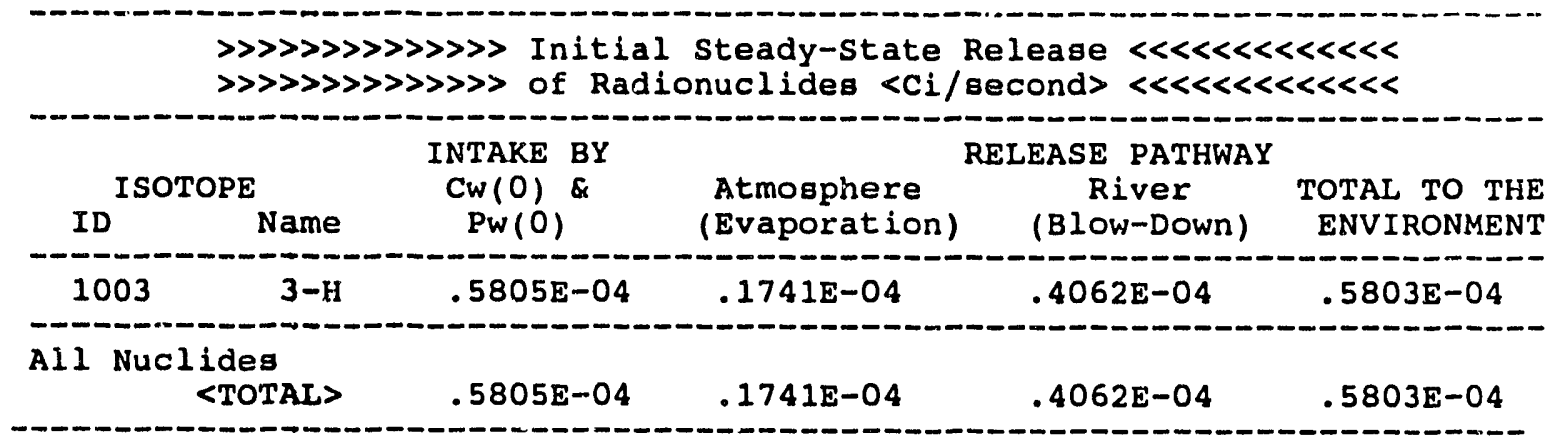

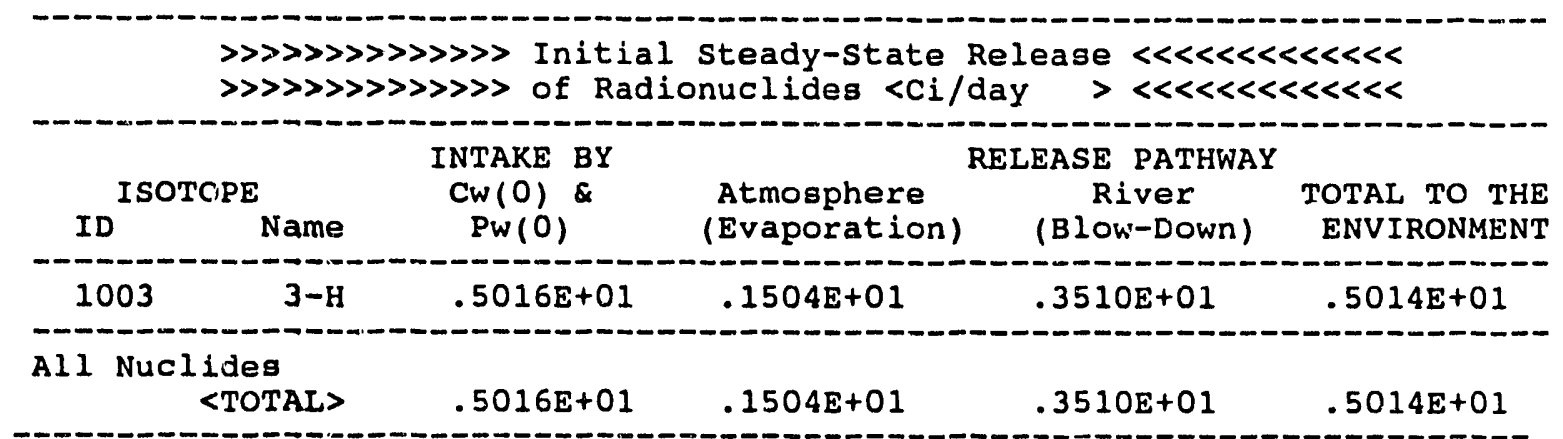

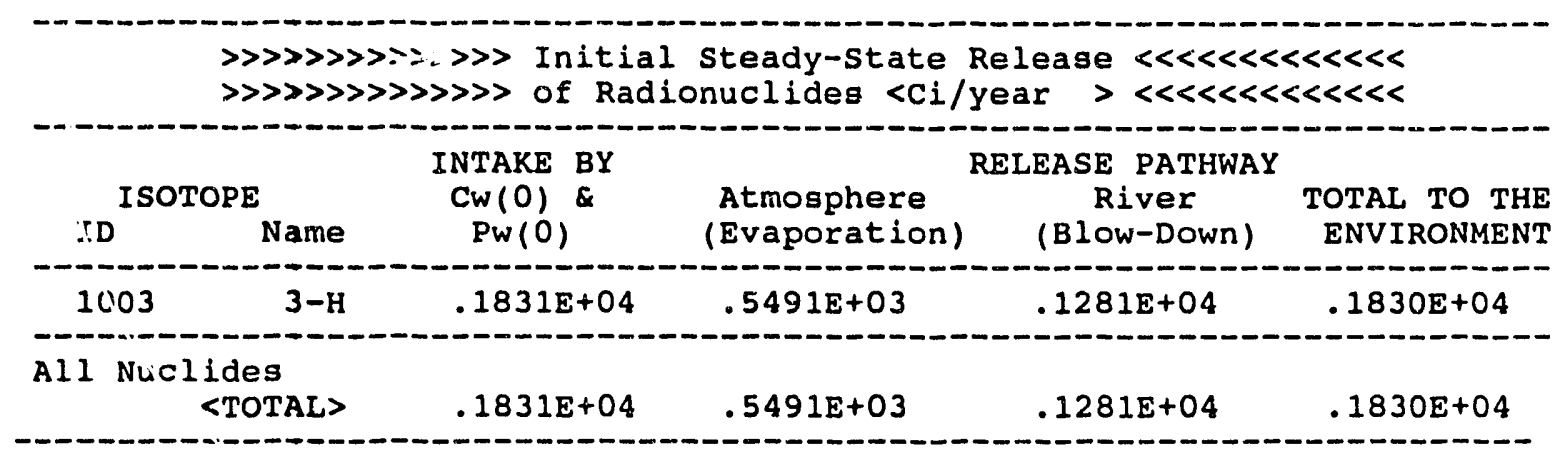

Figure A-4. Third Part of the Output File Produced by KCTA 
The following data relate to the 1 th nuclide, i.e.. $==\Rightarrow=3-H$

with the nuclide $10 \Rightarrow 1003$

\begin{tabular}{|c|c|c|c|c|c|c|c|c|c|}
\hline & $\begin{array}{r}\text { Act } i \\
\text { 186Bas i }\end{array}$ & & $\begin{array}{l}(\mathrm{C} i / L) \\
K-T \text { ower }\end{array}$ & & ate of $i$ & ( $\mathrm{Ci} / \mathrm{sec})$ & $\begin{array}{l}\text { Tota } \\
\text { Evapor. }\end{array}$ & $\begin{array}{l}\text { Reased } \\
\text { River }\end{array}$ & [i) Total \\
\hline $\begin{array}{l}.0000 E+00 \\
.1000 E+03 \\
.2000 E+03 \\
.3000 E+03 \\
.4000 E+03 \\
.5000 E+03 \\
.6000 E+03 \\
.7000 E+03 \\
.8000 E+03 \\
.9000 E+03 \\
.1000 E+04 \\
.1100 E+04 \\
.1200 E+04 \\
.1300 E+04 \\
.1400 E+04 \\
.1500 E+04 \\
.1600 E+04 \\
.1700 E+04 \\
.1800 E+04 \\
.1900 E+04 \\
.2000 E+04 \\
.2100 E+04 \\
.2200 E+04 \\
.2300 E+04 \\
.2400 E+04 \\
.2500 E+04 \\
.2600 E+04 \\
.2700 E+04 \\
.2800 E+04 \\
.2900 E+04 \\
.3000 E+04 \\
.3100 E+04 \\
.3200 E+04 \\
.3300 E+04 \\
.3400 E+04 \\
.3500 E+04 \\
.3600 E+04 \\
.3700 E+04 \\
.3800 E+04 \\
.3900 E+04 \\
.4000 E+04 \\
.4100 E+04 \\
.4200 E+04 \\
.4300 E+04 \\
.4400 E+04 \\
.4500 E+04 \\
.4600 E+04 \\
.4700 E+04 \\
.4800 E+04 \\
.4900 E+04 \\
.5000 E+04 \\
.5100 E+04 \\
.5200 E+04 \\
.5300 E+04 \\
.5400 E+04 \\
.5500 E+04 \\
.5600 E+04 \\
.5700 E+04 \\
.5800 E+04 \\
.5900 E+04 \\
.6000 E+04\end{array}$ & $\begin{array}{l}.4122 \mathrm{E}-07 \\
.4122 \mathrm{E}-07 \\
.4122 \mathrm{E}-07 \\
.4122 \mathrm{E}-07 \\
.4122 \mathrm{E}-07 \\
.4122 \mathrm{E}-07 \\
.4122 \mathrm{E}-07 \\
.4122 \mathrm{E}-07 \\
.4122 \mathrm{E}-07 \\
.4122 \mathrm{E}-07 \\
.4122 \mathrm{E}-07 \\
.4122 \mathrm{E}-07 \\
.4122 \mathrm{E}-07 \\
.4122 \mathrm{E}-07 \\
.4122 \mathrm{E}-07 \\
.4123 \mathrm{E}-07 \\
.4125 \mathrm{E}-07 \\
.4127 \mathrm{E}-07 \\
.4123 \mathrm{E}-07 \\
.4125 \mathrm{E}-07 \\
.4127 \mathrm{E}-07 \\
.4129 \mathrm{E}-07 \\
.4221 \mathrm{E}-07 \\
.4478 \mathrm{E}-07 \\
.4882 \mathrm{E}-07 \\
.5416 \mathrm{E}-07 \\
.6062 \mathrm{E}-07 \\
.6804 \mathrm{E}-07 \\
.7629 \mathrm{E}-07 \\
.8526 \mathrm{E}-07 \\
.9486 \mathrm{E}-07 \\
.1050 \mathrm{E}-06 \\
.1156 \mathrm{E}-06 \\
.1265 \mathrm{E}-06 \\
.1378 \mathrm{E}-06 \\
.1493 \mathrm{E}-06 \\
.1613 \mathrm{E}-06 \\
.1737 \mathrm{E}-06 \\
.1865 \mathrm{E}-06 \\
.1998 \mathrm{E}-06 \\
.2133 \mathrm{E}-06 \\
.2269 \mathrm{E}-06 \\
.2405 \mathrm{E}-06 \\
.2541 \mathrm{E}-06 \\
.2677 \mathrm{E}-06 \\
.2813 \mathrm{E}-06 \\
.2946 \mathrm{E}-06 \\
.3065 \mathrm{E}-06 \\
.3170 \mathrm{E}-06 \\
.3261 \mathrm{E}-06 \\
.3340 \mathrm{E}-06 \\
.3408 \mathrm{E}-06 \\
.3465 \mathrm{E}-06 \\
.3514 \mathrm{E}-06 \\
.3555 \mathrm{E}-06 \\
.3588 \mathrm{E}-06 \\
.3614 \mathrm{E}-06 \\
.3634 \mathrm{E}-06 \\
3649 \mathrm{E}-06\end{array}$ & $\begin{array}{l}.1823 \mathrm{E}-05 \\
.1811 \mathrm{E}-05 \\
.1777 \mathrm{E}-05 \\
.1742 \mathrm{E}-05 \\
.1707 \mathrm{E}-05 \\
.1672 \mathrm{E}-05 \\
.1653 \mathrm{E}-05 \\
.1637 \mathrm{E}-05 \\
.1621 \mathrm{E}-05 \\
.1605 \mathrm{E}-05 \\
.1589 \mathrm{E}-05 \\
.1573 \mathrm{E}-05 \\
.1567 \mathrm{E}-05 \\
.1563 \mathrm{E}-05 \\
.1559 \mathrm{E}-05 \\
.1555 \mathrm{E}-05 \\
.1551 \mathrm{E}-05 \\
.1547 \mathrm{E}-05 \\
.1543 \mathrm{E}-05 \\
.1539 \mathrm{E}-05 \\
.1535 \mathrm{E}-05 \\
.1531 \mathrm{E}-05 \\
.1527 \mathrm{E}-05 \\
.1523 \mathrm{E}-05 \\
.3724 \mathrm{E}-06 \\
.4625 \mathrm{E}-07 \\
.4130 \mathrm{E}-07 \\
.4122 \mathrm{E}-07 \\
.4122 \mathrm{E}-07 \\
.4122 \mathrm{E}-07 \\
.4122 \mathrm{E}-07 \\
.4122 \mathrm{E}-07 \\
.4122 \mathrm{E}-07 \\
.4122 \mathrm{E}-07 \\
.4122 \mathrm{E}-07 \\
.4122 \mathrm{E}-07 \\
.4122 \mathrm{E}-07 \\
.4122 \mathrm{E}-07 \\
.4122 \mathrm{E}-07 \\
.4122 \mathrm{E}-07 \\
.4122 \mathrm{E}-07 \\
.4122 \mathrm{E}-07 \\
.4122 \mathrm{E}-07 \\
.4122 \mathrm{E}-07 \\
.4122 \mathrm{E}-07 \\
.4122 \mathrm{E}-07 \\
.4122 \mathrm{E}-07 \\
.4122 \mathrm{E}-07 \\
.4122 \mathrm{E}-07 \\
.4122 \mathrm{E}-07 \\
.4122 \mathrm{E}-07 \\
.4122 \mathrm{E}-07 \\
.4122 \mathrm{E}-07 \\
.4122 \mathrm{E}-07 \\
.4122 \mathrm{E}-07 \\
.4122 \mathrm{E}-07 \\
.4122 \mathrm{E}-07 \\
.4122 \mathrm{E}-07 \\
.4122 \mathrm{E}-07 \\
.4122 \mathrm{E}-07\end{array}$ & $\begin{array}{l}.4600 \mathrm{E}-07 \\
.4600 \mathrm{E}-07 \\
.4600 \mathrm{E}-07 \\
.4600 \mathrm{E}-07 \\
.7482 \mathrm{E}-07 \\
.2272 \mathrm{E}-06 \\
.3700 \mathrm{E}-06 \\
.4969 \mathrm{E}-06 \\
.6092 \mathrm{E}-06 \\
.7084 \mathrm{E}-06 \\
.7955 \mathrm{E}-06 \\
.8728 \mathrm{E}-06 \\
.9417 \mathrm{E}-06 \\
.1003 \mathrm{E}-05 \\
.1057 \mathrm{E}-05 \\
.1105 \mathrm{E}-05 \\
.1148 \mathrm{E}-05 \\
.1185 \mathrm{E}-05 \\
.1219 \mathrm{E}-05 \\
.1250 \mathrm{E}-05 \\
.1277 \mathrm{E}-05 \\
.1302 \mathrm{E}-05 \\
.1324 \mathrm{E}-05 \\
.1344 \mathrm{E}-05 \\
.1361 \mathrm{E}-05 \\
.1377 \mathrm{E}-05 \\
.1391 \mathrm{E}-05 \\
.1403 \mathrm{E}-05 \\
.1410 \mathrm{E}-05 \\
.1335 \mathrm{E}-05 \\
.1221 \mathrm{E}-05 \\
.1115 \mathrm{E}-05 \\
.1018 \mathrm{E}-05 \\
.9303 \mathrm{E}-06 \\
.8504 \mathrm{E}-06 \\
.7776 \mathrm{E}-06 \\
.7114 \mathrm{E}-06 \\
.6512 \mathrm{E}-06 \\
.5964 \mathrm{E}-06 \\
.5465 \mathrm{E}-06 \\
.5010 \mathrm{E}-06 \\
.4597 \mathrm{E}-06 \\
.4221 \mathrm{E}-06 \\
.3878 \mathrm{E}-06 \\
.3567 \mathrm{E}-06 \\
.3283 \mathrm{E}-06 \\
.3025 \mathrm{E}-06 \\
.2790 \mathrm{E}-06 \\
.2577 \mathrm{E}-06 \\
.2382 \mathrm{E}-06 \\
.2205 \mathrm{E}-06 \\
.2044 \mathrm{E}-06 \\
.1897 \mathrm{E}-06 \\
.1764 \mathrm{E}-06 \\
.1642 \mathrm{E}-06 \\
.1532 \mathrm{E}-06 \\
.1431 \mathrm{E}-06 \\
.1339 \mathrm{E}-06 \\
.1256 \mathrm{E}-06 \\
.1180 \mathrm{E}-06 \\
.1111 \mathrm{E}-06\end{array}$ & $\begin{array}{l}.1741 E-04 \\
.1741 E-04 \\
.1741 E-04 \\
.1741 E-04 \\
.2832 E-04 \\
.8601 E-04 \\
.1400 E-03 \\
.1881 E-03 \\
.2306 E-03 \\
.2681 E-03 \\
.3011 E-03 \\
.3304 E-03 \\
.3564 E-03 \\
.3796 E-03 \\
.4002 E-03 \\
.4183 E-03 \\
.4344 E-04 \\
.0000 E+00 \\
.0000 E+00 \\
.0000 E+00 \\
.0000 E+00 \\
.0000 E+00 \\
.0000 E+00 \\
.0000 E+00 \\
.0000 E+00 \\
.0000 E+00 \\
.0000 E+00 \\
.0000 E+00 \\
.0000 E+00 \\
.0000 E+00 \\
.0000 E+00 \\
.0000 E+00 \\
.0000 E+00 \\
.0000 E+00 \\
.0000 E+00 \\
.0000 E+00 \\
.0000 E+00 \\
.0000 E+00 \\
.0000 E+00 \\
.0000 E+00 \\
.0000 E+00 \\
.0000 E+00 \\
.0000 E+00 \\
.0000 E+00 \\
.0000 E+00 \\
.0000 E+00 \\
.0000 E+00 \\
.0000 E+00 \\
.0000 E+00 \\
.0000 E+00 \\
.0000 E+00 \\
.0000 E+00 \\
.0000 E+00 \\
.0000 E+00 \\
.0000 E+00 \\
.0000 E+00 \\
.0000 E+00 \\
.0000 E+00 \\
.0000 E+00 \\
0000 E+00\end{array}$ & $\begin{array}{l}.4062 E-04 \\
.4062 E-04 \\
.4062 E-04 \\
.4062 E-04 \\
.6608 E-04 \\
.2007 E-03 \\
.3267 E-03 \\
.4388 E-03 \\
.5380 E-03 \\
.6256 E-03 \\
.7026 E-03 \\
.7708 E-03 \\
.8317 E-03 \\
.8858 E-03 \\
.9337 E-03 \\
.9761 E-03 \\
.1013 E-02 \\
.1047 E-02 \\
.1077 E-02 \\
.1104 E-02 \\
.1128 E-02 \\
.1150 E-02 \\
.1169 E-02 \\
.1187 E-02 \\
.1202 E-02 \\
.1216 E-02 \\
.1228 E-02 \\
.1239 E-02 \\
.1245 E-02 \\
.1179 E-02 \\
.1078 E-02 \\
.9844 E-03 \\
.8992 E-03 \\
.8216 E-03 \\
.7510 E-03 \\
.6868 E-03 \\
.6283 E-03 \\
.4313 E-03 \\
.2633 E-03 \\
.1207 E-03 \\
.1106 E-04 \\
.0000 E+00 \\
.0000 E+00 \\
.0000 E+00 \\
.0000 E+00 \\
.0000 E+00 \\
.0000 E+00 \\
.0000 E+00 \\
.0000 E+00 \\
.0000 E+00 \\
.0000 E+00 \\
.0000 E+00 \\
.0000 E+00 \\
.0000 E+00 \\
.0000 E+00 \\
0000 E+00\end{array}$ & $\begin{array}{l}.5803 \mathrm{E}-04 \\
.5803 \mathrm{E}-04 \\
.5803 \mathrm{E}-04 \\
.5803 \mathrm{E}-04 \\
.9440 \mathrm{E}-04 \\
.2867 \mathrm{E}-03 \\
.4668 \mathrm{E}-03 \\
.6269 \mathrm{E}-03 \\
.7686 \mathrm{E}-03 \\
.8937 \mathrm{E}-03 \\
.1004 \mathrm{E}-02 \\
.1101 \mathrm{E}-02 \\
.1188 \mathrm{E}-02 \\
.1265 \mathrm{E}-02 \\
.1334 \mathrm{E}-02 \\
.1394 \mathrm{E}-02 \\
.1057 \mathrm{E}-02 \\
.1047 \mathrm{E}-02 \\
.1077 \mathrm{E}-02 \\
.1104 \mathrm{E}-02 \\
.1128 \mathrm{E}-02 \\
.1150 \mathrm{E}-02 \\
.1169 \mathrm{E}-02 \\
.1187 \mathrm{E}-02 \\
.1202 \mathrm{E}-02 \\
.1216 \mathrm{E}-02 \\
.1228 \mathrm{E}-02 \\
.1239 \mathrm{E}-02 \\
.1245 \mathrm{E}-02 \\
.1179 \mathrm{E}-02 \\
.1078 \mathrm{E}-02 \\
.9844 \mathrm{E}-03 \\
80025-02\end{array}$ & $\begin{array}{l}.0000 E+00 \\
.1741 E-02 \\
.3482 E-02 \\
.5223 E-02 \\
.7155 E-02 \\
.1313 E-01 \\
.2476 E-01 \\
.4145 E-01 \\
.6264 E-01 \\
.8780 E-01 \\
.1165 E+00 \\
.1482 E+00 \\
.1827 E+00 \\
.2196 E+00 \\
.2588 E+00 \\
.2998 E+00 \\
.3193 E+00 \\
.3193 E+00 \\
.3193 E+00 \\
.3193 E+00 \\
.3193 E+00 \\
.3193 E+00 \\
.3193 E+00 \\
.3193 E+00 \\
.3193 E+00 \\
.3193 E+00 \\
.3193 E+00 \\
.3193 E+00 \\
.3193 E+00 \\
.3193 E+00 \\
.3193 E+00 \\
.3193 E+00 \\
.3193 E+00 \\
.3193 E+00 \\
.3193 E+00 \\
.3193 E+00 \\
.3193 E+00 \\
.3193 E+00 \\
.3193 E+00 \\
.3193 E+00 \\
.3193 E+00 \\
.3193 E+00 \\
.3193 E+00 \\
.3193 E+00 \\
.3193 E+00 \\
.3193 E+00 \\
.3193 E+00 \\
.3193 E+00 \\
.3193 E+00 \\
.3193 E+00 \\
.3193 E+00 \\
.3193 E+00 \\
.3193 E+00 \\
.3193 E+00 \\
.3193 E+00 \\
.3193 E+00 \\
.3193 E+00 \\
.3193 E+00 \\
.3193 E+00 \\
.3193 E+00 \\
.3193 E+00\end{array}$ & $\begin{array}{l}.0000 E+00 \\
.4062 E-02 \\
.8125 E-02 \\
.1219 E-01 \\
.1669 E-01 \\
.3065 E-01 \\
.5777 E-01 \\
.9672 E-01 \\
.1462 E+00 \\
.2049 E+00 \\
.2717 E+00 \\
.3458 E+00 \\
.4263 E+00 \\
.5125 E+00 \\
.6038 E+00 \\
.6995 E+00 \\
.7992 E+00 \\
002 \angle E+00\end{array}$ & $\begin{array}{l}.0000 E+00 \\
.5803 E-02 \\
.1161 E-01 \\
.1741 E-01 \\
.2385 E-01 \\
.4378 E-01 \\
.8253 E-01 \\
.1382 E+00 \\
.2088 E+00 \\
.2927 E+00 \\
.3882 E+00 \\
.4940 E+00 \\
.6090 E+00 \\
.7321 E+00 \\
.8625 E+00 \\
.9993 E+00 \\
.1119 E+01 \\
.1222 E+01 \\
.1328 E+01 \\
.1437 E+01 \\
.1549 E+01 \\
.1663 E+01 \\
.1779 E+01 \\
.1897 E+01 \\
.2017 E+01 \\
.2138 E+01 \\
.2260 E+01 \\
.2383 E+01 \\
.2508 E+01 \\
.2629 E+01 \\
.2742 E+01 \\
.2844 E+01 \\
.2938 E+01 \\
.3024 E+01 \\
.3102 E+01 \\
.3173 E+01 \\
.3239 E+01 \\
.3291 E+01 \\
.3324 E+01 \\
.3343 E+01 \\
.3348 E+01 \\
.3348 E+01 \\
.3348 E+01 \\
.3348 E+01 \\
.3348 E+01 \\
.3348 E+01 \\
.3348 E+01 \\
.3348 E+01 \\
.3348 E+01 \\
.3348 E+01 \\
.3348 E+01 \\
.3348 E+01 \\
.3348 E+01 \\
.3348 E+01 \\
.3348 E+01 \\
.3348 E+01 \\
.3348 E+01 \\
.3348 E+01 \\
.3348 E+01 \\
.3348 E+01 \\
.3348 E+01\end{array}$ \\
\hline
\end{tabular}

Figure A-5. Fourth Part of the Output File Produced by KCTA 
Table A-1

Names and Identification Numbers of The Radionuclides Employed in "KCTA.d"

\begin{tabular}{|c|c|c|c|}
\hline Nuclide & Nuclide ID & Nuclide & Nuclide ID \\
\hline $3-\mathrm{H}$ & 1003 & $129-\mathrm{Sb}$ & 51129 \\
\hline $16-N$ & 7016 & $127-\mathrm{Te}$ & 52127 \\
\hline $19-0$ & 8019 & $129-\mathrm{Te}$ & 52129 \\
\hline $24-\mathrm{Na}$ & 11024 & $131 \mathrm{~m}-\mathrm{Te}$ & 52131 \\
\hline $52-\mathrm{Cr}$ & 24051 & $132-\mathrm{Te}$ & 52132 \\
\hline 54-Mn & 25054 & 131-I & 53131 \\
\hline $59-\mathrm{Fe}$ & 26059 & $132-I$ & 53132 \\
\hline $57-\mathrm{Co}$ & 27057 & 133-I & 53133 \\
\hline $58-\mathrm{Co}$ & 27058 & 134-I & 53134 \\
\hline $60-\mathrm{Co}$ & 27060 & $135-I$ & 53135 \\
\hline $65-\mathrm{Zn}$ & 30065 & $133-\mathrm{Xe}$ & 54133 \\
\hline $85-K r$ & 36085 & $135-\mathrm{Xe}$ & 54135 \\
\hline $87-\mathrm{Kr}$ & 36087 & 134-Cs & 55134 \\
\hline $88-\mathrm{Kr}$ & 36088 & 136-Cs & 55136 \\
\hline $86-\mathrm{Kr}$ & 37086 & 137-Cs & 55137 \\
\hline $89-\mathrm{Sr}$ & 38089 & $139-\mathrm{Ba}$ & 56139 \\
\hline $91-\mathrm{Sr}$ & 38091 & $140-\mathrm{Ba}$ & 56140 \\
\hline $92-\mathrm{Sr}$ & 38092 & $140-\mathrm{La}$ & 57140 \\
\hline $90-Y$ & 39090 & $141-\mathrm{La}$ & 57141 \\
\hline $91-Y$ & 39091 & $142-\mathrm{La}$ & 57142 \\
\hline $92-Y$ & 39092 & $141-\mathrm{Ce}$ & 58141 \\
\hline $93-Y$ & 39093 & 143-Ce & 58143 \\
\hline $95-\mathrm{Zr}$ & 40095 & 144-Ce & 58144 \\
\hline $97-\mathrm{Zr}$ & 40097 & $147-\mathrm{Nd}$ & 60147 \\
\hline $95-\mathrm{Nb}$ & 41095 & $237-U$ & 92237 \\
\hline 99-Mo & 42099 & 238-Np & 93238 \\
\hline $99 \mathrm{~m}-\mathrm{Tc}$ & 43099 & 239-Np & 93239 \\
\hline $103-\mathrm{Ru}$ & 44103 & 238-Pu & 94238 \\
\hline $105-\mathrm{Ru}$ & 44105 & $239-\mathrm{Pu}$ & 94239 \\
\hline $105-\mathrm{Rh}$ & 45105 & 241-Am & 95241 \\
\hline $109-\mathrm{Cd}$ & 48109 & $242-\mathrm{Cm}$ & 96242 \\
\hline $124-\mathrm{Sb}$ & 51124 & 244-Cm & 96244 \\
\hline $127-\mathrm{Sb}$ & 51127 & & \\
\hline
\end{tabular}




\section{APPENDIX B \\ FORTRAN LISTING OF THE KCTA CODE}

\section{B.1 The MAIN Module}

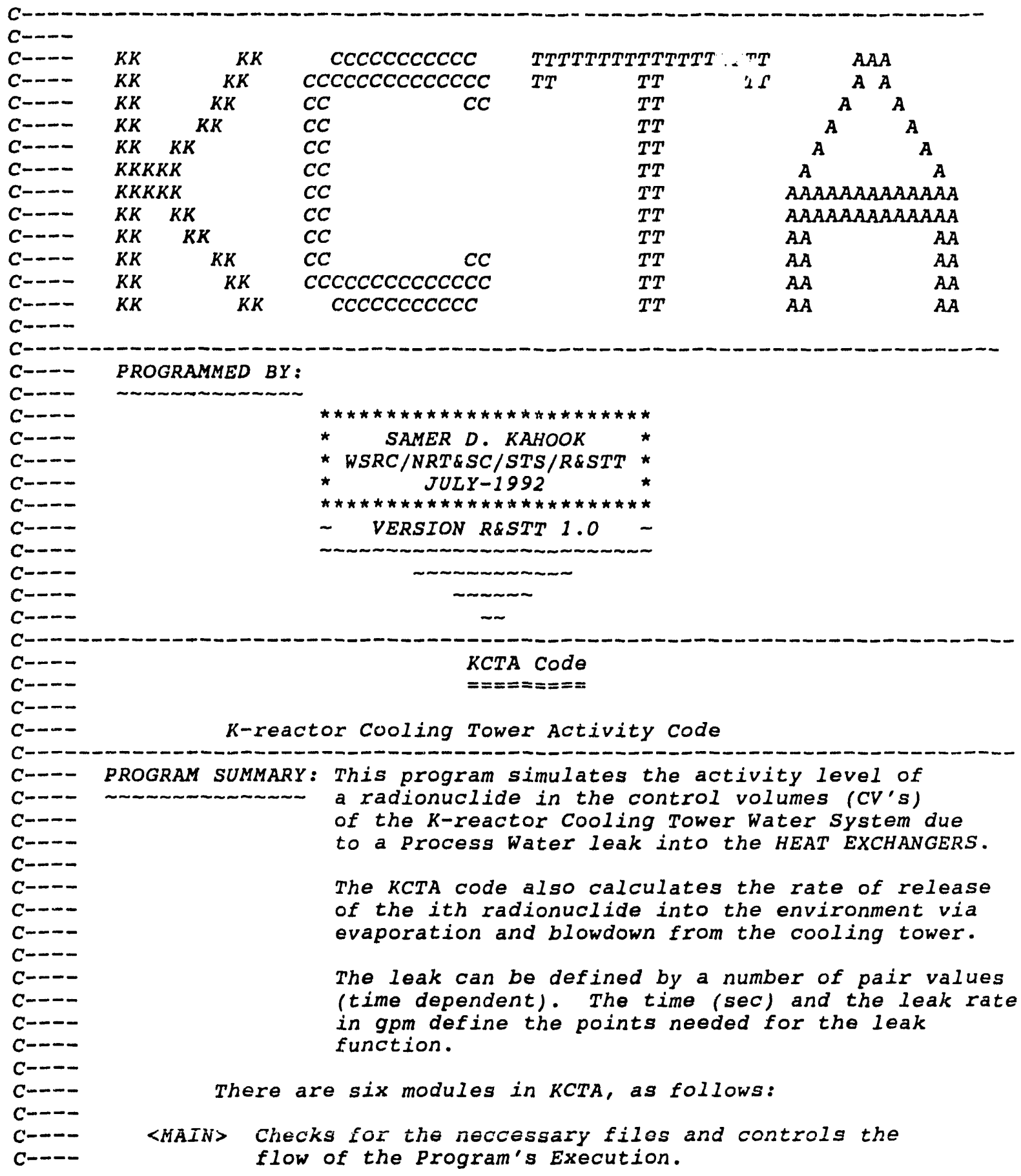




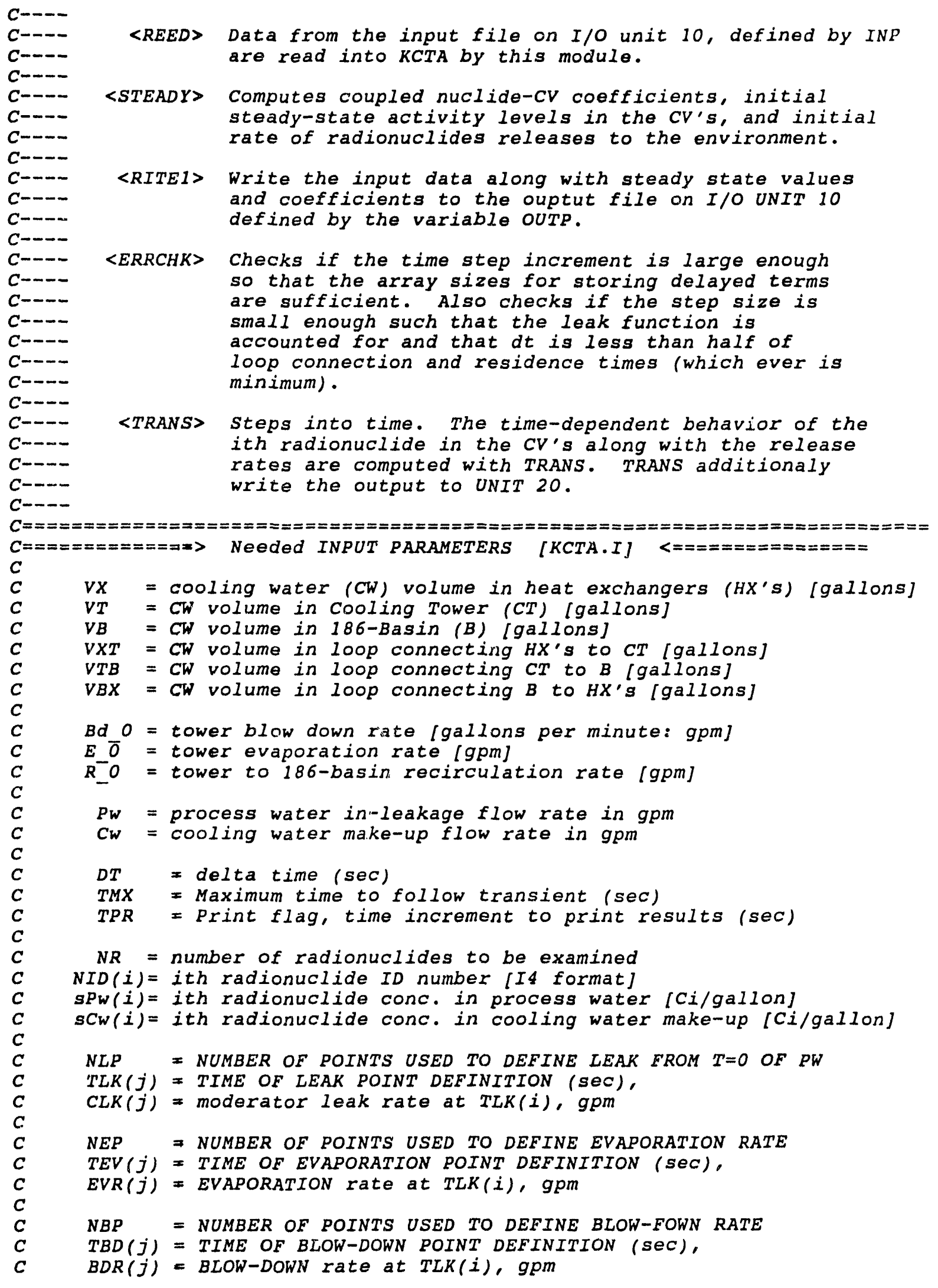




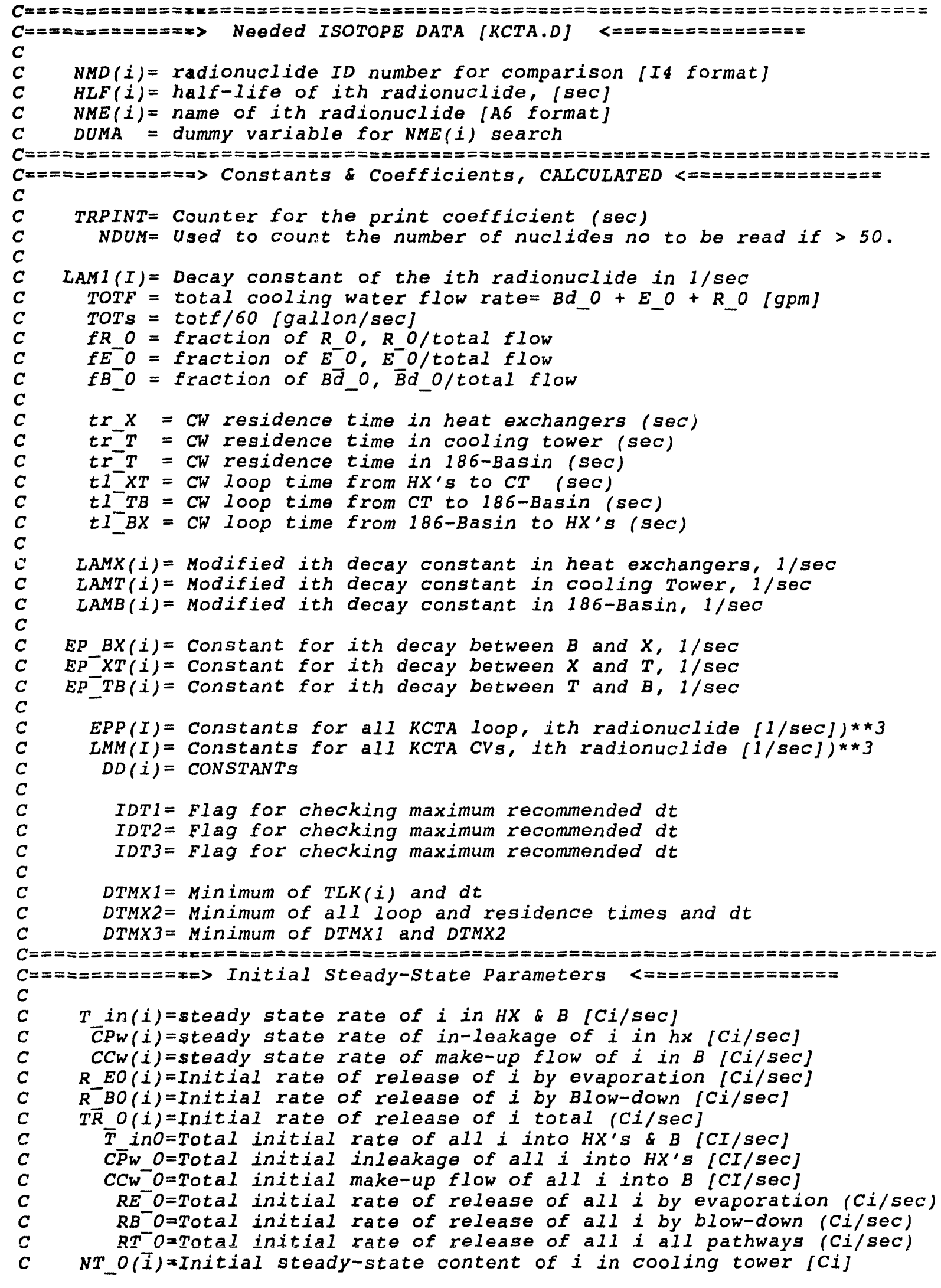




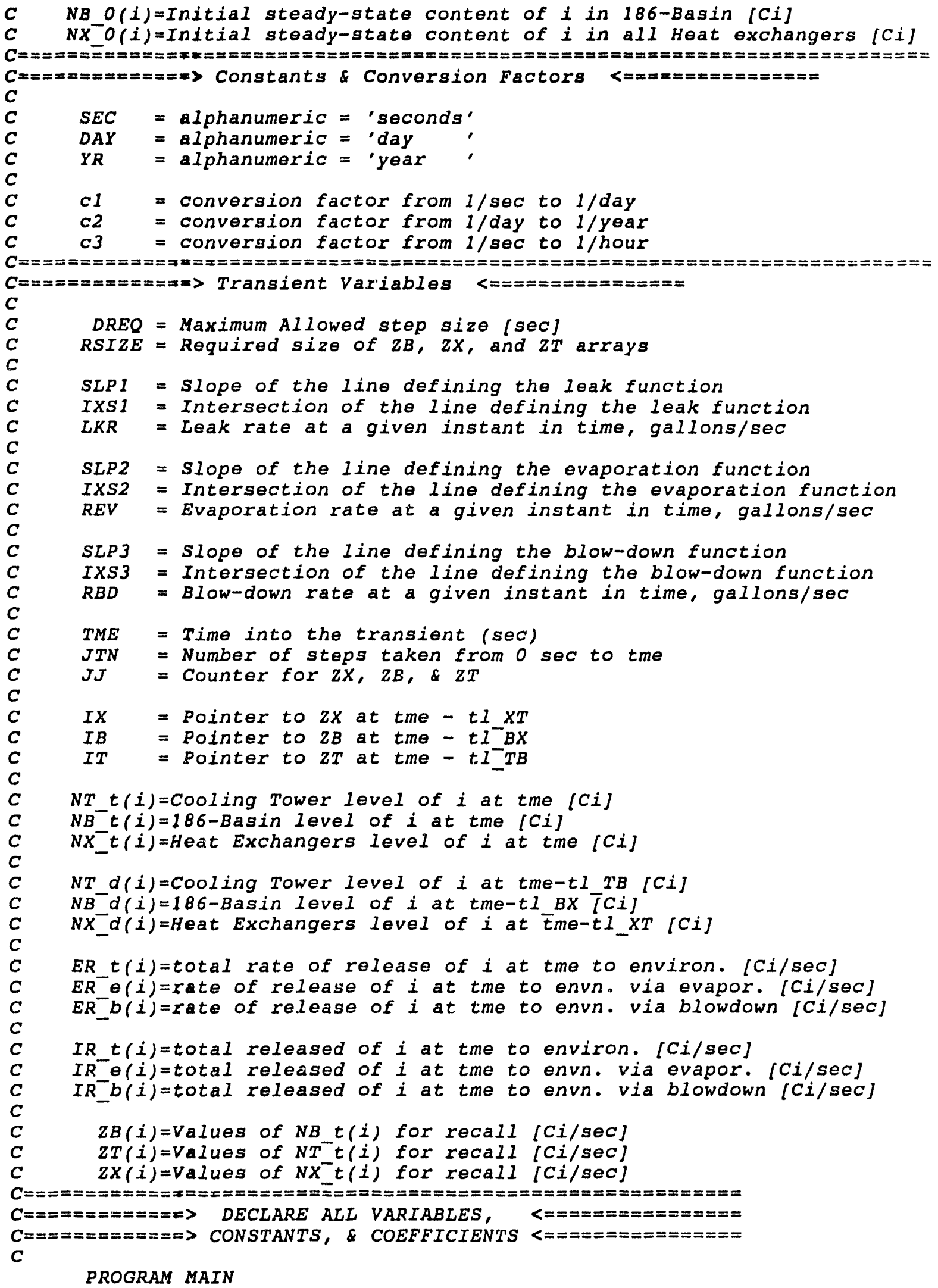




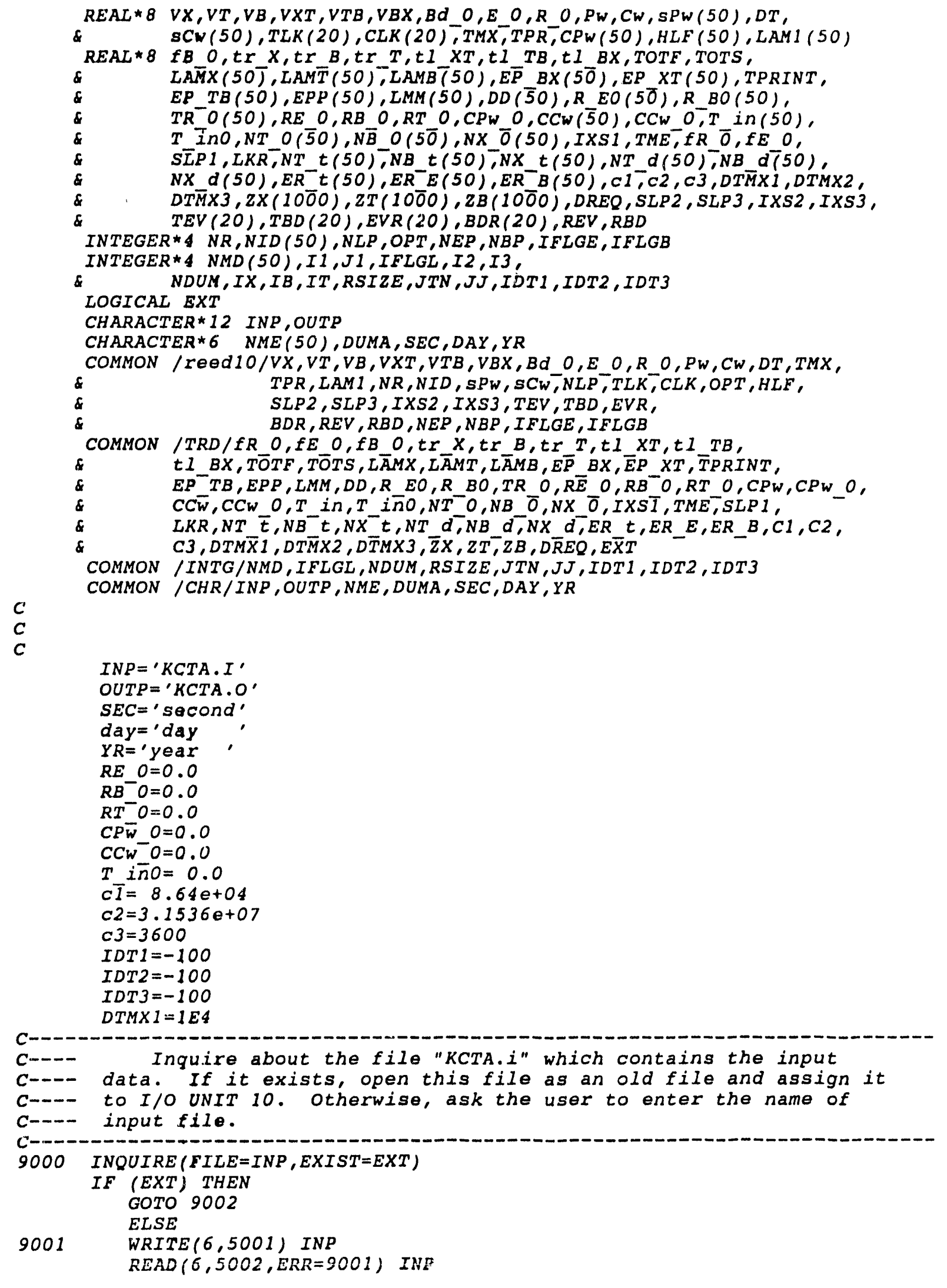




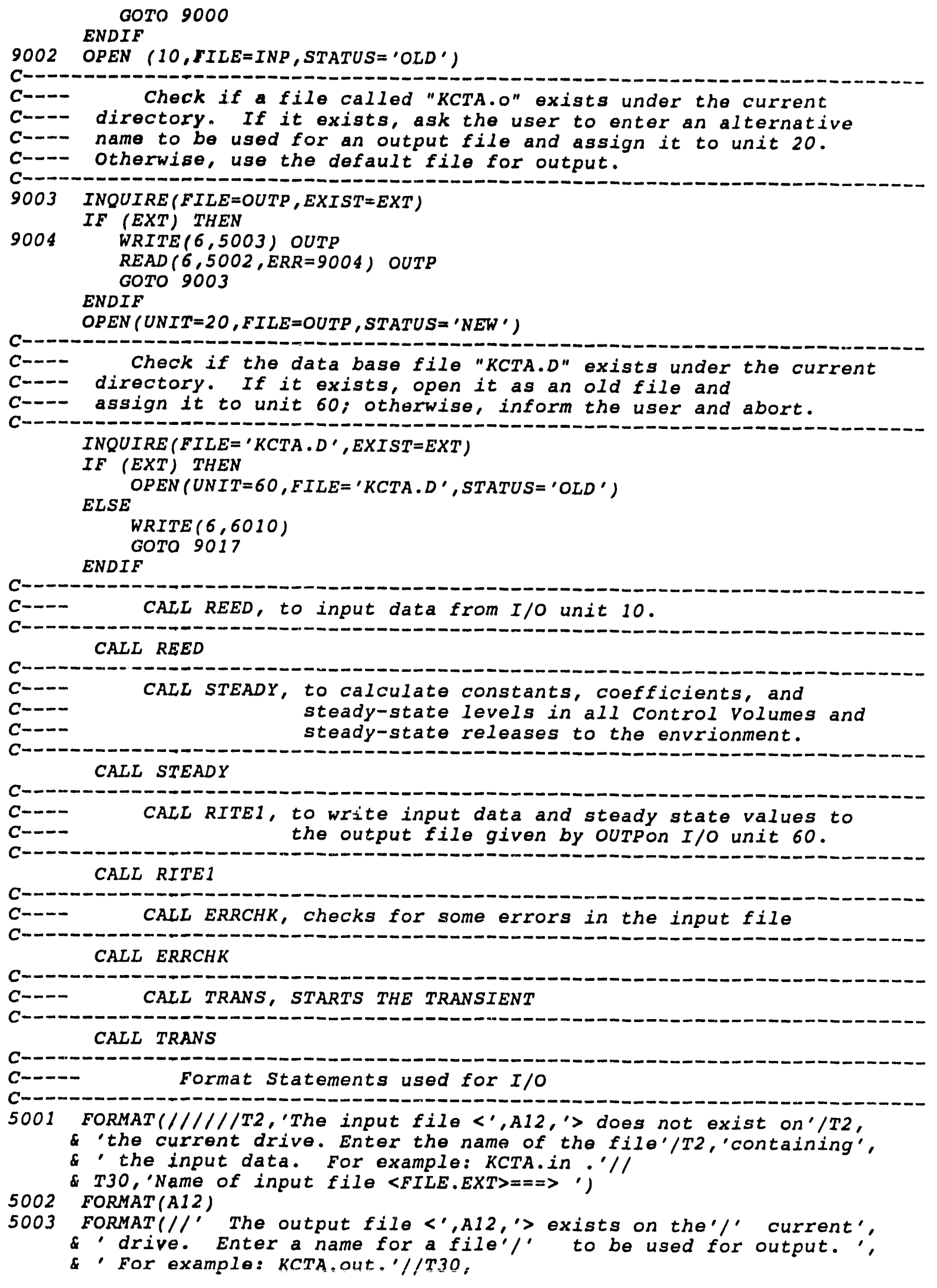




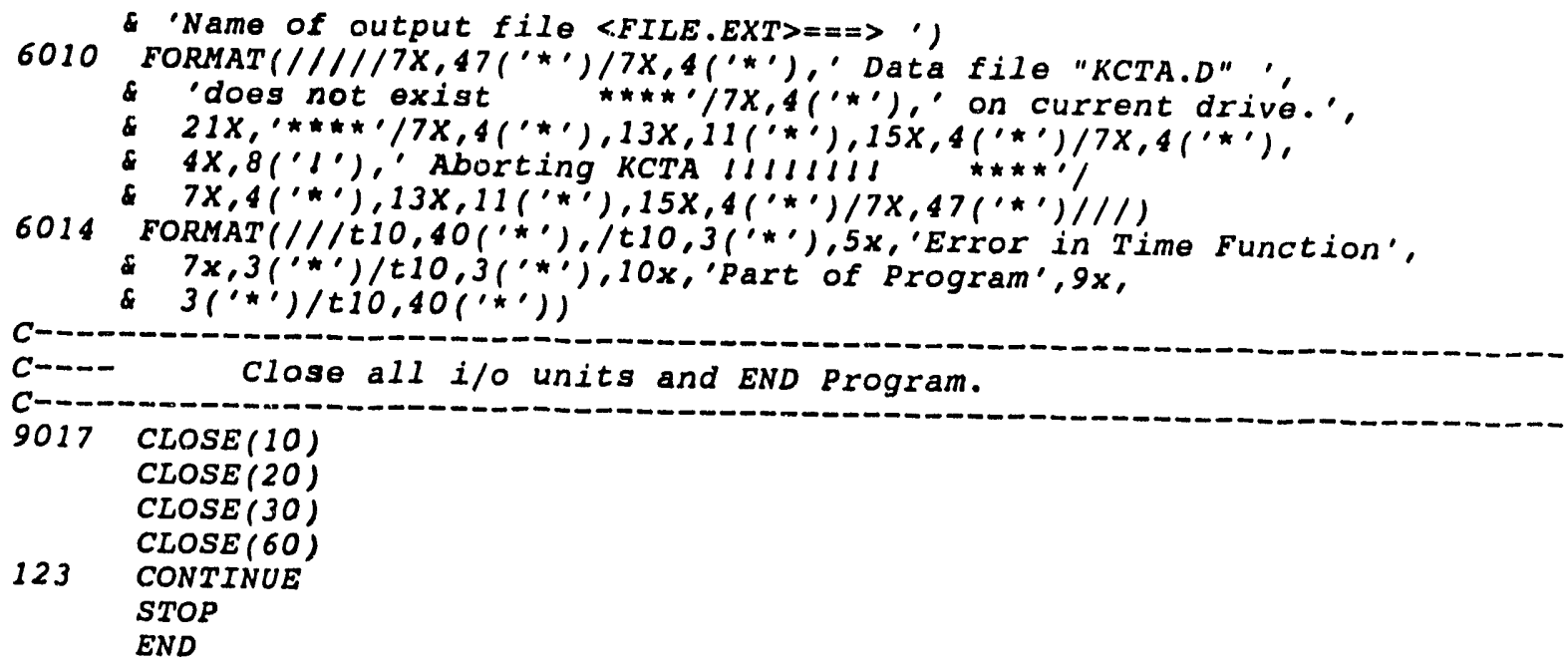




\section{B.2 The REED Module}

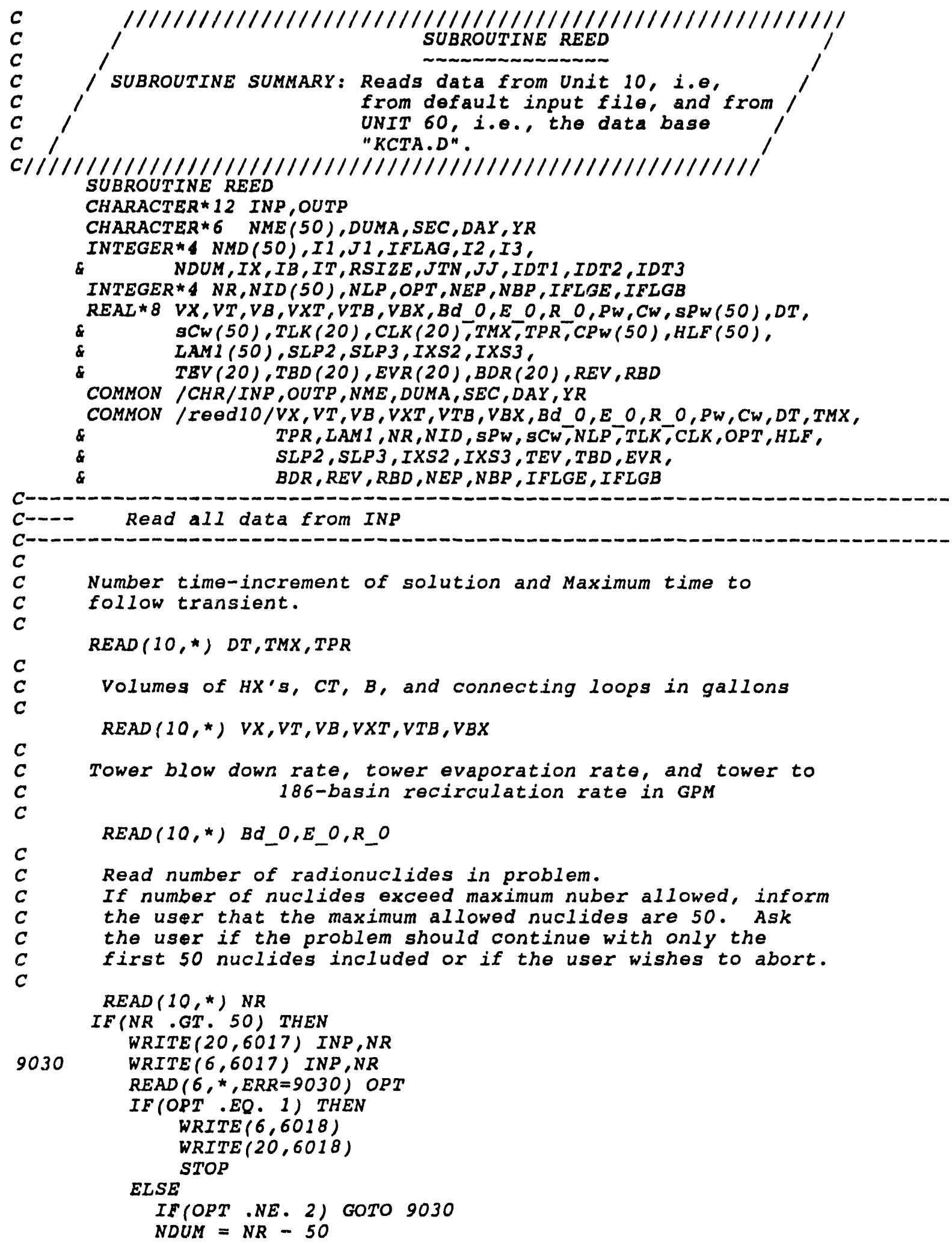




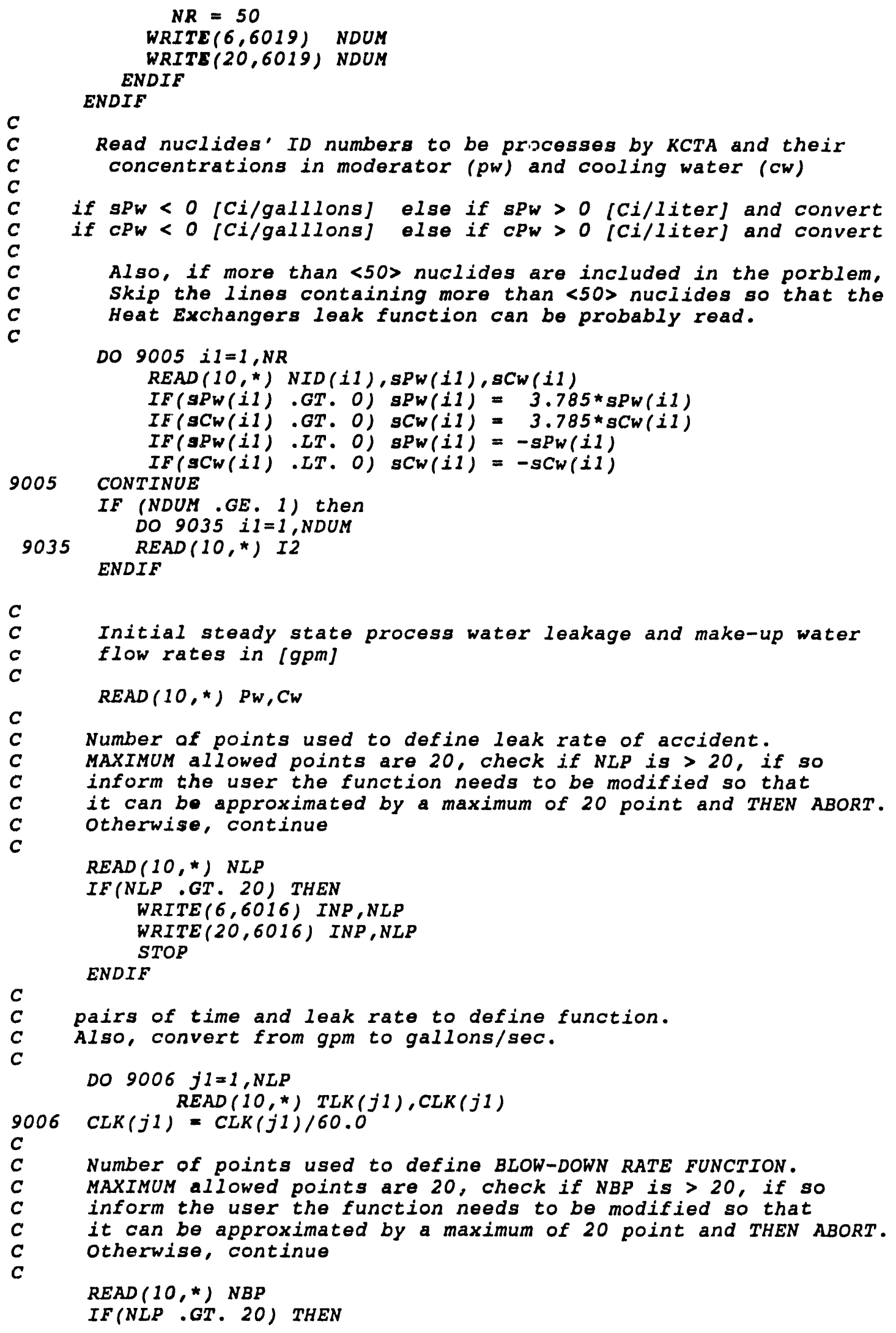




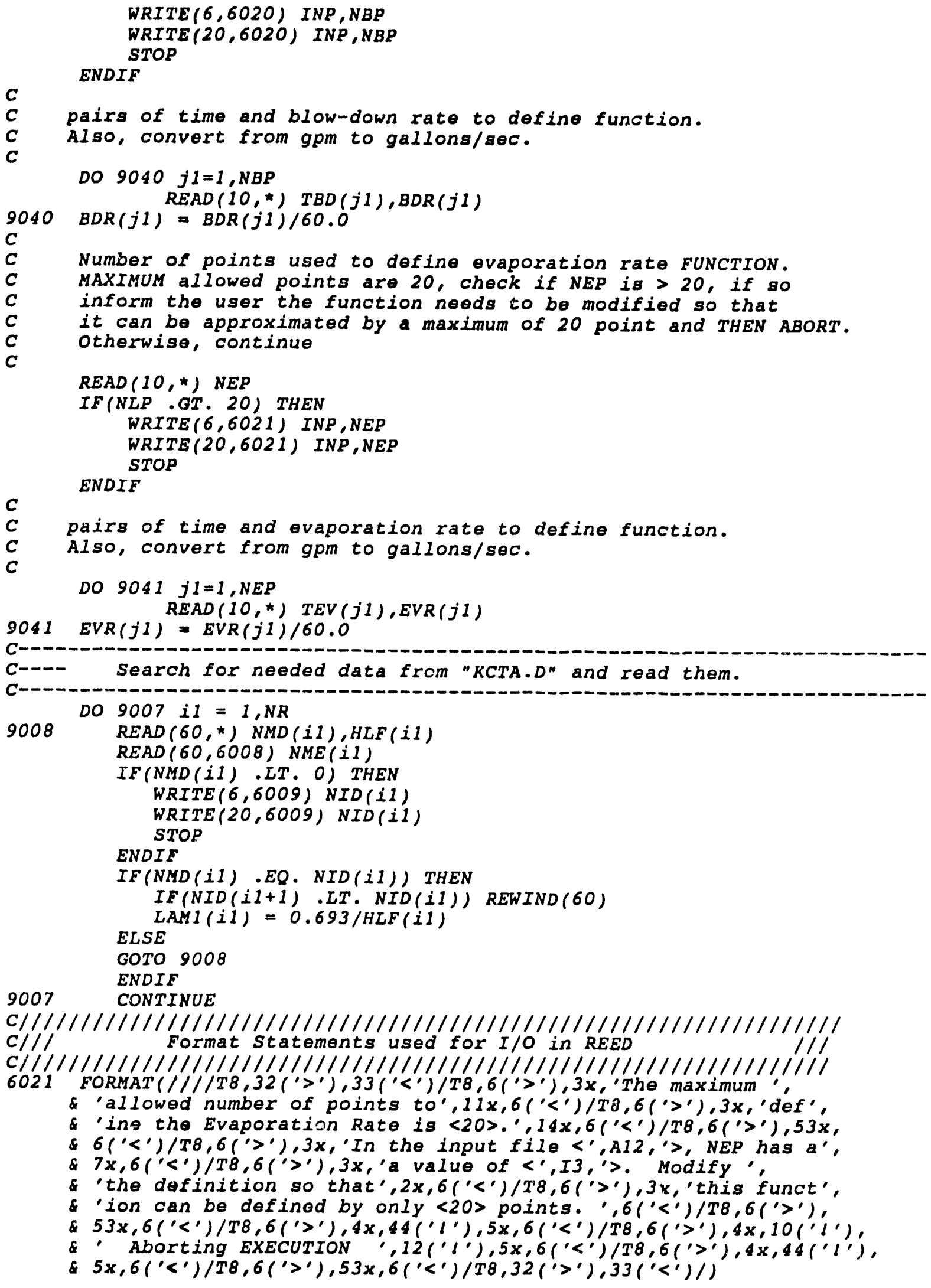


6020 FORMAT $\left(/ / / / T 8,32\left(^{\prime}>^{\prime}\right), 33\left(^{\prime}<^{\prime}\right) / T 8,6\left(^{\prime}>^{\prime}\right), 3 x\right.$, the maximum ', \& 'allowed number of points to', $11 \times, 6\left(^{\prime}<\right.$ ') $/ T 8,6\left(^{\prime}>\right.$ '), $3 x$, 'def', \& 'ine the Blow-Down Rate is <20>.', $14 x, 6('<\prime) / T 8,6('>$ '), $53 x$,

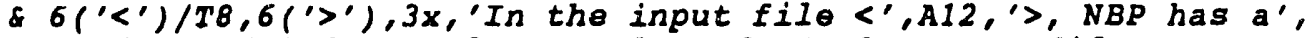
\& $\left.7 x, 6('<\prime) / T 8,6('\rangle^{\prime}\right), 3 x,{ }^{\prime}$ a value of $\left\langle{ }^{\prime}, I 3,,^{\prime}\right\rangle$. Modify',

\& 'the definition so that', $2 x, 6\left({ }^{\prime}<\right.$ ') $/ T 8,6$ (' $\left.^{\prime}\right), 3 x$, 'this funct', \& 'ion can be defined by only <20> points. ',6('<')/T8,6('>'), \& $\left.53 x, 6\left(^{\prime}<^{\prime}\right) / T 8,6\left(^{\prime}>^{\prime}\right), 4 x, 44\left(^{\prime} l^{\prime}\right), 5 x, 6\left(^{\prime}<{ }^{\prime}\right) / T 8,6\left(^{\prime}\right)^{\prime}\right), 4 x, 10\left(^{\prime} l^{\prime}\right)$, $\alpha^{\prime}$ Aborting EXECUTION ', 12(', $\left(^{\prime}\right), 5 x, 6\left(^{\prime}<<^{\prime}\right) / T 8,6\left(^{\prime}>^{\prime}\right), 4 x, 44\left(^{\prime} l^{\prime}\right)$, \& $\left.5 x, 6\left(^{\prime}<{ }^{\prime}\right) / T 8,6\left(^{\prime}>^{\prime}\right), 53 x, 6\left(^{\prime}<{ }^{\prime}\right) / T 8,32\left({ }^{\prime}>^{\prime}\right), 33\left(^{\prime}<\prime\right) /\right)$

6016 FORMAT $\left(/ / / / T 8,32\left(^{\prime}\right\rangle^{\prime}\right), 33\left(^{\prime}<\prime\right) / T 8,6\left(^{\prime}>^{\prime}\right), 3 x$, 'The maximum ', \& 'allowed number of points to',11x,6('<')/T8,6('>'),3x,'def', \& 'ine the $H X$ leak function is $\left.<20>0^{\prime}, 14 x, 6\left({ }^{\prime}<{ }^{\prime}\right) / T 8,6\left({ }^{\prime}>\right\rangle^{\prime}\right), 53 x$, \& $6\left({ }^{\prime}<'\right) / T 8,6\left(^{\prime}>{ }^{\prime}\right), 3 x$, 'In the input file $<', A 12, '>, N L P$ has $a^{\prime}$, \& $\left.7 x, 6\left({ }^{\prime}<^{\prime}\right) / T 8,6('\rangle^{\prime}\right), 3 x$, ,a value of $\left\langle{ }^{\prime}, I 3,{ }^{\prime}\right\rangle$. Modify',

\& 'the definition so that',2x,6('<')/T8,6('>'),3x, 'this funct', \& 'ion can be defined by only <20> points. ',6('<')/T8,6('>'), \& $\left.53 x, 6\left(^{\prime}<{ }^{\prime}\right) / T 8,6\left(^{\prime}>^{\prime}\right), 4 x, 44\left(^{\prime} \prime^{\prime}\right), 5 x, 6\left(^{\prime}<\prime\right) / T 8,6\left(^{\prime}\right\rangle^{\prime}\right), 4 x, 10\left(^{\prime} !^{\prime}\right)$,

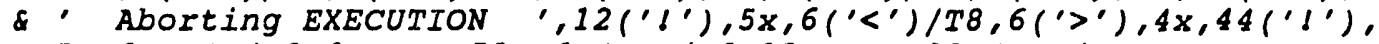
\& $\left.5 x, 6\left(^{\prime}<^{\prime}\right) / T 8,6\left(^{\prime}>^{\prime}\right), 53 x, 6\left(^{\prime}<\prime\right) / T 8,32\left(^{\prime}>^{\prime}\right), 33\left(^{\prime}<{ }^{\prime}\right) /\right)$

6017 FORMAT(////T8,32('>'),33('<')/T8,6('>'),3x, 'The maximum allowe', * 'd number of nuclides in the', $5 x, 6\left({ }^{\prime}<'\right) / T 8,6\left(^{\prime}>\right.$ '), $3 x$, 'problem',

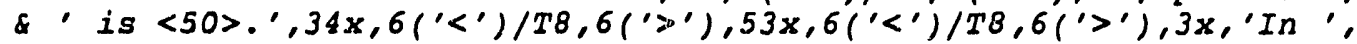

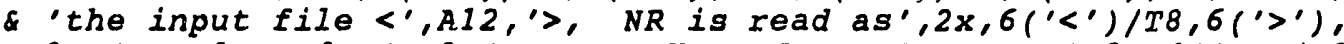
\& $3 x,{ }^{\prime}$ a value of $\left.<{ }^{\prime}, I 3,,^{\prime}\right\rangle$. YOU HAVE TWO OPTIONS: ', $8 x, 6\left({ }^{\prime}<{ }^{\prime}\right) / T 8$, \& $6\left(^{\prime}>^{\prime}\right), 53 x, 6\left(^{\prime}<\prime\right) / T 8,6\left(^{\prime}>^{\prime}\right), 3 x,,^{\prime} 1$. ENTER 1 to abort program,', $\&$ ' or', 19x',6('<')/T8,6('>'),3x,'2. ENTER 2 to continue with pro', \& 'gram with only ',2x,6('<')/T8,6('>'),3x,' the first 5', \& 'O nuclides included in the problem', $2 x, 6('<$ '),

\& $/ T 8,6\left({ }^{\prime}>{ }^{\prime}\right), 53 x, 6\left({ }^{\prime}<'\right) / T 8$,

\& $32\left({ }^{\prime}>\prime\right), 33\left({ }^{\prime}<\prime\right) / / / T 40$, 'ENTER OPTION $====><1$ or 2$\rangle$ ')

6018 FORMAT(///T20, 'YOU HAVE SELECTED OPTION $\left.\left.1^{\prime}, / / / T 8,32\left(^{\prime}\right\rangle^{\prime}\right), 331^{\prime}<{ }^{\prime}\right) /$

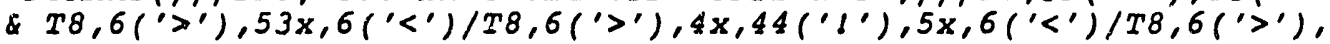

\& $4 \mathrm{x}, 10(' \mathrm{l})$ ), 'EXECUTION ABORTED BYE',12('l'),5x,6('<')/T8,

\& $\left.\left.6\left({ }^{\prime}\right)^{\prime}\right), 4 x, 44\left(^{\prime} l^{\prime}\right), 5 x, 6\left({ }^{\prime}<^{\prime}\right) / T 8,6\left(^{\prime}\right)^{\prime}\right), 53 x, 6\left(^{\prime}<\prime\right) / T 8$,

\& $\left.\left.32(')^{\prime}\right), 33\left({ }^{\prime}<\prime\right) /\right)$

6019 FORMAI(/T8,'YOU HAVE SELECTED OPTION 2\%/T8,'OnIy the data',

\& 'for the first <50> nuclides will be read', $/ T 8$, 'AND <', I3,

\& '> Data points will be skipped/'//T8,

\& 'EXECUTION CONTINUES.......')

6008 FORMAT $(A 6)$

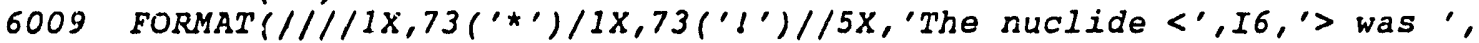
\& 'not found in the data file <KCTA.D>. ' $/ 5 \mathrm{x}$, 'Check the nuclid', $\&$ 'e"'s I.D. or modify the data file $\langle K C T A . D\rangle$ ', //20x,24('l')/20x,

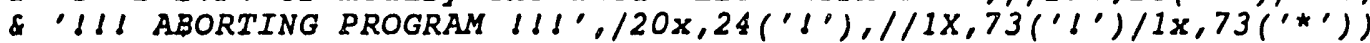
$c / 1 / 1 / 1 / 1 / 1 / 1 / 1 / 1 / 1 / 1 / 1 / 1 / 1 / 1 / 1 / 1 / 1 / 1 / 1 / 1 / 1 / 1 / 1 / 1 / 1 / 1 / 1 / 1 / 1 / 1 / 11$ $c / / / /$ The End of The Format statements used in REED \& $/ / /$

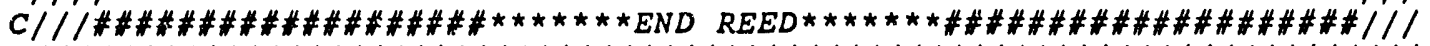

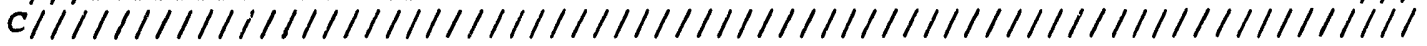
RETURN

END 


\section{B.3 The STEADY module}

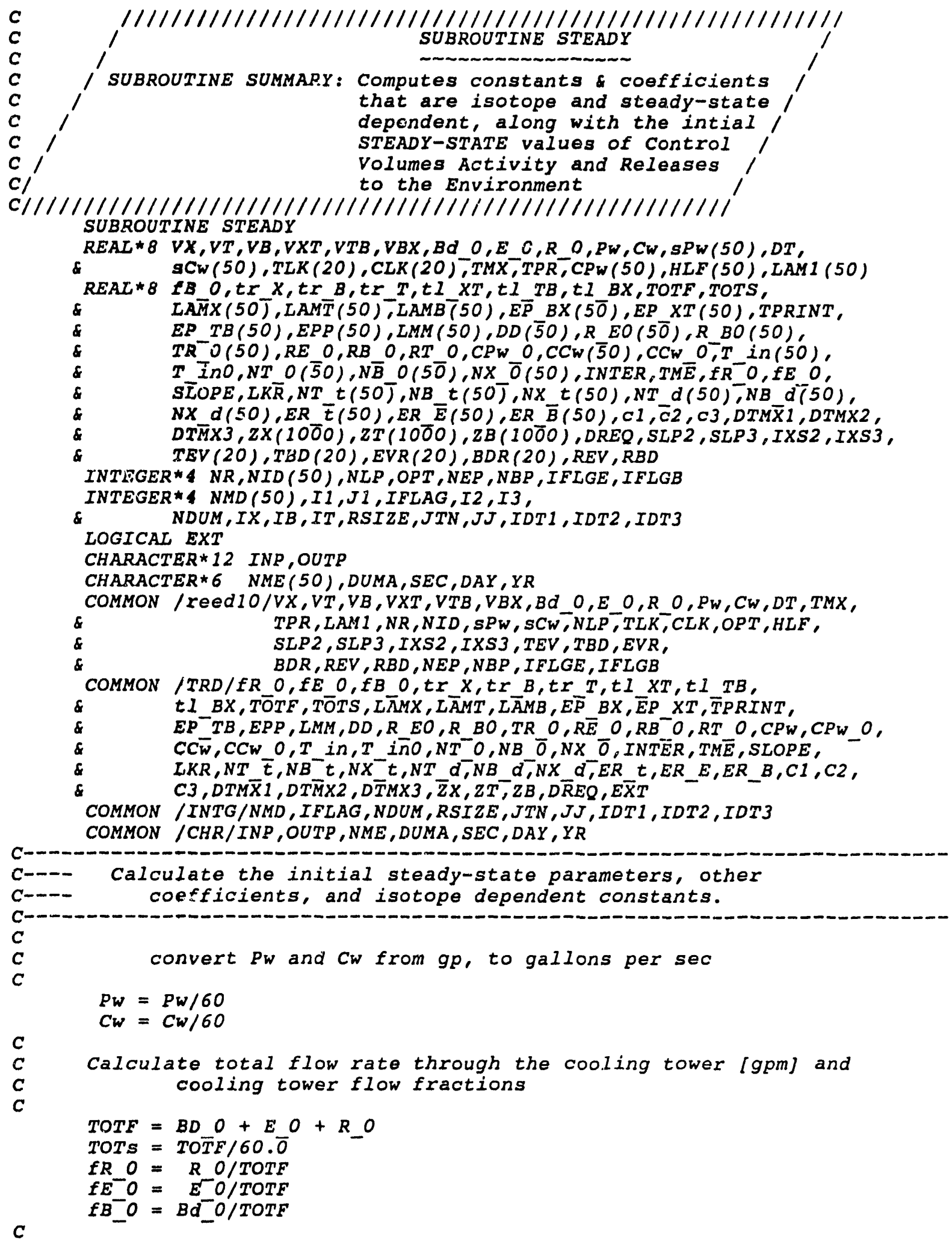


A Model for Radionuclide Transport

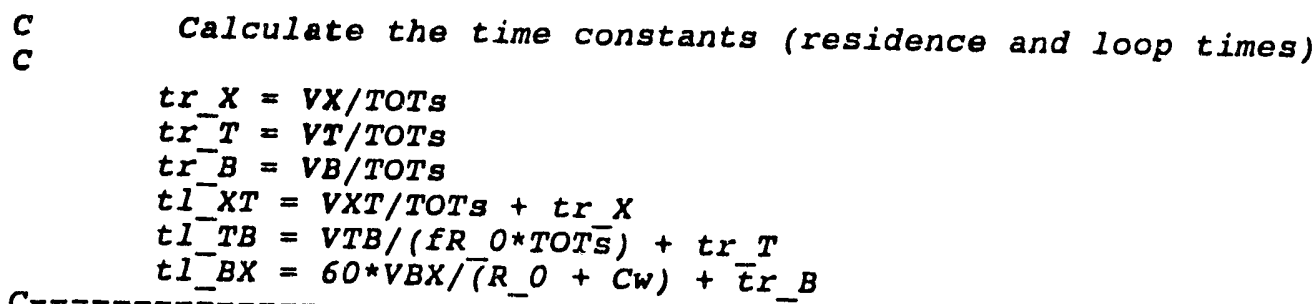




\section{B.4 The RITE1 Module}

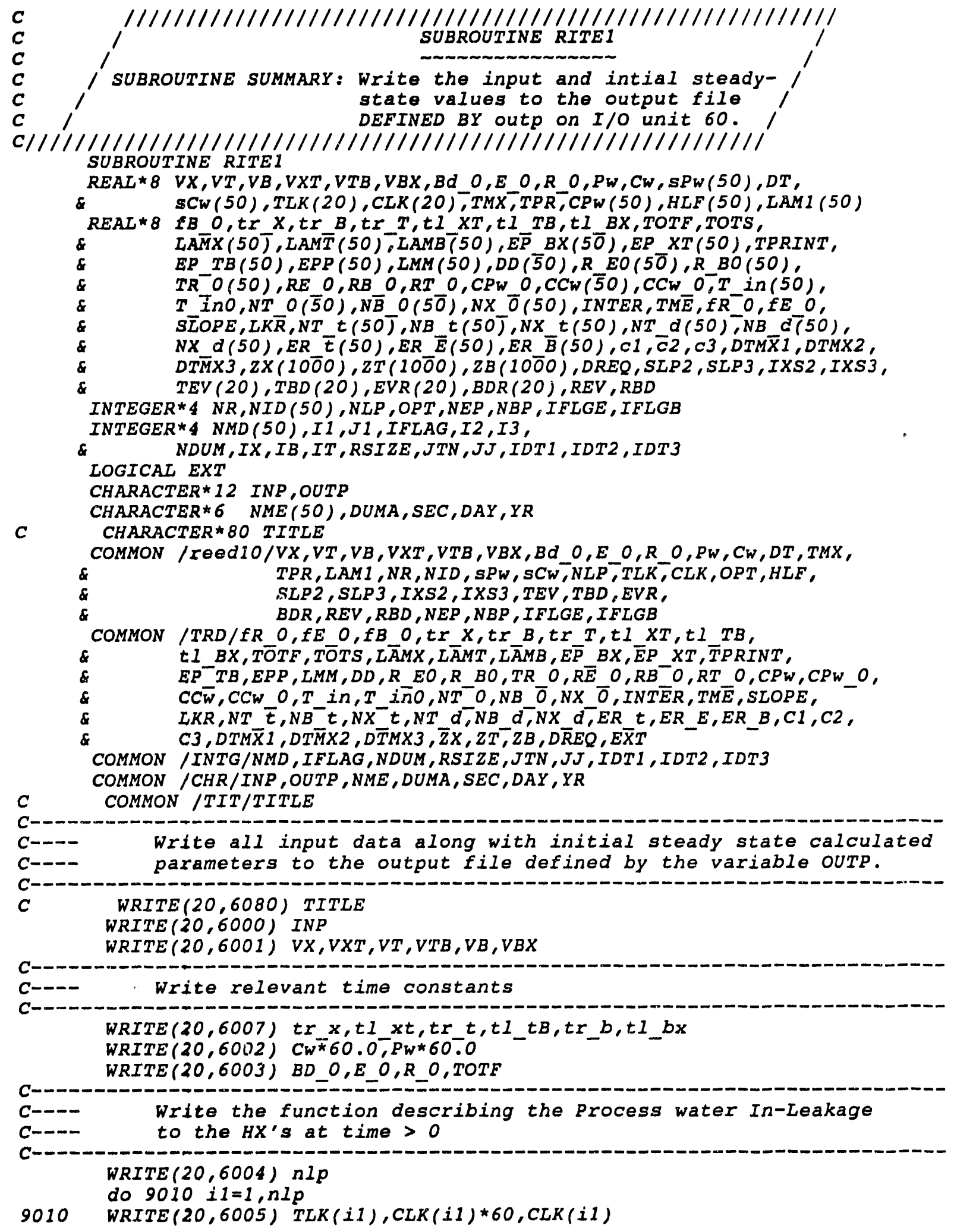


A Model for Radionuclide Transport

FORTRAN LISTING in The Cooling Water System

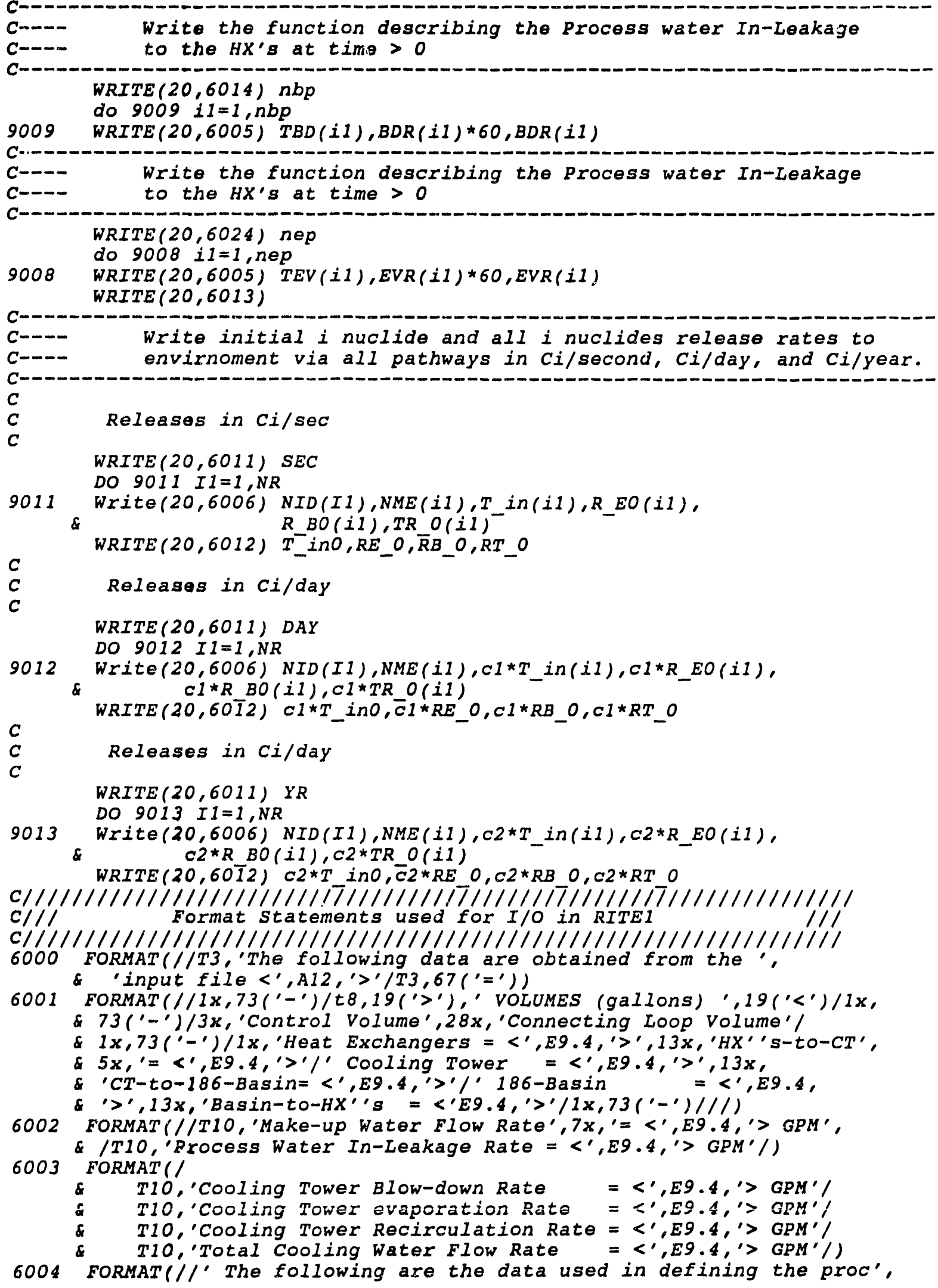




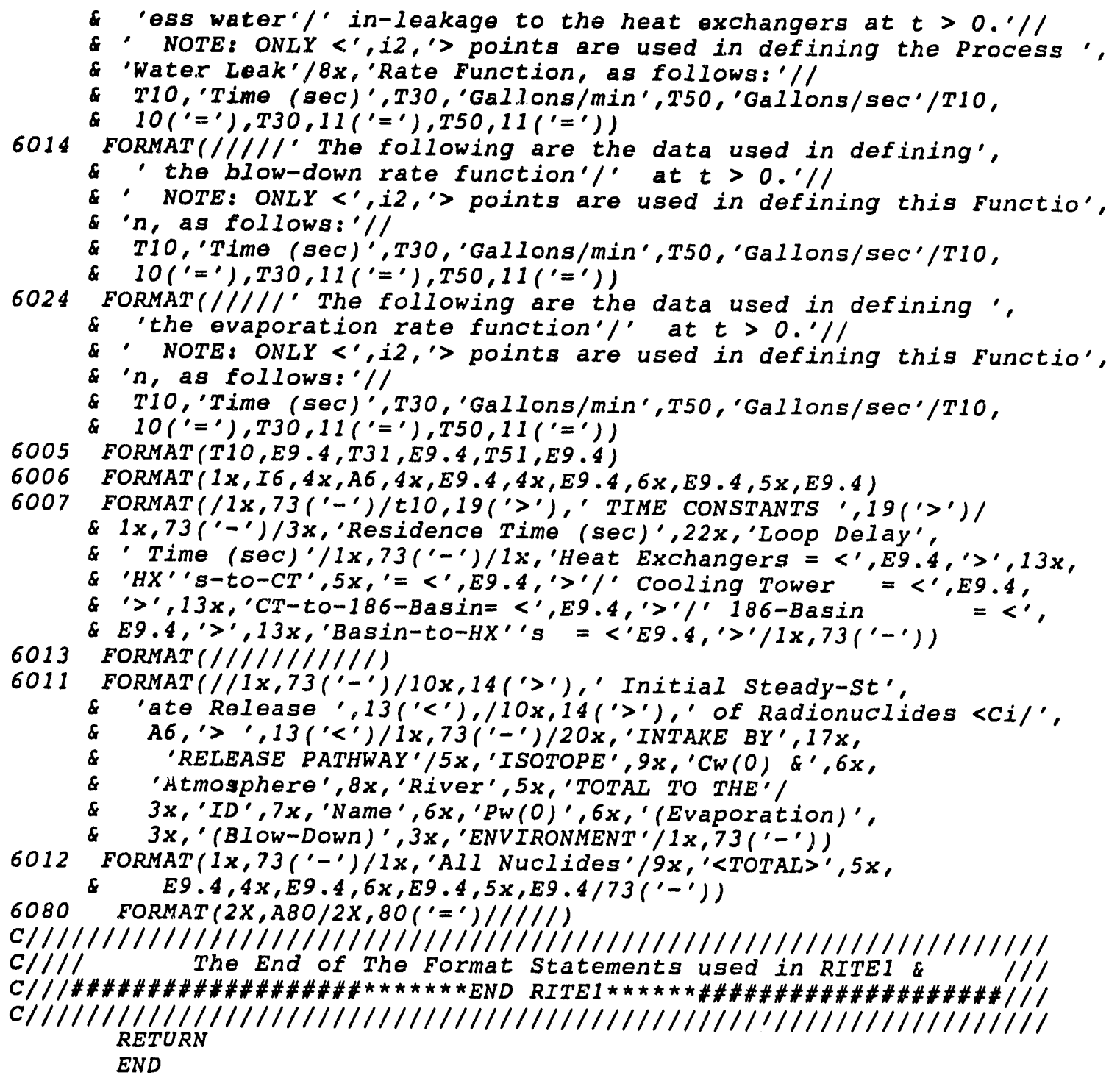




\section{B.5 The ERRCHK Module}

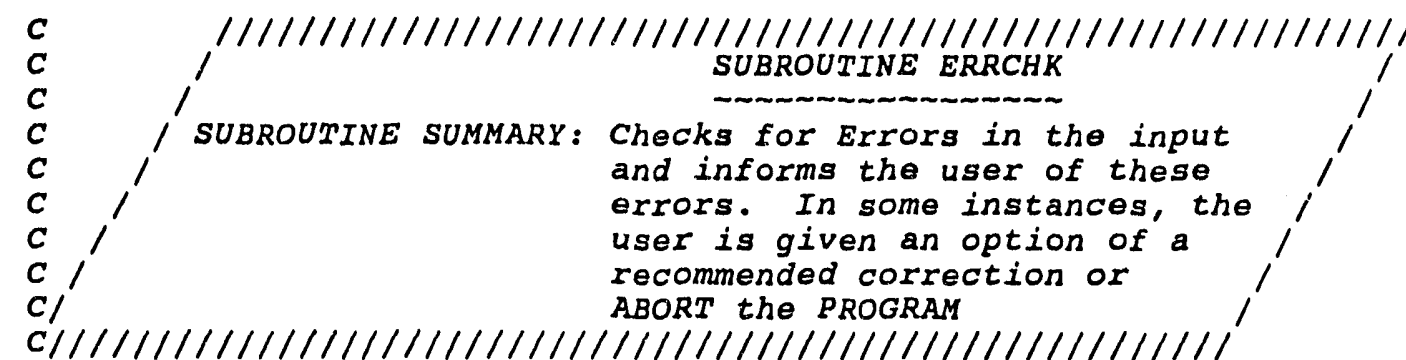

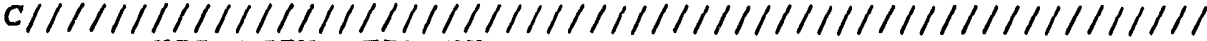

SUBROUTINE ERRCHK

$R E A L * 8 V X, V T, V B, V X T, V T B, V B X, B d \_0, E\left[0, R \_0, P_{W}, C W, S P_{W}(50), D T\right.$, SCW(50),TLK(20),CLK(20),TMX,TPR,CPW(50),HLF (50), LAM1(50)

$R E A L \star 8$ FB $0, t r X, t r B, t r T, t I X T, t 1 T B, t 1 \quad B X, T O T F, T O T S$,

\& LAM $X(50), L A M \bar{T}(50), \operatorname{LAMB}(50), E \bar{P} B X(5 \overline{0}), E P X T(50), T P R I N T$,

$\& \quad E P T B(50), E P P(50), \operatorname{LMM}(50), D D(\overline{50}), R_{E O}(5 \overline{0}), R_{B} B O(50)$,

\& $T R O(50), R E O, R B O, R T O, C P W O, C C W(\overline{5} 0), C C W O, T$ in $(50)$,

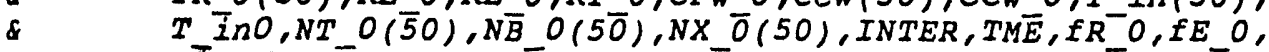

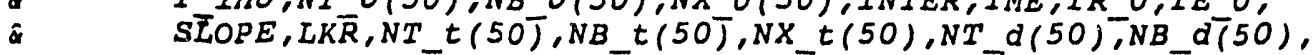

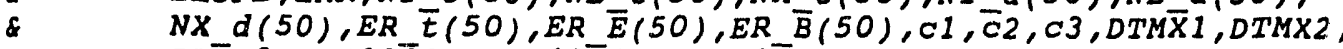

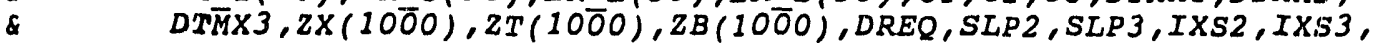

\& $\quad T E V(20), T B D(20), E V R(20), B D R(20), R E V, R B D$

INTEGER * $4 R, N I D(50), N L P, O P T, N E P, N B P$, IFLGE, IFLGB

INTEGER 4 NMD (50), I1, J1, IFLAG,I2,I3,

\& NDUM, IX,IB,IT, RSIZE,JTN,JJ,IDT1,IDT2,IDT3

LOGICAL EXT

CHARACTER* 12 INP,OUTP

CHARACTER $* 6$ NME (50), DUMA, SEC,DAY,YR

COMMON / reed10/VX,VT,VB,VXT, VTB,VBX,Bd_O,E_O, $R \_0, P_{w}, C w, D T, T M X$,

\& $T P R, L A M 1, N R, N I D, S P W, S C W, N L P, T L K, C L K, O P T, H L F$, $S L P 2, S L P 3, I X S 2, I X S 3, T E V, T B D, E V R$,

\& $B D R, R E V, R B D, N E P, N B P, I F L G E, I F L G B$

COMMON /TRD/fR $0, f E 0, f B O, t T X, t r B, t r T, t I X T, t I T B$,

\& $\quad t 1 B X, T \bar{O} T F, T \bar{O} T S, L \bar{A} M X, L \bar{A} M T, L \bar{A} M B, E \bar{P}-B X, \bar{E} P, X T, \bar{T} P R I N T$,

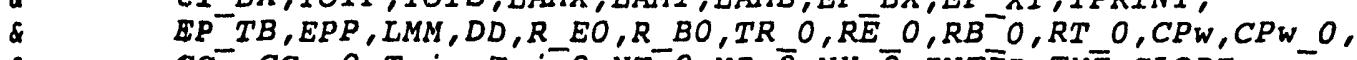

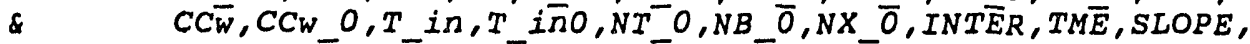

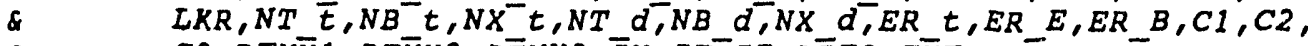

\& $\quad C 3, D T M \bar{X} 1, D T \bar{M} X 2, D \bar{T} M X 3, \bar{Z} X, Z T, Z B, D \bar{R} E Q, E \bar{X} T$

COMMON /INTG/NMD, IFLAG, NDUM,RSIZE,JTN,JJ,IDT1,IDT2, IDT3

COMMON /CHR/INP, OUTP, NME, DUMA, SEC, DAY, YR

\begin{tabular}{|c|c|}
\hline 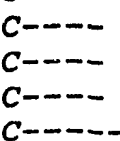 & $\begin{array}{l}\text { Check if the } Z B, Z T \text {, and } 2 X \text { array sizes are sufficient } \\
\text { for } S \text { toring data as defined by dt and the maximum of } \\
t I X T, t I T B, \text { and } t I B X, \text { as follows: }\end{array}$ \\
\hline 9001 & $\begin{array}{l}R S I Z E=\text { DMAX1(tI_XT,tI_TB,tI_BX)/dt+1 } \\
D R E Q=R S I Z E \star D T / 1000- \\
I F(R S I Z E \cdot G T \text {. } 1000) \text { THEN } \\
\text { WRITE }(6,6021) \text { RSIZE,DREQ,RSIZE } \\
\text { WRITE(20,6021) RSIZE,DREQ,RSIZE } \\
\text { STOP }\end{array}$ \\
\hline
\end{tabular}

Check if the requested time step is within the recommended

C

C $\# 1$ Find the minimum time increment between two adjacent points in 


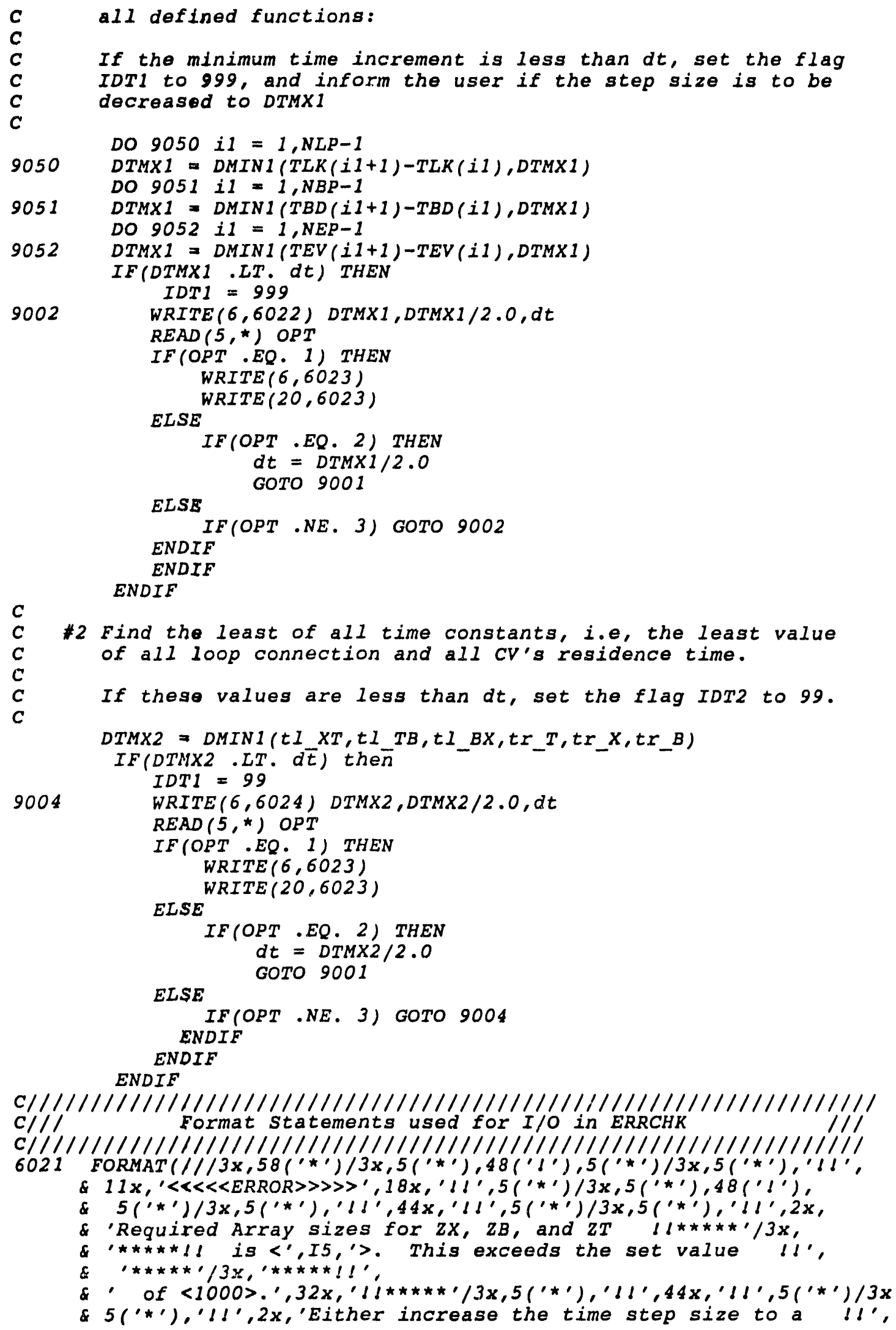




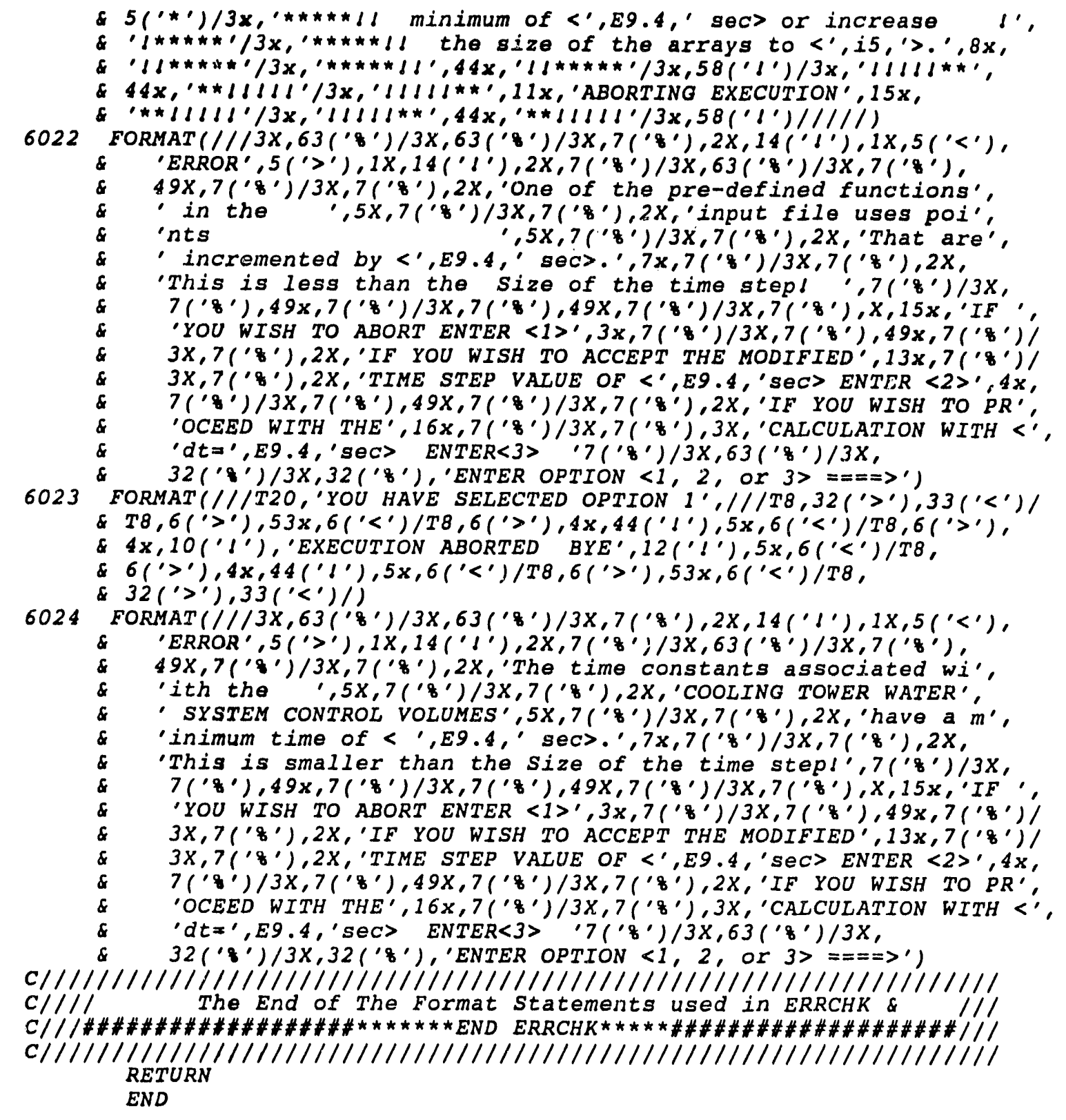


A Model for Radionuclide Transport

FORTRAN LISTING in The Cooling Water System

\section{B.6 The TRANS Module}

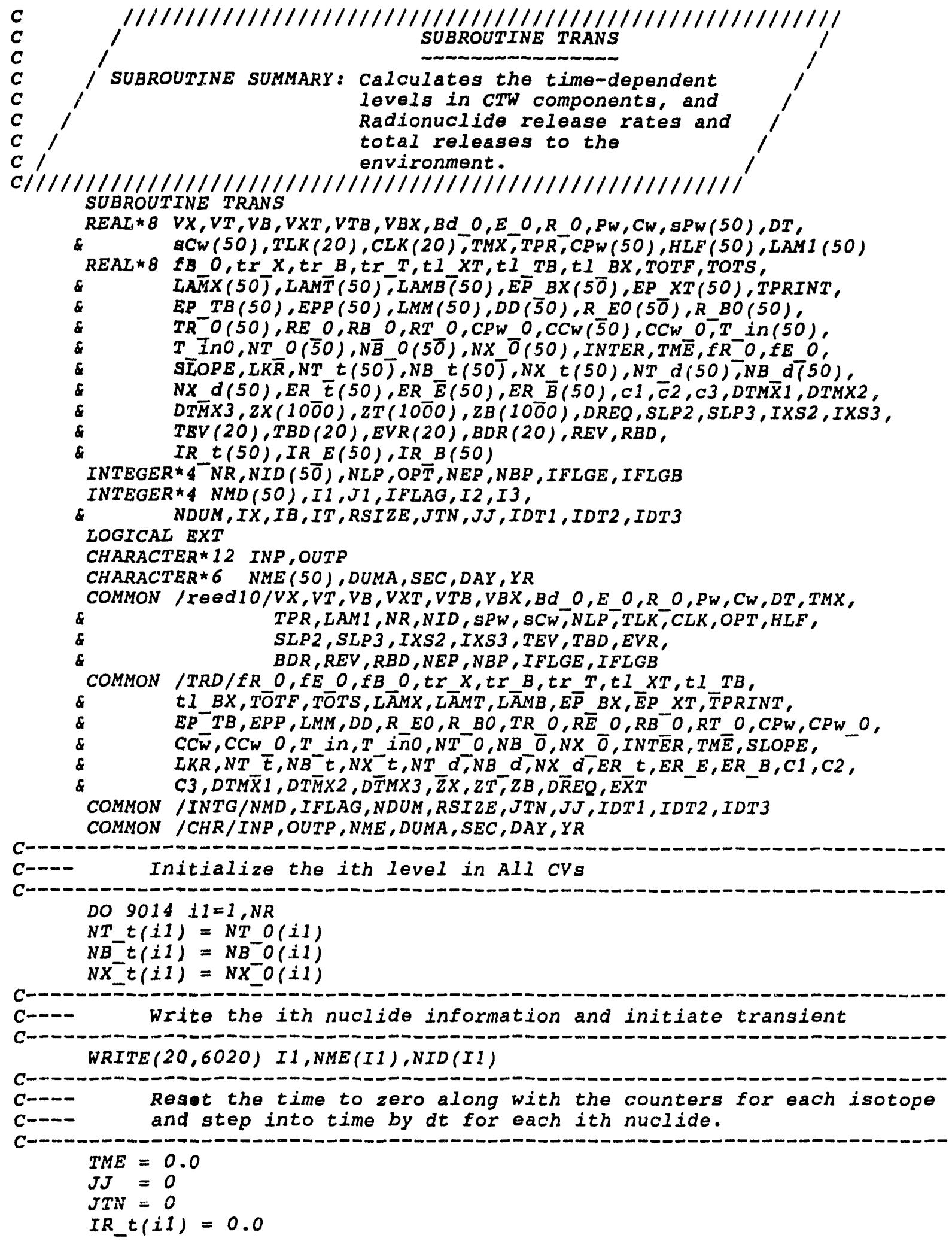




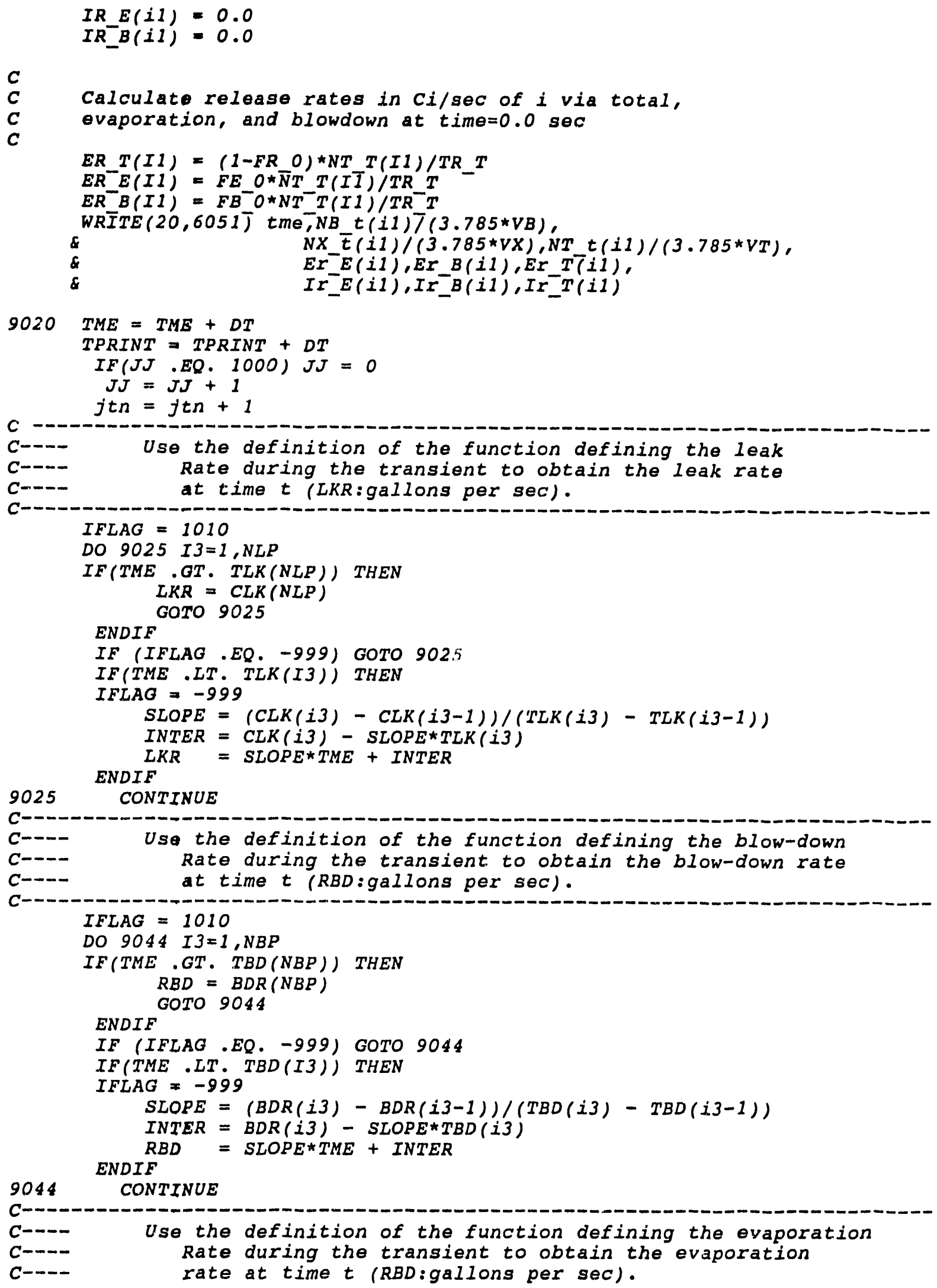




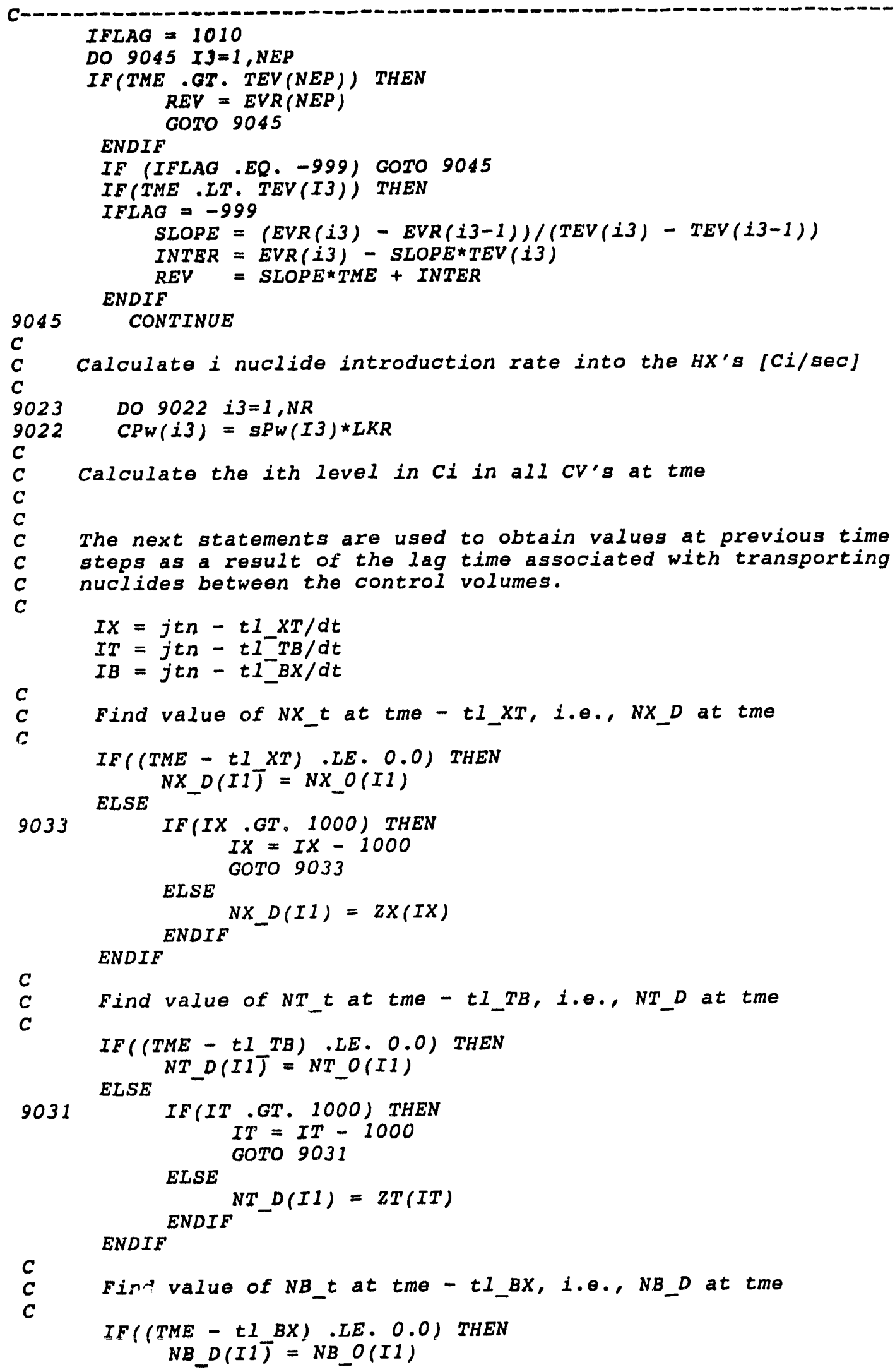




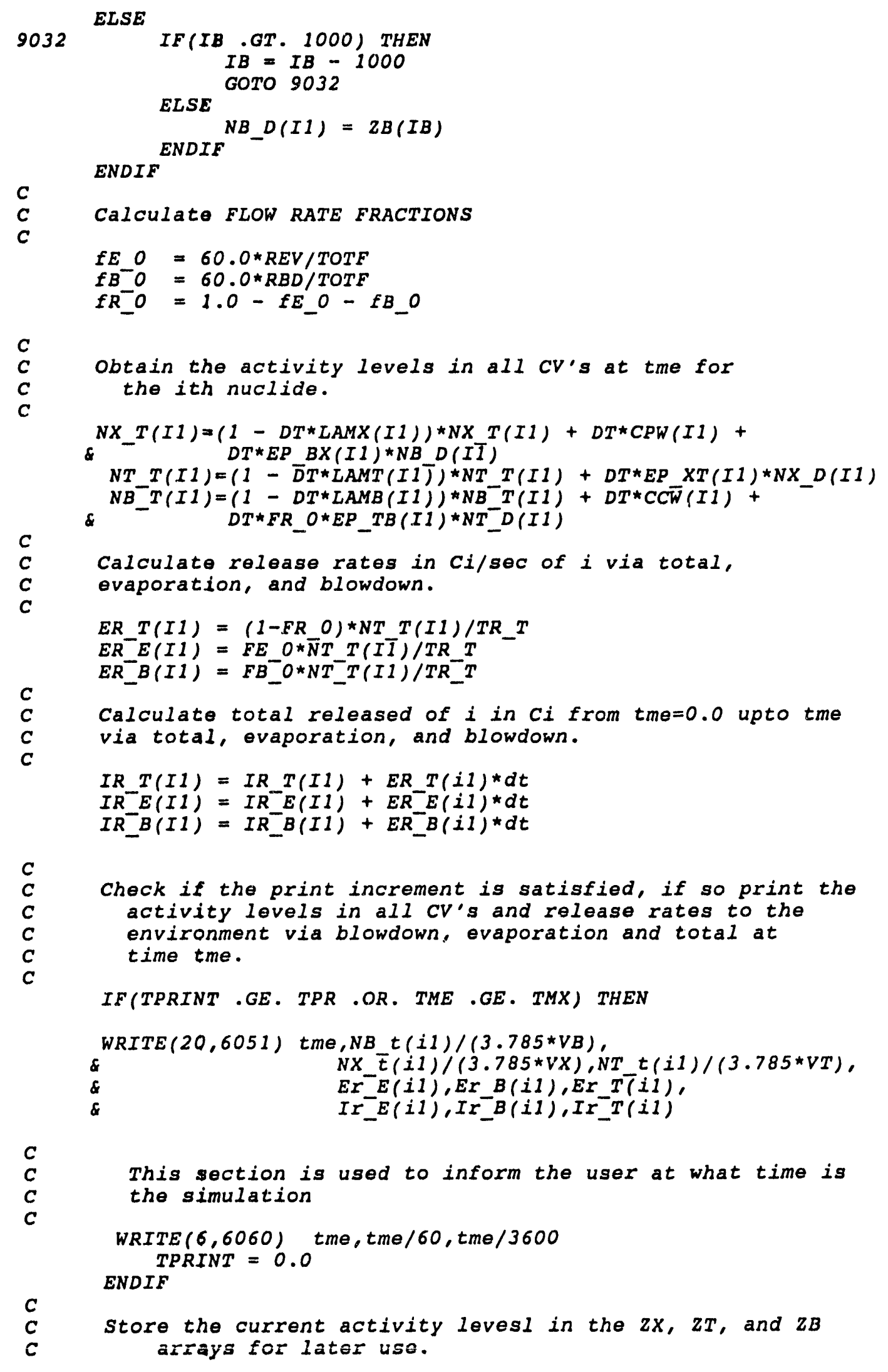

C

Check if the print increment is satisfied, if so print the activity levels in all CV's and release rates to the environment via blowdown, evaporation and total at time tme.

IF(TPRINT .GE. TPR .OR. TME .GE. TMX) THEN

WRITE $(20,6051)$ tme,NB_t(i1)/(3.785*VB),

C This section is used to inform the user at what time is the simulation

C 
c

$$
\begin{aligned}
& \operatorname{ZX}(j j)=N X t(i 1) \\
& \operatorname{ZT}(j j)=N T_{-t(i 1)} \\
& Z B(j j)=N B t(i 1)
\end{aligned}
$$

$c$
$C$

Check if the transient time is at maximum examination time

9014 CONTINUE

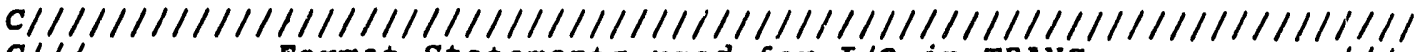

C// Format statements used for $I / 0$ in TRANS $/ / /$

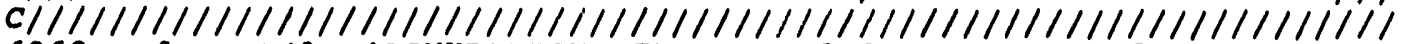

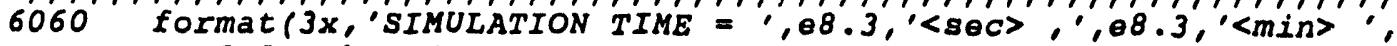
\& $\left., e 8.3,(<h r s\rangle^{\prime}\right)$

6020 FORMAT('1'///T4,' The following data relate to the ',I4,'th', \& 'nuclide, $i . \theta .,===\Rightarrow$ ',AG/41x,'with the nuclide' ID' $\Rightarrow>^{\prime}, I 6 / / /$

\& 1x,109('-')/3x,'TIME',9x,'Activiry Levels (Ci/L)',8x,'Relea',

\& 'se Rate of ith (Ci/sec)',7x,'Total Released (Ci)'/2x,'(sec)',

\& 6x,'186Basin Heat-Ex. K-Tower',5x, 'Evapor.',5x,'River',

6051 6x,'Total',5x,'Evapor.',5x,'River',5x,'Total'/1x,109('-1))

6051 Format $(1 X, E 9.4,2 x, 3(E 9.4,2 X), 3(E 9.4,2 X), 3(E 9.4,2 X))$

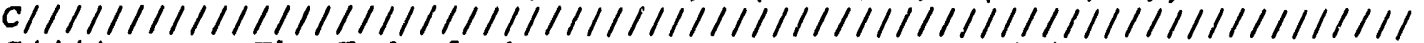

C/l/ The End of the Format statements used in TRANS \& $/ / \mid$

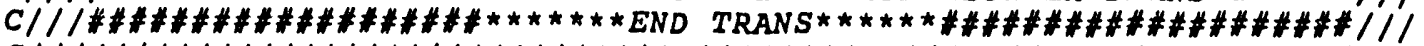

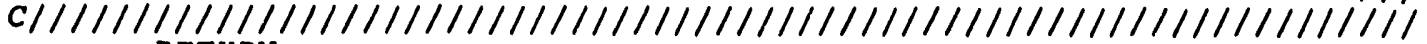
RETURN

END 

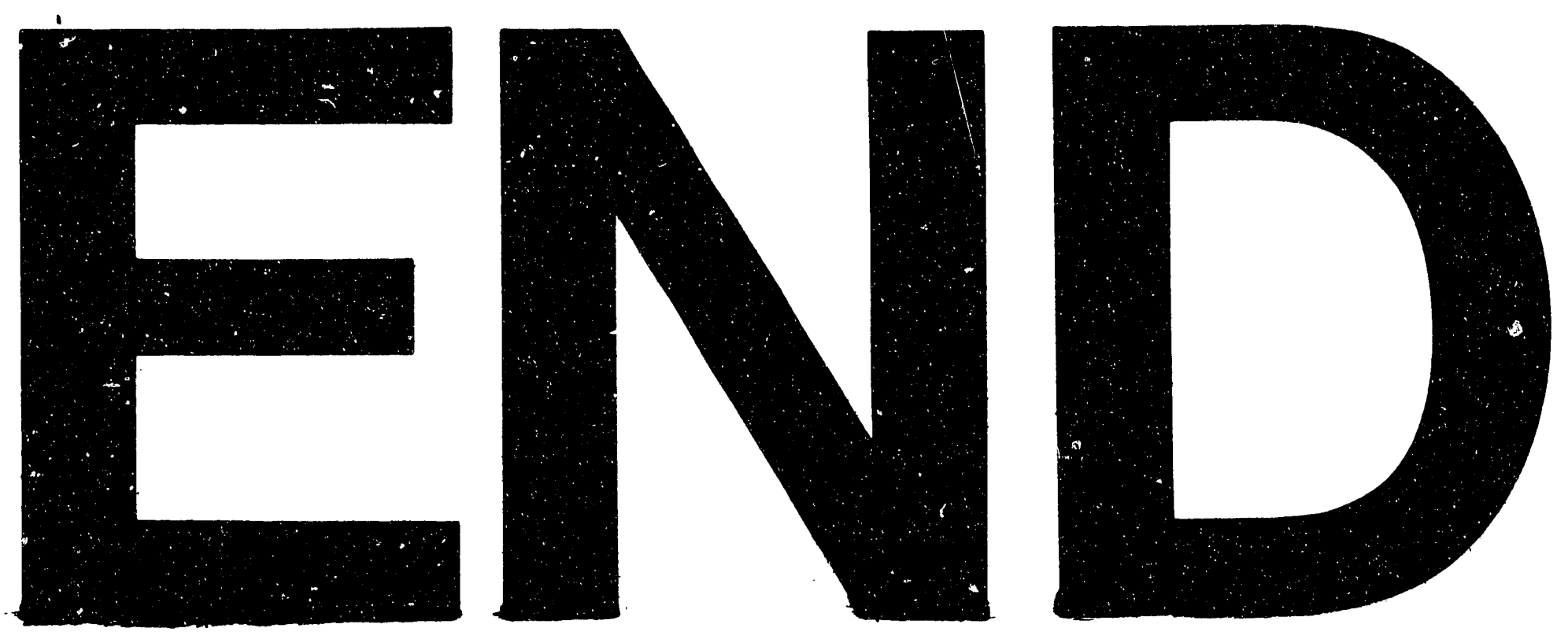

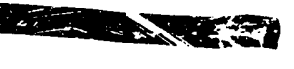

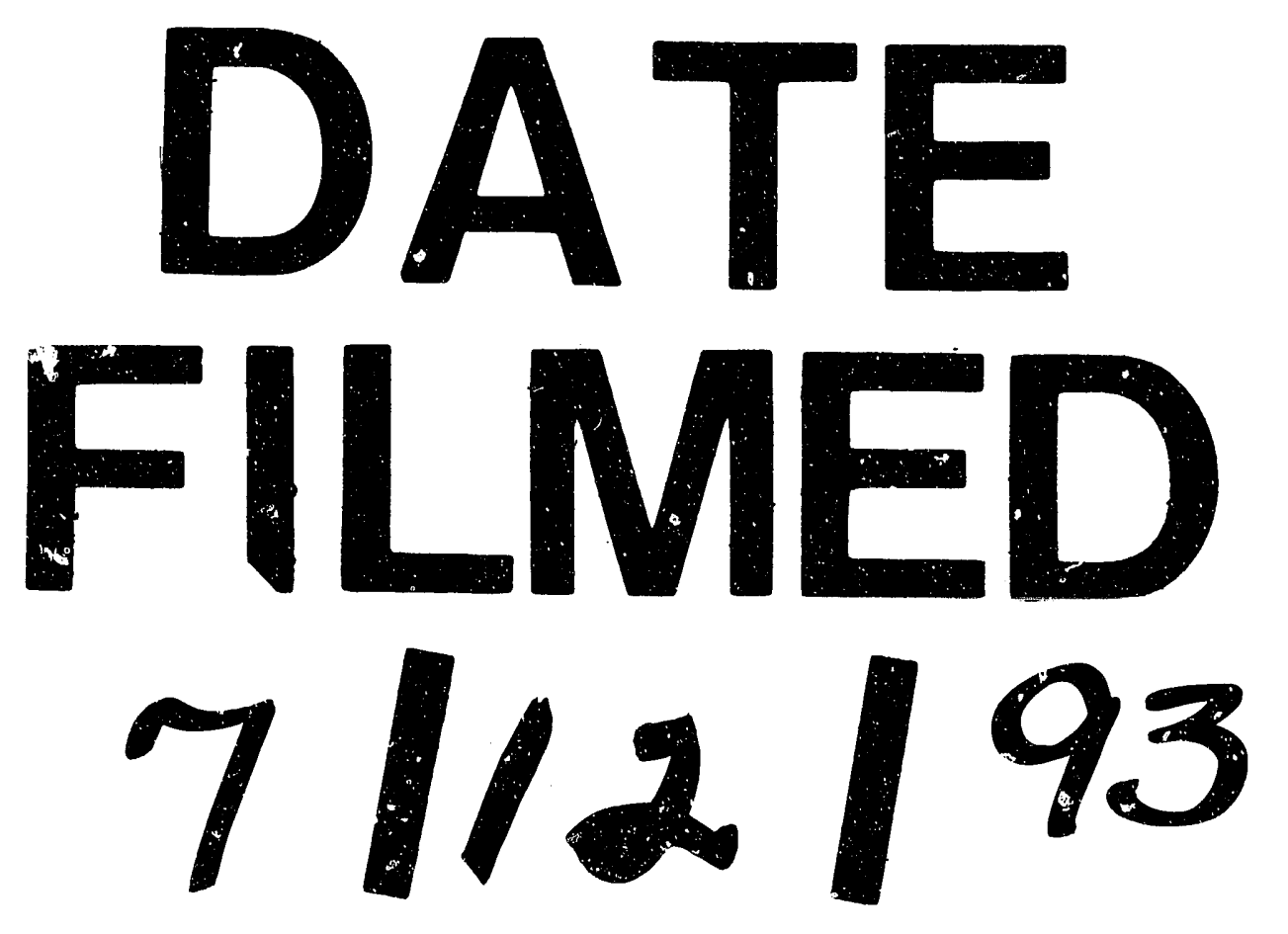


